\title{
الطاقة الايجابية في المسكن وعلاقتها بأداء الواجبات الأسرية لربة الأسرة
}

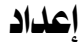 \\ عبير عبده محمد علمــ

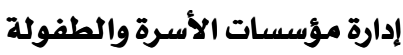 \\ كلية الاقتصاد المنزلى - جامعة الأزهر
}

مجلة بحوث التربية النوعية ـ جامعة المنصورة

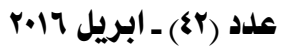




\title{
الطاقة الايجابية في المسكن وعلاقتها بأداء الواجبات الأسرية لربة الأسرة
}

\author{
إعداد \\ عبرعبدهمحمد علم*
}

|لالفص

يستهدف البحث بصفة رئيسة دراسة العلاقة بـين الطاقة الايجابيـة ِِّ المسكن ومستوى أداء

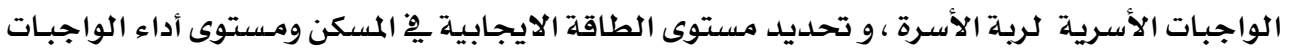

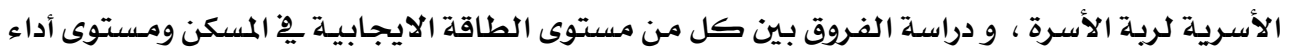

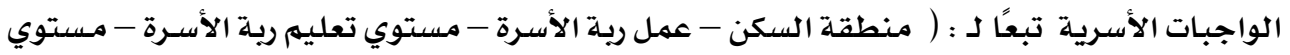

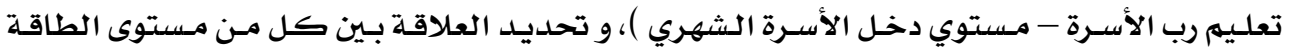

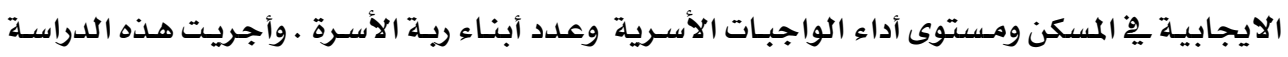

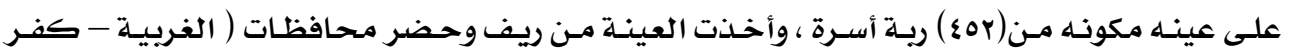

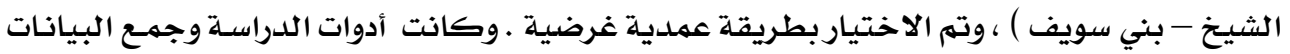

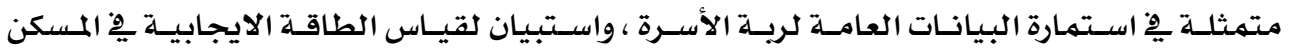

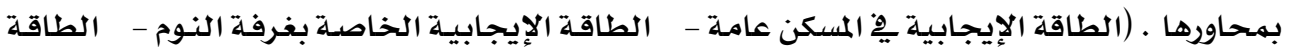

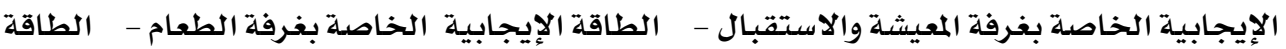

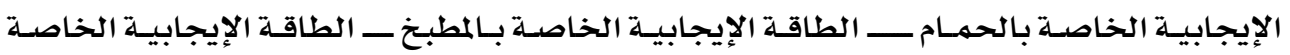

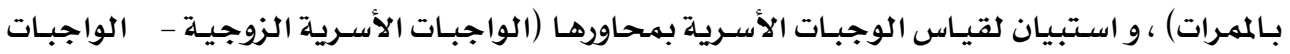

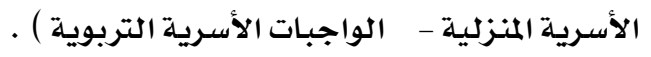

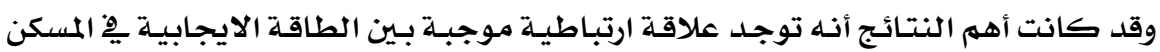

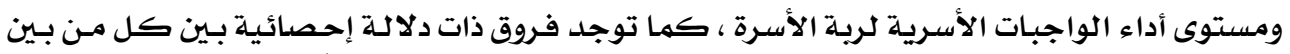

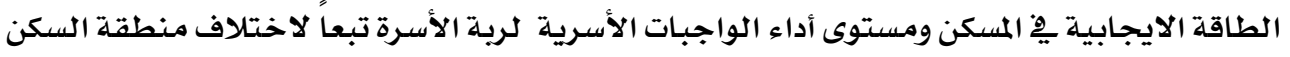

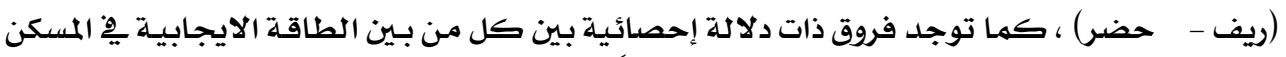

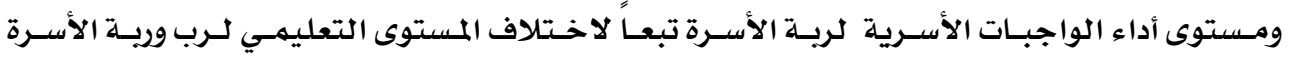

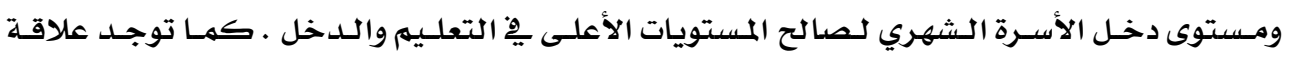

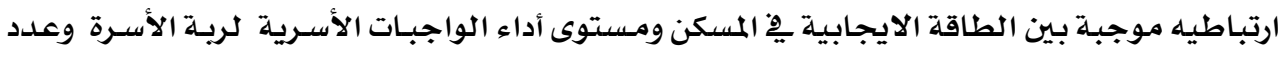

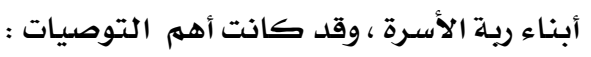

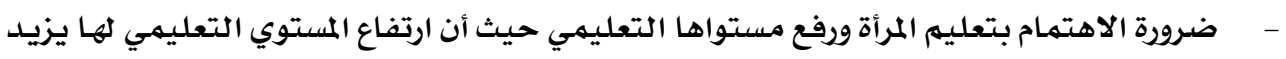
" إدارة مؤسسات الأسرة والطفولة - كلية الاقتصاد المنزلى - جامعة الأزهر 
معرفة ودراية رية الأسرة وقدرتها علي ترتيب وتنسيق وتجميل منزلها وبعث السكينة والخصوصية

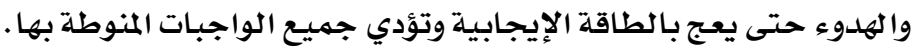

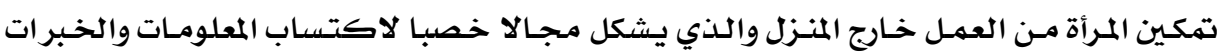

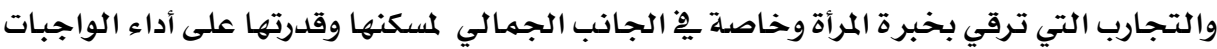

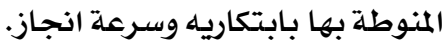

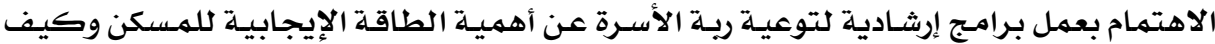

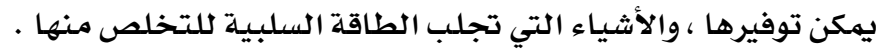

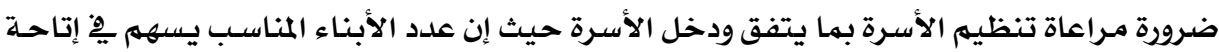

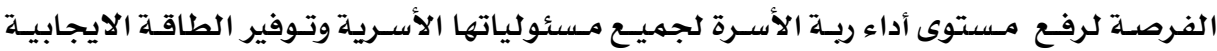

\section{همدهمة وهشكالة البحث:}

الطاقة الايجابية يِّ المسكن تعتمد على مقومات بسيطة تساعد على تكوين المكان وتجميله ،

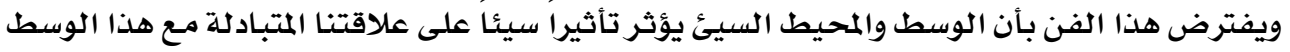

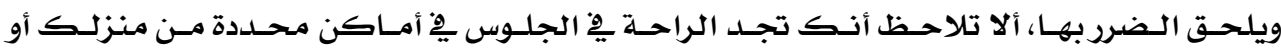

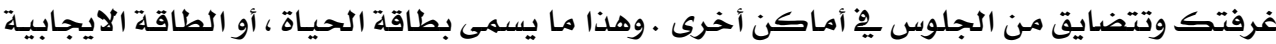

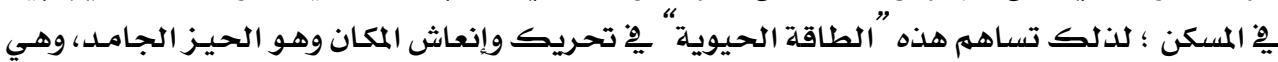

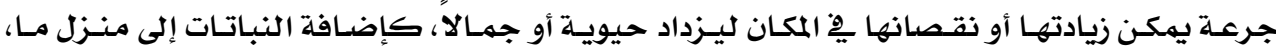

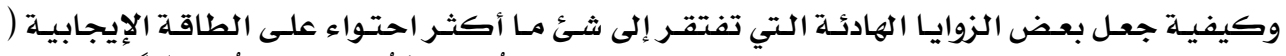

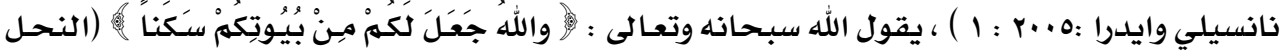

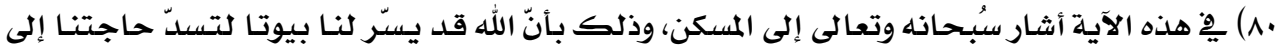

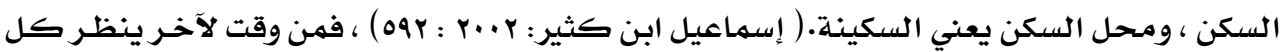

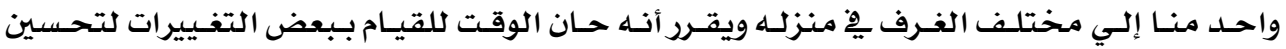

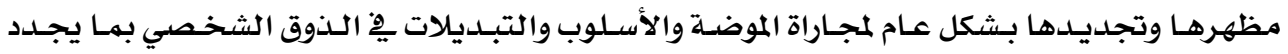

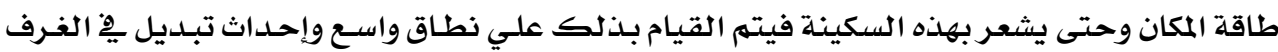

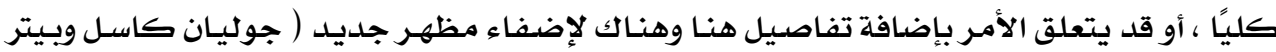

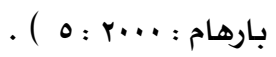

فتعرف الطاقة الايجابية يِّ المسكن على أنها كل ما يضفى على الحياة معنى ولونا وطعما

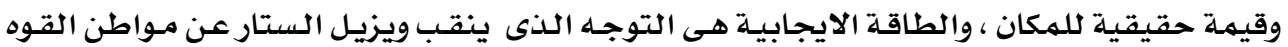

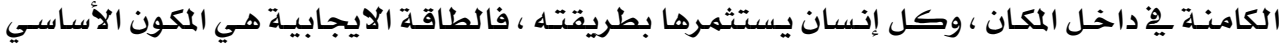

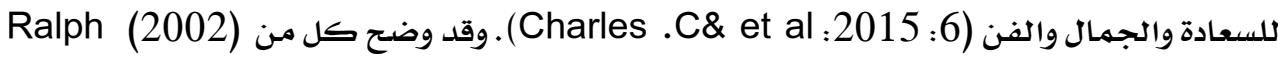

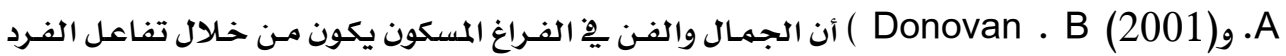
مـع الأثياء البيئية الموجودة يْ هذا الفراغ بشكل مباشر أو غير مباشر. 


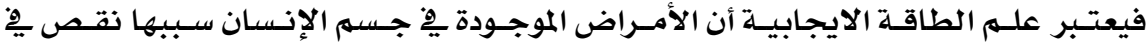

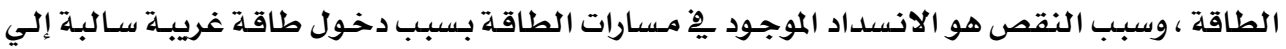

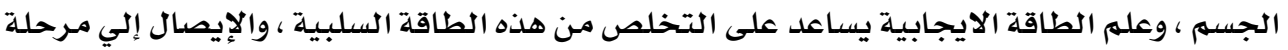

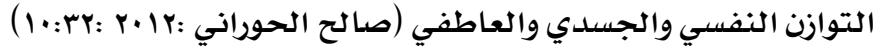

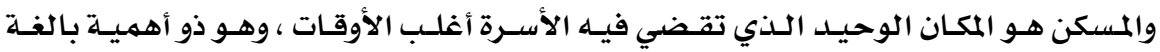

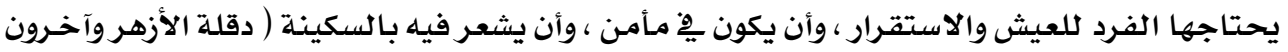

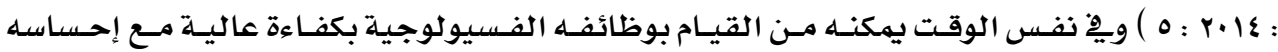

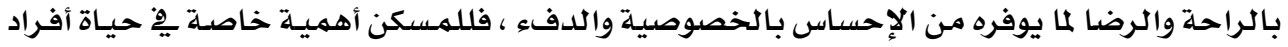

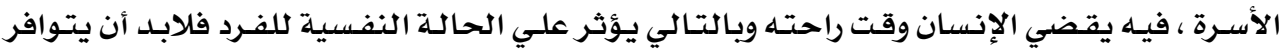

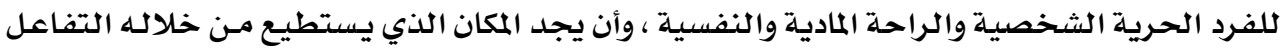

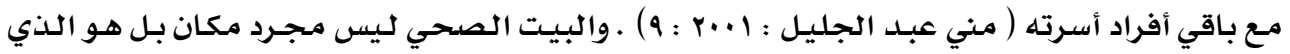

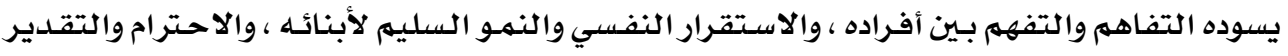

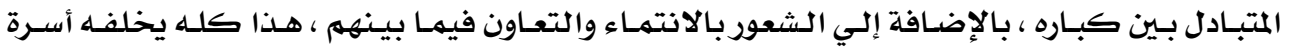

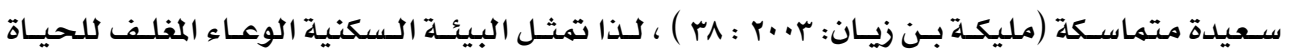

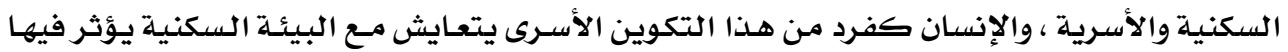

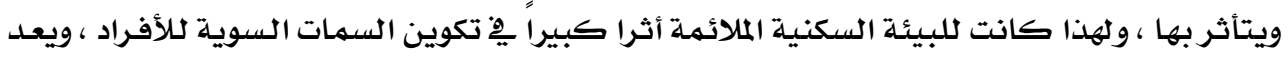

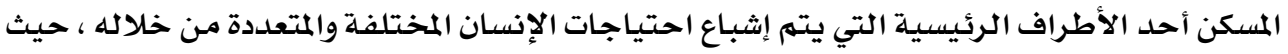

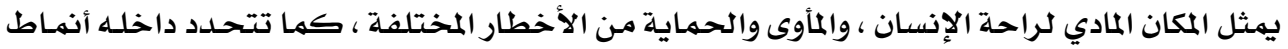

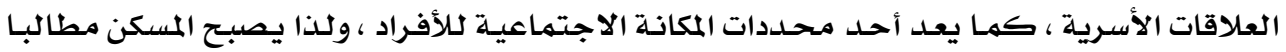

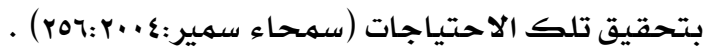

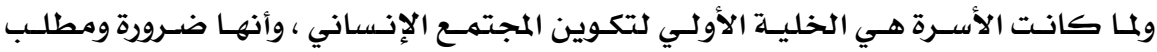

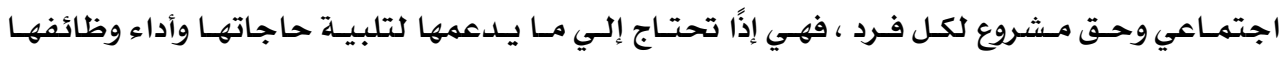

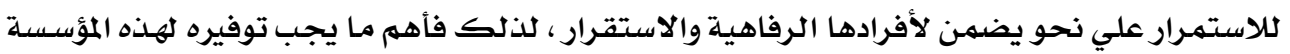

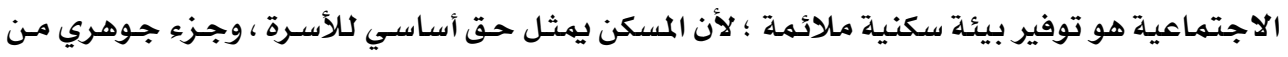

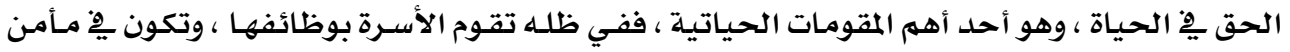

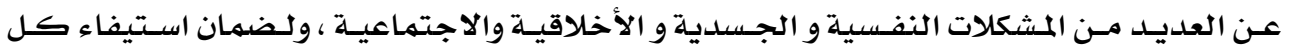

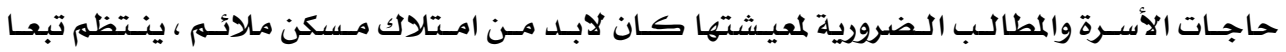

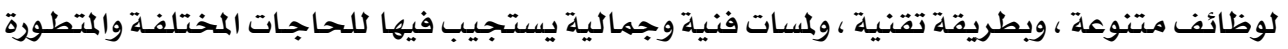

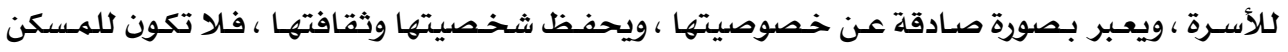

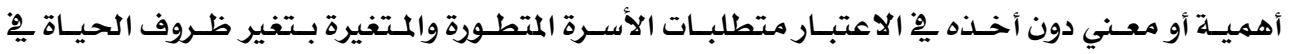

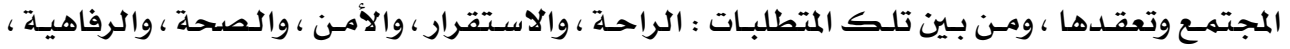

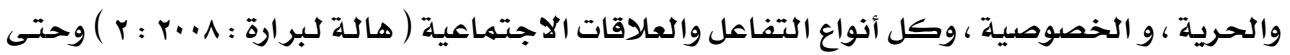

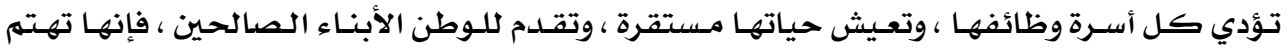


بالحصول علي مسكن مناسـب ، وتؤسسـه بطريقـة تسهل لها مزاولــة جميـع أنشطتها ( مهجـة مسلهم : . (rr: r...

وتعدد ريبة الأسرة مسئولة شرعا وعرفا عن مجموعة من المهام التي تعد من قبيل الواجبـات ،

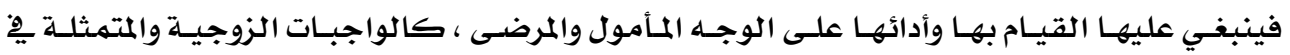

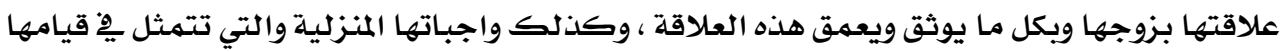

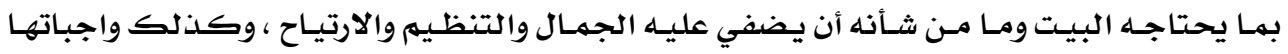

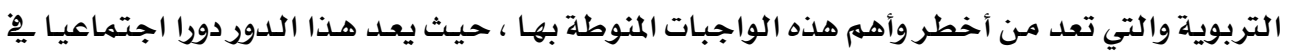

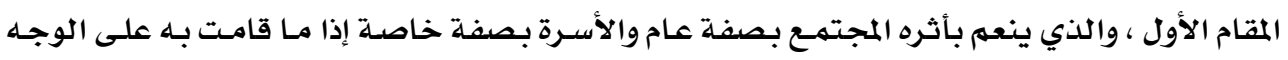

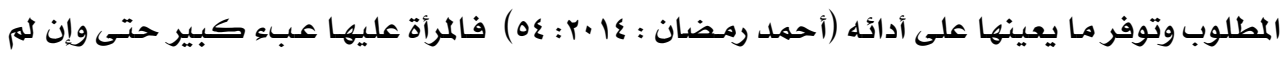

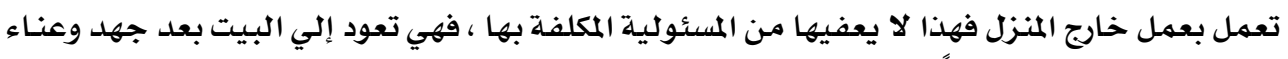

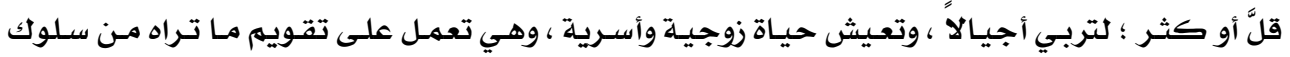

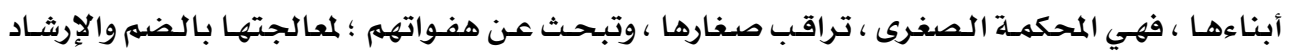

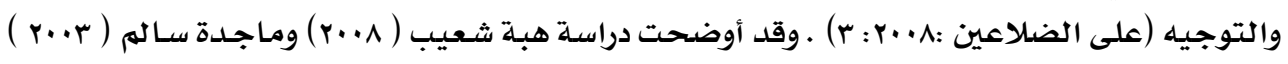

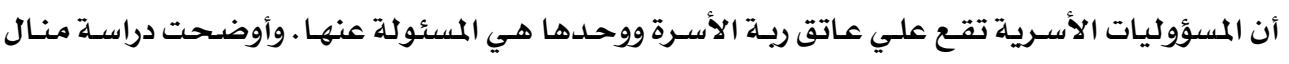

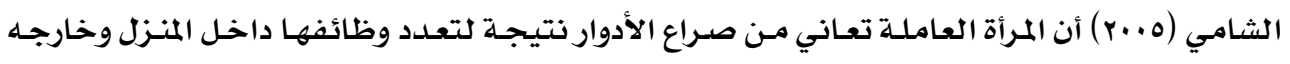

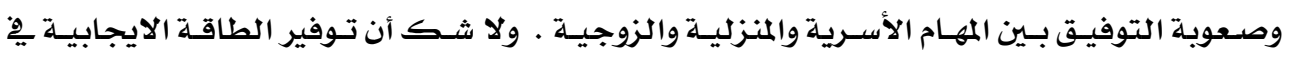

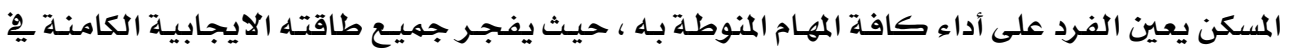

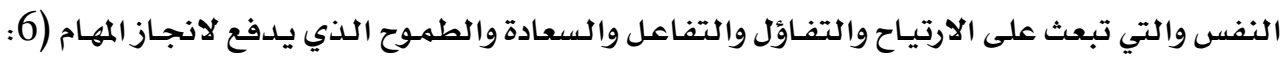

.Charles .C\& et al :2015

وتتلخص مشكلة البحث يِ أن تقاعس المرأة عن أداء الواجبات الأسرية المنوطة بها قد يؤدي

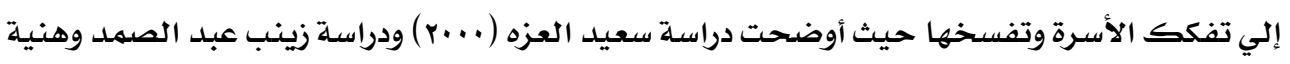

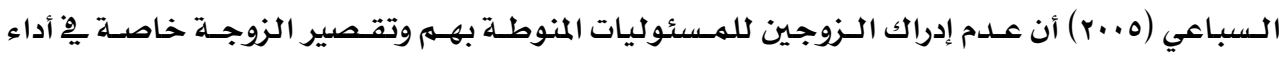

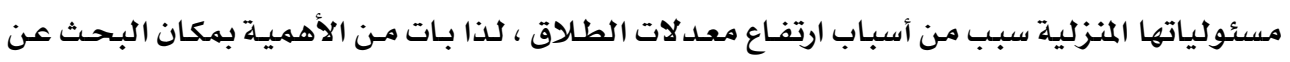

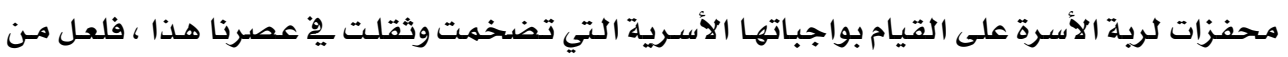

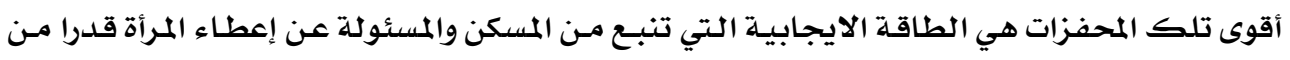

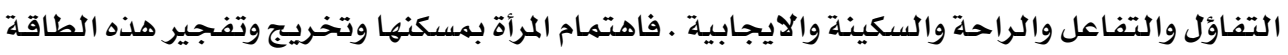

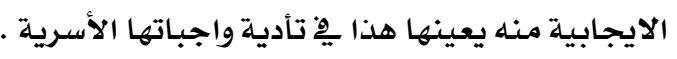

\section{ومن خلال هذا البحث يمكن الإجابة علي التساؤلات الآتية :}

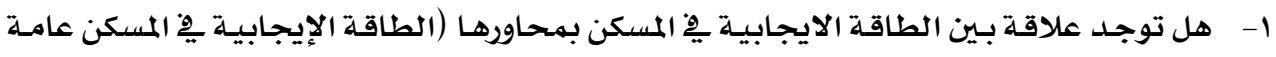

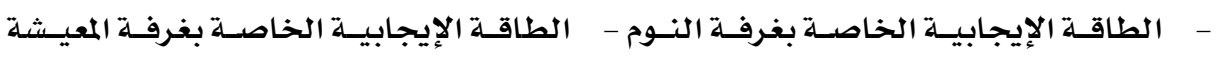

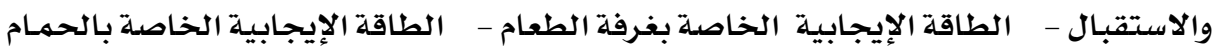

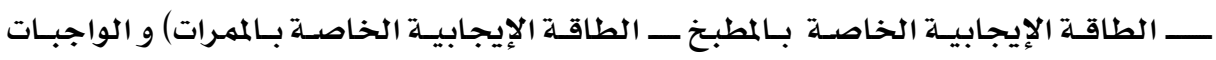




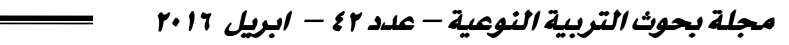

الأسـرية لريـة الأسـرة بهحاورهـا (الواجبـات الأسـرية الزوجيـة - الواجبـات الأسـرية المنزليـة -

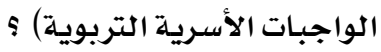

r- ما علاقة بعض العوامل الاجتماعية والاقتصادية بكل من الطاقة الايجابية يِّ المسكن بمحاورها

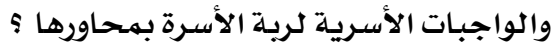

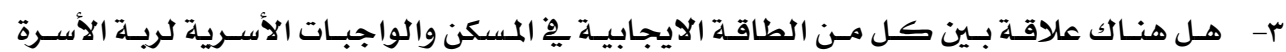
وعدد الأبناء

يستهدف البحثث بصفة رئيسية دراسـة العلاقة بـين الطاقـة الايجابيـة يِّ المسكن والواجبـات

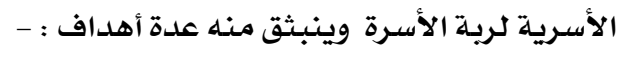

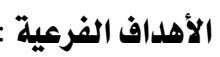

$$
\text { تحديد مستوى الطاقة الايجابية يِّ المسكن. }
$$

دراسـة الفـروق بـين كـل مـن الطاقـة الإيجابيـة يِّ المسكن والواجبـات الأسـرية لريسة الأسـرة تبعـا دـ

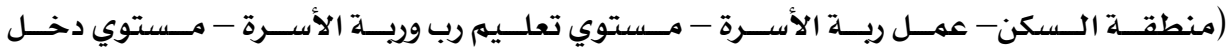
الأسرة الشهري).

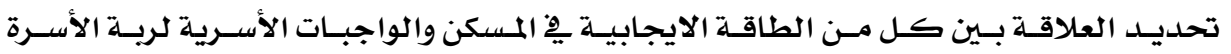
وعدد أبنائها .

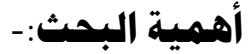

يقتفي البحث أثر العلاقة بـين الطاقـة الإيجابيـة للهسكن و أداء الواجبـات الأسـرية المنوطـة بريسة

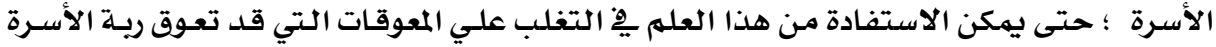

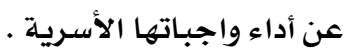

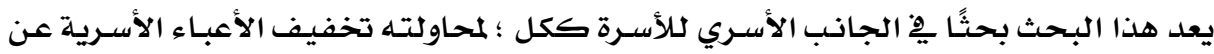

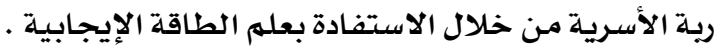

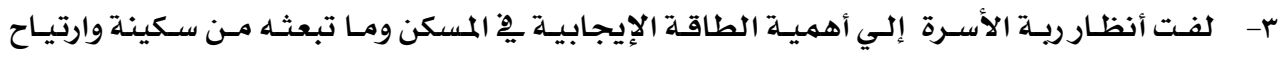
وثعور بالسعادة بما ينعكس علي أداء مختلف الأعمال .

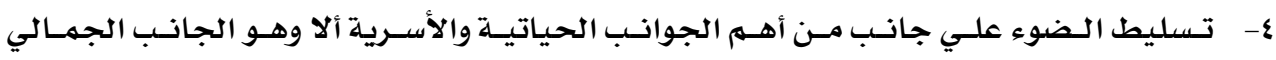

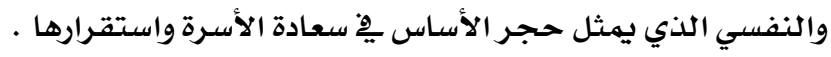

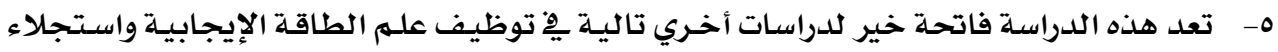

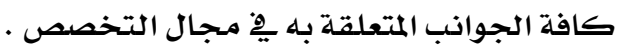




\section{فروض البحث :}

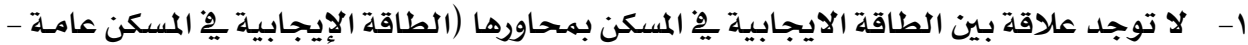

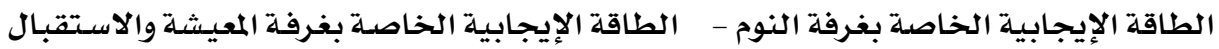

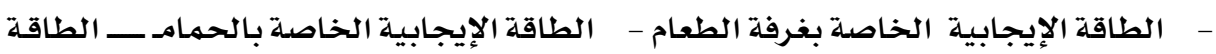

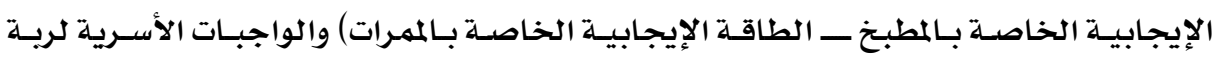

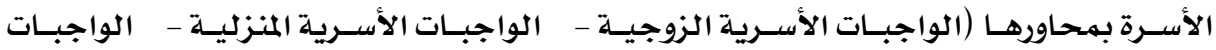
الأسريـة التربوية).

r- لا توجد فروق ذات دلالة إحصائية بين كل من الطاقة الايجابية يِّ المسكن و والواجبات الأسـرية

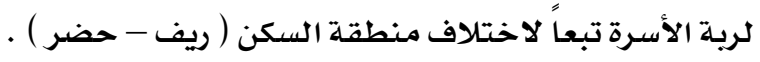

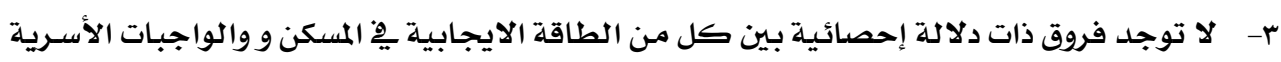

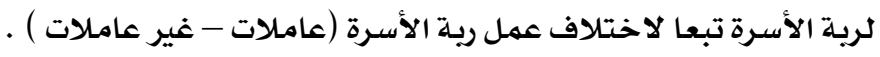

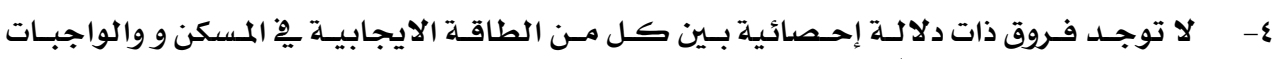

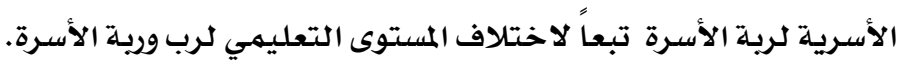
هـ لا توجد فروق ذات دلالة إحصائية بين كل من الطاقة الايجابية يِّ المسكن و والواجبات الأسرية

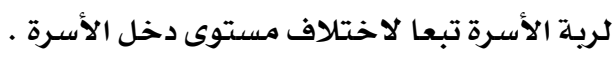

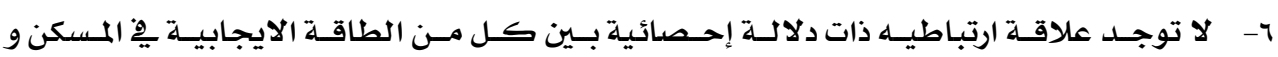

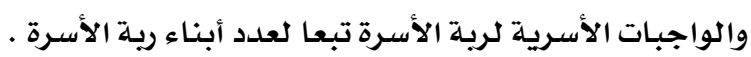

الأاسلوب البمثي أولًا : حدود الدراسة

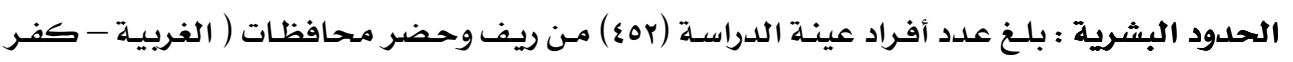

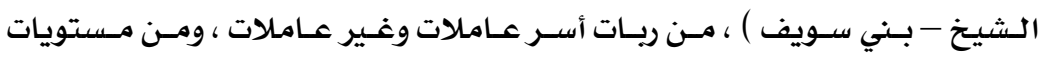

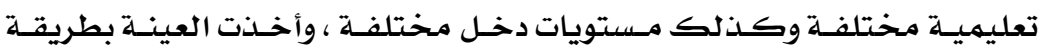

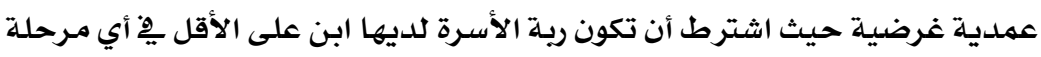

$$
\text { من مراحل التعليهم }
$$

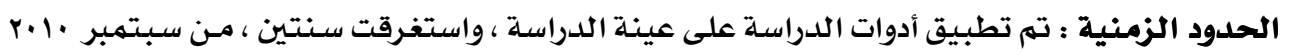

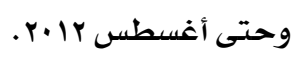

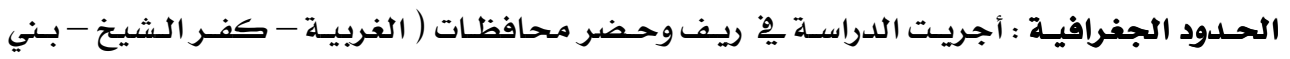

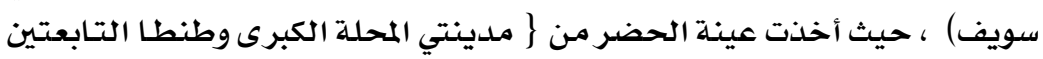

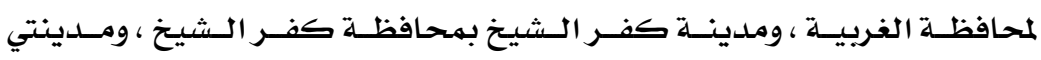

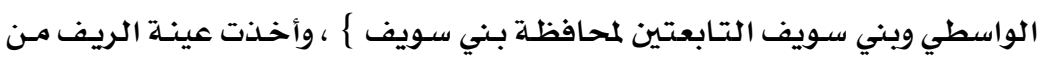




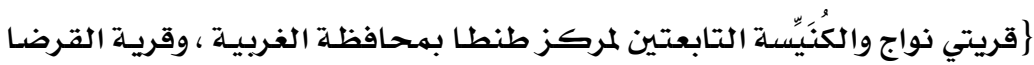

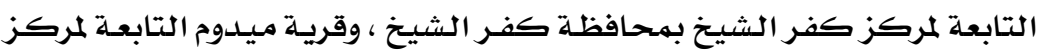

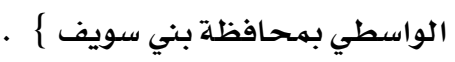

ثانيا:ـ منهج الدراسة

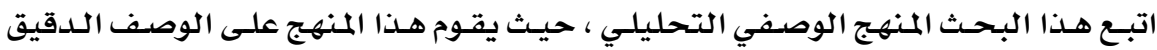

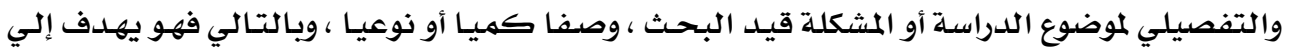

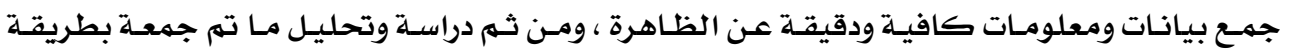

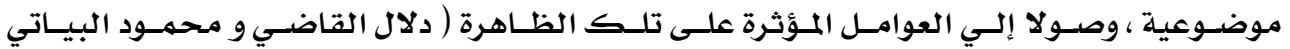
. ( 7 : $Y \cdots \wedge$ :

\section{ثالثًاً : المصطلحات العلمية والمقاهيه الإجرائية المستخدمة في البحث}

المصطلحات العلمية :-

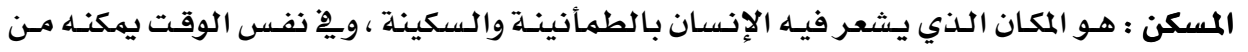

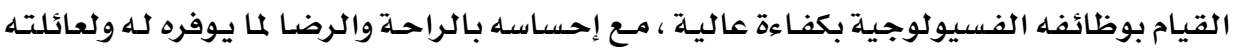

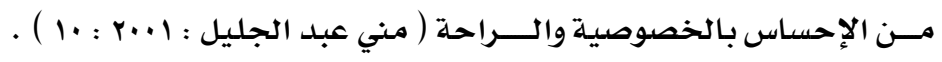

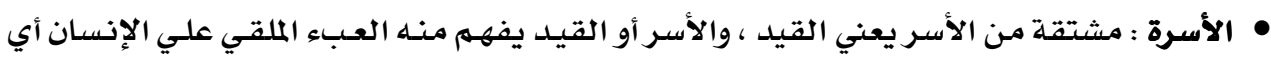

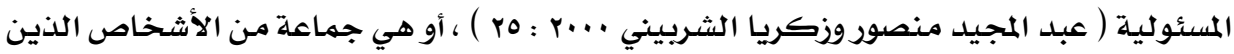

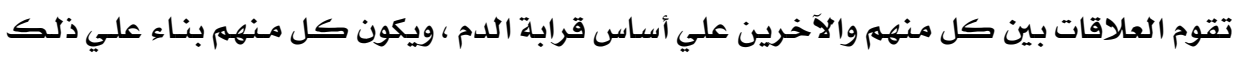

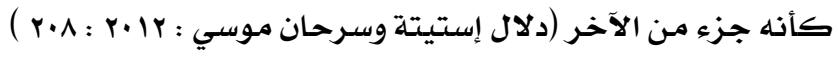

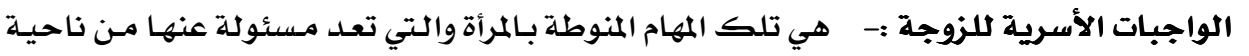

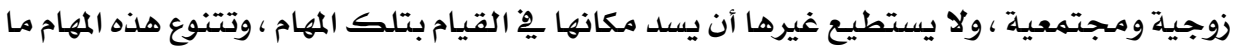

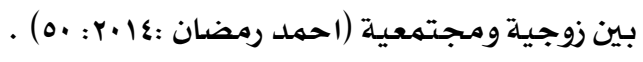

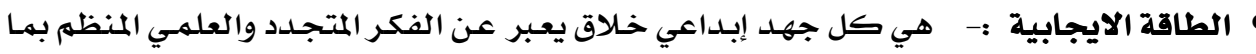

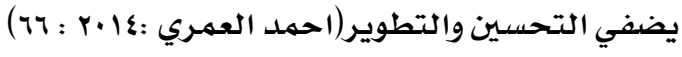

$$
\text { المفاهيم الإجرائية :- }
$$

• رية الأسرة : كل امرأة متزوجلة ولديها ابن على الأقل ِِّ أي مرحلة مـن مراحل التعليهم ـ (وذلك الك

$$
\text { حتى يمكن قياس الواجبات التربوية ) . }
$$

• الطاقة الايجابية ِِِ المسكن : كل ما يجعل المسكن باعثًا علي السعادة والارتياح والتفاؤل والإنجاز

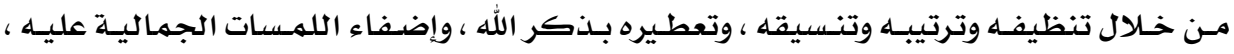

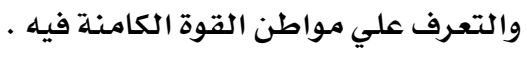


الواجبات الأسرية لرية الأسرة : هي كل المهام و الالتزامات والمسئوليات التي تقع يِّن نطاق الأسرة

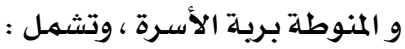

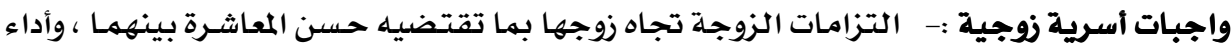

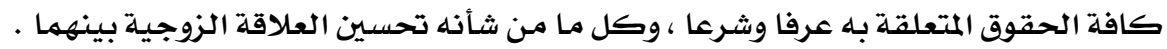

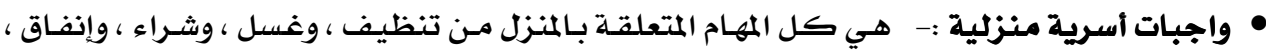

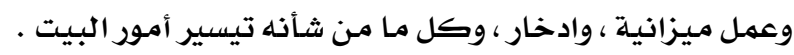

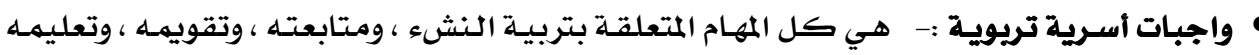

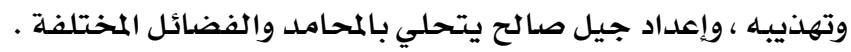

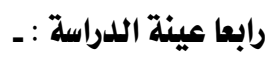

كانت عينة الدراسـة من ريف وحضر محافظات ( الغربيـة - كفر الشيخ - بـني سـويف ) ،

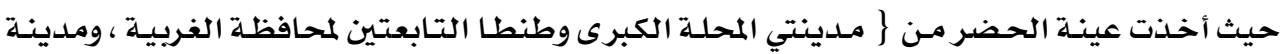

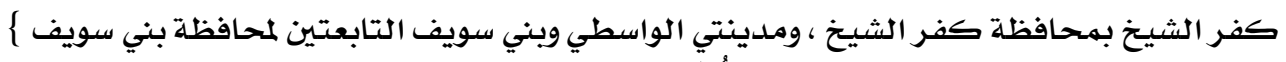

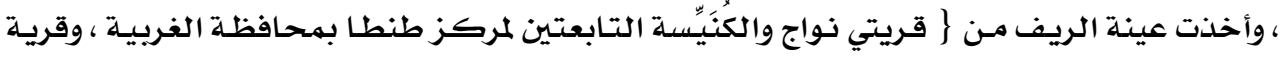

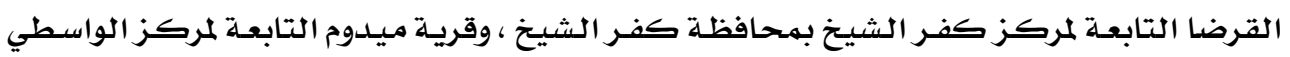

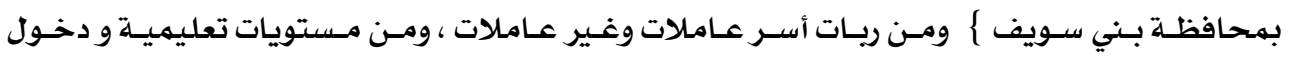

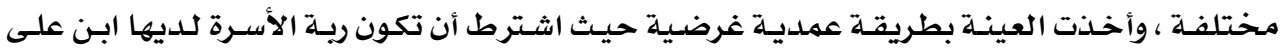

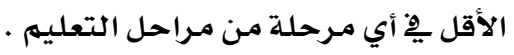

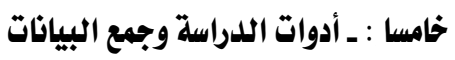

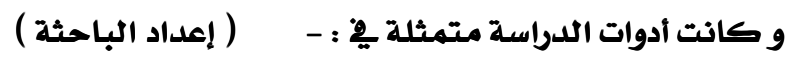

أولا : استمارة البيانات العامة لربـة الأسـرة .

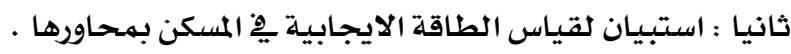

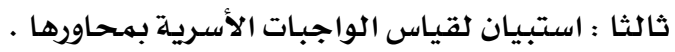

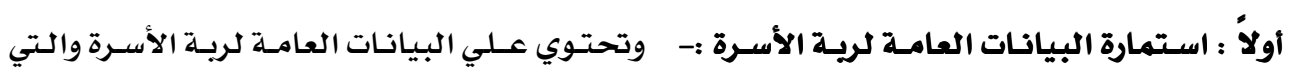

$$
\text { اشتملت علي البيانات التالية : }
$$

- منطقة السكن ( ريف ـ حضر ) - عدد الأبناء لدى رية الأسرة ـ عمل رية الأسرة ( تعمل . لا

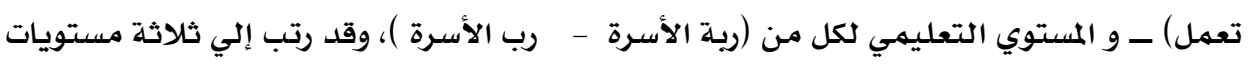

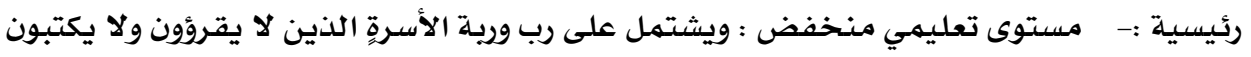

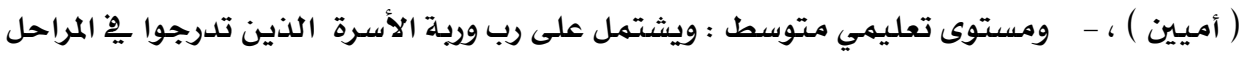

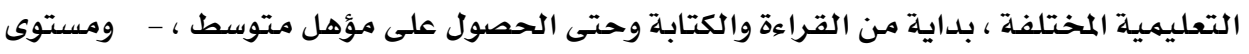




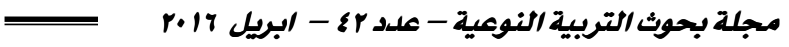

تعليهي مرتفع : ويشتمل على رب ورية الأسرة الحاصلين على مؤهل جامعي أو دراسات عليا

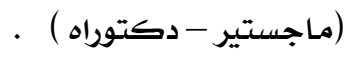

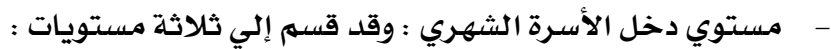

• مستوي دخل منخفض ( إلي أقل من : (1) )

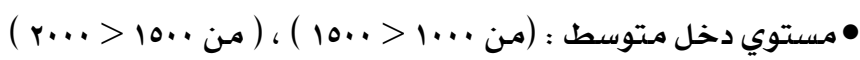

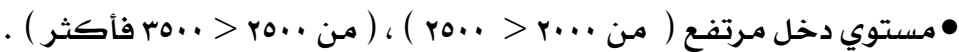

ثانيا : استبيان لقياس الطاقة الايجابية ِِّ المسكن بمحاورها : أعد هـا الاستبيان يِّ ضـوء التعريف

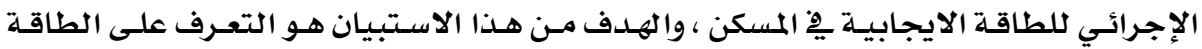

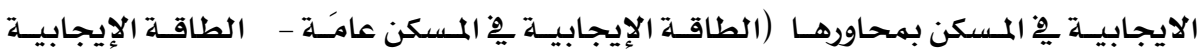

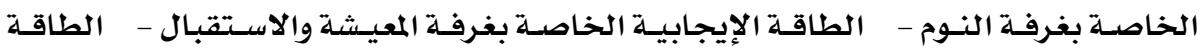
الإيجابية الخاصدة بغرفة الطعام - الطاقة الإيجابية الخاصدة بالحمامـ ـ الطاقـة الإيجابيـة الخاصدة بالمطبخ - الطاقة الإيجابية الخاصدة بالممرات) . كما أعد هـذا الاستبيان بعـد الإطلاع

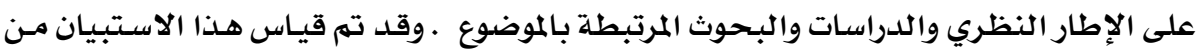

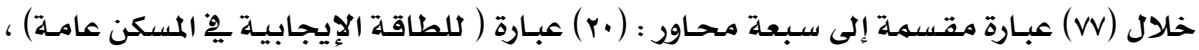

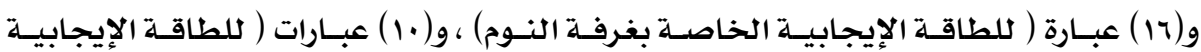
الخاصدة بغرفة المعيشة والاستقبال) ،و (11) عبارة ( للطاقة الإيجابية الخاصة بغرفة الطعام) ،

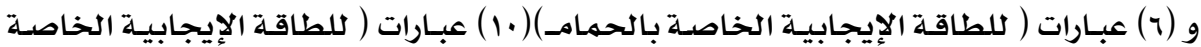

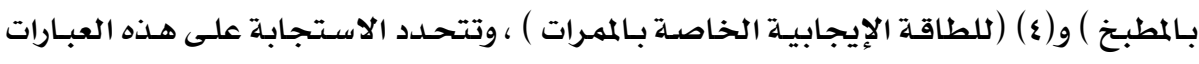
وفقا لثلاث استجابات وعلى مقياس متصل ( نعم - إلي حد مـا - لا ) كما تنوعت العبارات فِّه اتجاهاتها فكان بعضها إيجابيًا والآخر سلبيًا .

$$
\text { صدق وثبات الاستبيان :- }
$$

الصدق المنطقي كلاستبيان :- ويهدف إلي الحكم علي مدي تمثيل الاستبيان للهدف الذي

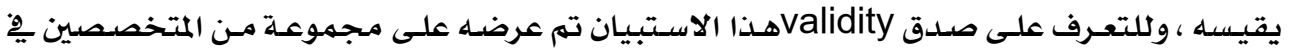

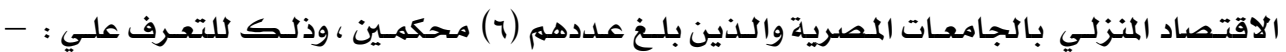

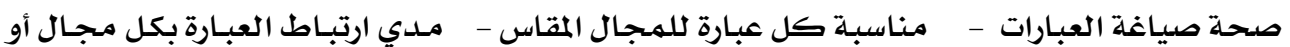

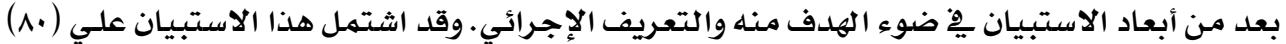

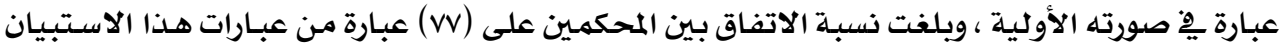

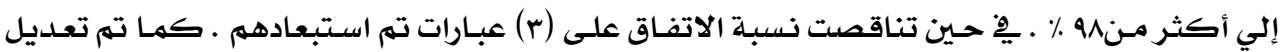


صياغة بعض العبارات وفقا لآراء المحكمين ، ويصبح هذا الاستبيان يْ صورته النهائية مكون مـن (vV)

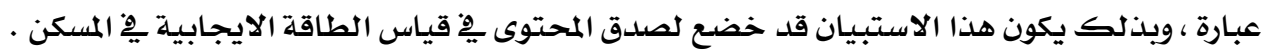
الدراسة الاستطلاعية :- وقد تم تطبيق الاستبيان بعد إجراء تعديلات المحكمـين علي عينة

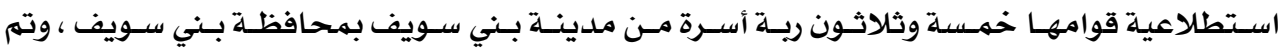

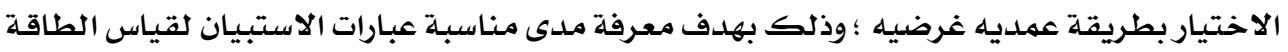

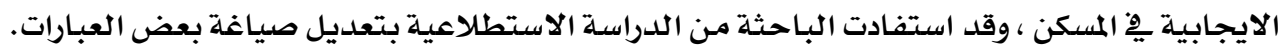

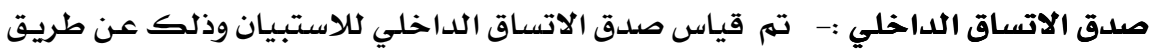

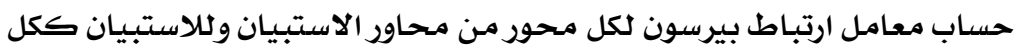
جدول (1) قيم معاملات الارتباط بين الدرجة الكلية لكل محوروالدرجة الكلية للاستبيان

\begin{tabular}{|c|c|c|}
\hline الدلالة & الارتباط & المحاور \\
\hline$\ldots 1$ & $.909 * \%$ & الطاقة الإيجابية في المسكن عامة \\
\hline$\ldots 1$ & $.9 \vee 1 * \%$ & الطاقة الإيجابية الخاصة بغرفة النوم \\
\hline$\ldots 1$ & $.9 r V^{*} *$ & الطاقة الإيجابية الخاصة بفرفة المعيشة والاستقبال \\
\hline$\ldots 1$ & $.9 \wedge \wedge * *$ & الطاقة الإيجابية الخاصة بغرفة الطعام \\
\hline$\ldots 1$ &.$\leqslant \wedge \bullet * \%$ & الطاقة الإيجابية الخاصة بالحمام \\
\hline$\ldots 1$ & $.9 \wedge \wedge * *$ & الطاقة الإيجابية الخاصة بالمطبخ \\
\hline$\ldots 1$ & $.9 \cdot r * \%$ & الطاقة الإيجابية الخاصة بالممرات \\
\hline
\end{tabular}

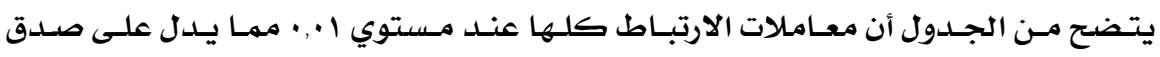
وتجانس محاور الاستبيان.

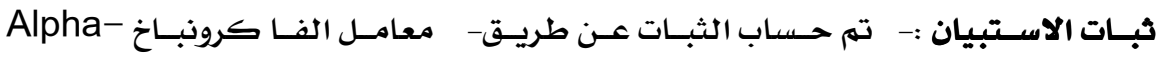

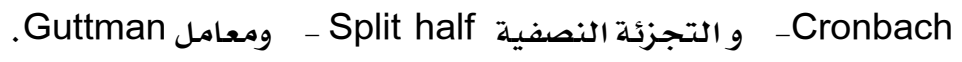
جدول (ץ) قيم التجزئة النصفية و معامل ألفا وجيوتمان لكل محور من محاور الاستبيان وللاستبيان ككل

\begin{tabular}{|c|c|c|c|c|}
\hline معامل ألثا & معامل جيوتمان & التجزئة النصفية & عدد العبارات & المحاور \\
\hline$\cdot, 979$ & - 90r & $\cdot, 970$ & r. & الطاقة الإيجابية في المسكن عامة \\
\hline$\cdot, \wedge$ ¿ & $\cdot, \wedge \xi \cdot$ & - A9r & 17 & الطاقة الإيجابية الخاصة بفرفة النوم \\
\hline$\cdot$, Arr & $\cdot, 9 \wedge \wedge$ & $\cdot, 9 \cdot 1$ & 1. & الطاقة الإيجابية الخاصة بغرفة المعيشة والاستقبال \\
\hline$\cdot, 90 \mathrm{r}$ & $\cdot, 9 r \mathrm{r}$ & $\cdot, 971$ & 11 & الطاقة الإيجابية الخاصة بغرفة الطعام \\
\hline$\cdot, 017$ & $\cdot 914$ & $\cdot, \mathrm{*}$ & 7 & الطاقة الإيجابية الخاصة بالحمام \\
\hline$\cdot, 919$ & $\cdot, 9 \cdot 0$ & -, AOr & 1. & الطاقة الإيجابية الخاصة بالمطبخ \\
\hline$\cdot$, Alr & $\cdot, 9$ 9ro & •, OVY & $\xi$ & الطاقة الإيجابية الخاصة بالممرات \\
\hline$\cdot, 919$ & $\cdot, 9 \Lambda \mathrm{r}$ & $\cdot, 994$ & rv & المجموع الكلي للطاقة الإيجابية في المسكن \\
\hline
\end{tabular}

يتضح من الجدول أن جميعها قيه عالية وتؤكد على ثبات الاستبيان . 
(ج) - استبيان لقياس الواجبات الأسرية بمحاورها : أعد هذا الاستبيان يِّوض ضوء التعريف الإجرائي

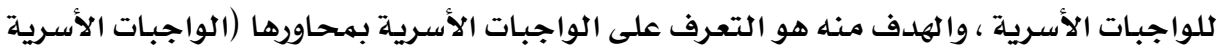

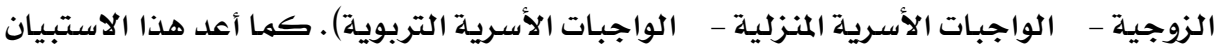

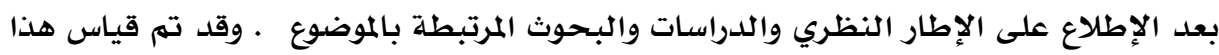

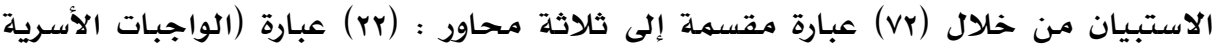

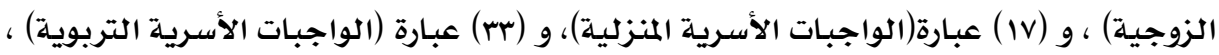

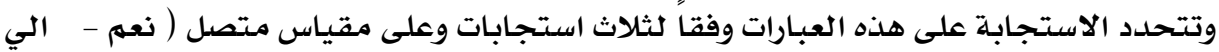

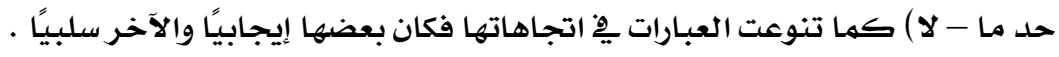

$$
\text { صدق وثبات الاستبيان :- }
$$

الصدق المنطقي للاستبيان :- ويهدف إلي الحكم علي مدي تمثيل الاستبيان للهدف الذي الني

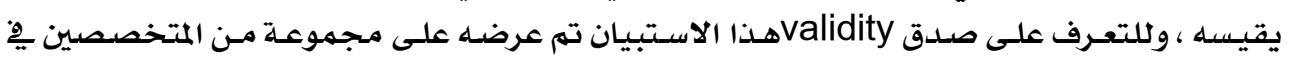

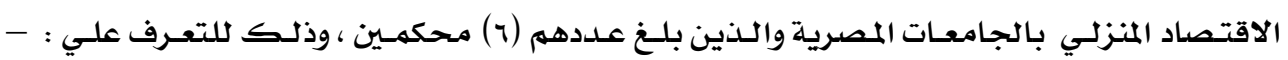

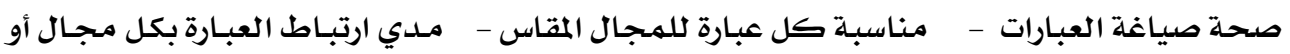

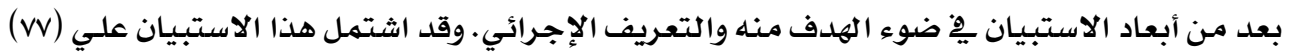

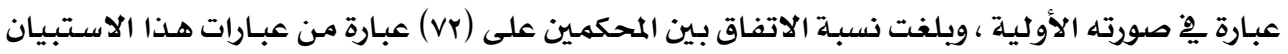

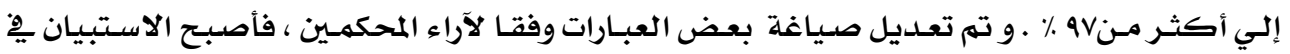

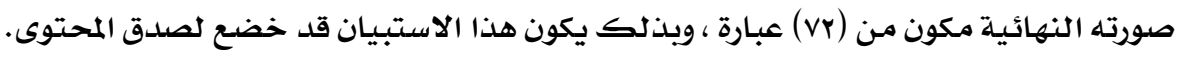

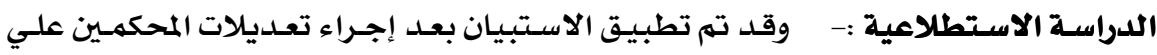

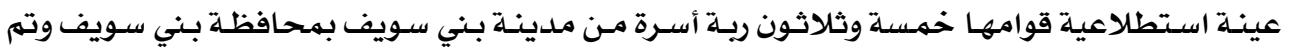

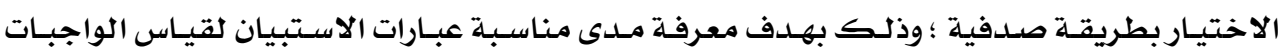

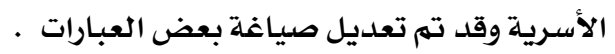
صلدق الاتساق الداخلي :- تم قياس صدق الاتساق الداخلي للاستبيان وذلك عن طريق

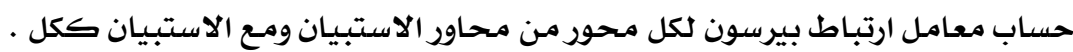
جدول (r) قيم معاملات الارتباط بين الدرجة الكلية لكل محوروالدرجة الكلية للاستبيان

\begin{tabular}{|c|c|c|}
\hline الدلالة & الارتباط & المحاور \\
\hline$\ldots 1$ & $.9 \wedge 7 \% *$ & الواجبات الأسرية الزوجية \\
\hline$\cdots 1$ & $.991 * *$ & الواجبات الأسرية المنزلية \\
\hline$\ldots 1$ & $\cdot .9 \cdot r * \%$ & الواجبات الأسرية التربوية \\
\hline
\end{tabular}

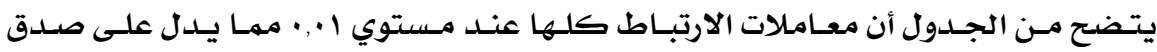
وتجانس محاور الاستبيان 


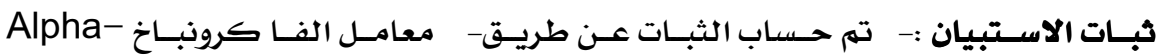

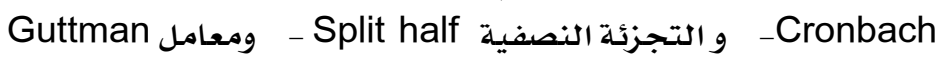

جدول (ع) قيم التجزئة النصفية و معامل ألفا وجيوتمان لكل محور من محاور الاستبيان وللاستبيان ككل

\begin{tabular}{|c|c|c|c|c|}
\hline معامل ألفا & معامل جيوتمان & التجزئة النصفية & عدد العبارات & المحاور \\
\hline$\bullet, ৭ \& \cdot$ & -, ara & $\cdot, 9 \leqslant \vee$ & rr & الواجبات الأسرية الزوجية \\
\hline -,9Y1 & -,9Ar & -,90r & iv & الواجبات الأسرية المنزلية \\
\hline$\cdot, 980$ & $\cdot 974$ & $\cdot, 90$ & $r r$ & الواجبات الأسرية التزبوية \\
\hline$\cdot, 9 \wedge \mathrm{V}$ & $\cdot, 91 \cdot$ & $\cdot, 99 \xi$ & VY & مجموع الواجبات الأسرية \\
\hline
\end{tabular}

يتضح من الجدول أن جميعها ق قيه عالية وتؤكد على ثبات الاستبيان .

سادسا : تحليل البيانات والمعاملات الإحصائية المتبعة:

اسـتخدمت بعـض الأسـاليب الإحســائية لكسف العلاقــة بـين مستغيرات الدراســة واختبـار

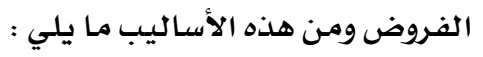

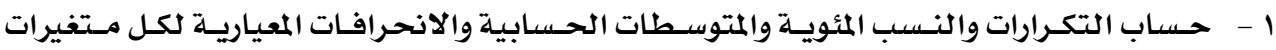

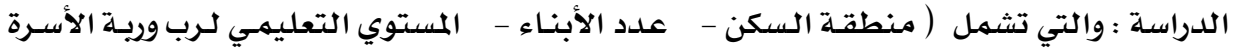

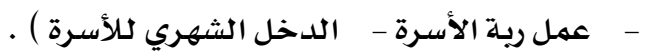

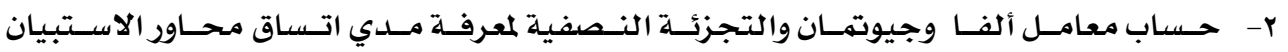

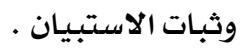

$$
\text { - حساب معامل الارتباط . - }
$$

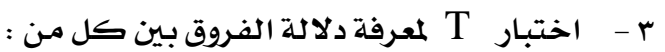

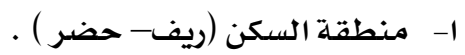

ب - ريات الأسر العاملات وغير العاملات .

ع - حساب تحليل التباين ANOVA وذلك لمعرفة :

أ - دلالة الفروق بين المستويات التعليمية المختلفة لرب وريـة الأسرة .

ب - دلالة الفروق بين مستويات الدخل المختلفة للأسرة . 


\section{النتائج وهناقشتها}

أولاً : وصف العينة

1- منطقة سكن رية الأسرة (ريف - حضر):-

جدول (ه ) التوزيع النسبي لعينة الدراسة تبعا منطقة السكن

\begin{tabular}{|c|c|c|}
\hline النسبة المئوية & العلد & منطقة السكن \\
\hline$r q, q$ & iro & ريف \\
\hline$v \cdot, 1$ & riv & حضر \\
\hline $1 \cdots$ & हor & المجحموع \\
\hline
\end{tabular}

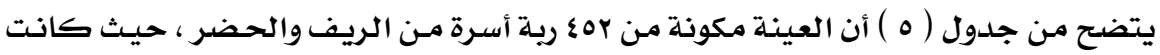

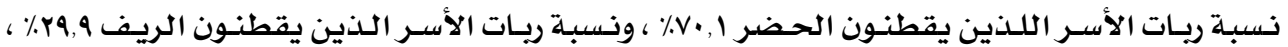
ويلاحظ أن نسبـة ريـات الأسـر يِّ الحضـر ثلثي العينـة تقريبـا. r- عمل رية الأسرة (عاملات -غير عاملات ):-

جدول ( ج) التوزيع النسبي لعينة الدراسة تبعا لعمل عمل ربة الأسرة (عاملات -غير عاملات )

\begin{tabular}{|c|c|c|}
\hline النسبة المئوية & العدد & عمل الأم \\
\hline $07, \%$ & roo & غير عاملات \\
\hline$\varepsilon r, q$ & 198 & عاملات \\
\hline $1 \cdots$ & SOY & المجموع \\
\hline
\end{tabular}

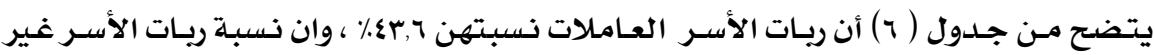

العامـلات ع.40٪ ، ويلاحظ أنه تكاد تقترب نسبـة العاملات من نسبة غير العاملات .

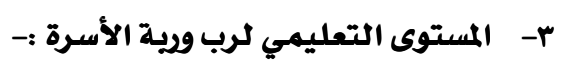

جدول ( v التوزيع النسبي لعينة الدراسة تبعًا لتعليم رية الأسرة

\begin{tabular}{|c|c|c|}
\hline النسبة المئوية & العدد & تعليم ربة الأسرة \\
\hline IV,0 & va & مستوي تعليي منخفض \\
\hline 18,7 & 77 & مستوي تعليم متوسط \\
\hline $7 V, 9$ & $r \cdot r$ & مستوي تعليم مرتفع \\
\hline 1.9 & SOY & المجموع \\
\hline
\end{tabular}

\section{أولا : مستوى تعليه رية الأسرة}

يتضح من جلدول (V) أن أعلى نسبـة يْ مستوى تعليهم ريسة الأسـرة كانت للهستوى التعليمي

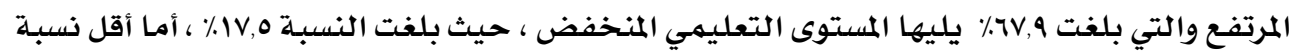

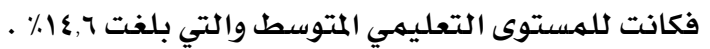




\begin{tabular}{|c|c|c|}
\hline النسبة المئوية & العلدد & مستوى تعليم رب الأسرة \\
\hline $\mid \Lambda, 1$ & Ar & مستوي تعليم منخفض \\
\hline 17,1 & Vy & مستوي تعليم متوسط \\
\hline 70 & rq々 & مستوي تعليم مرتفع \\
\hline $1 \cdots$ & sor & المجموع \\
\hline
\end{tabular}

\section{ثانيا : مستوى تعليم رب الأسرة}

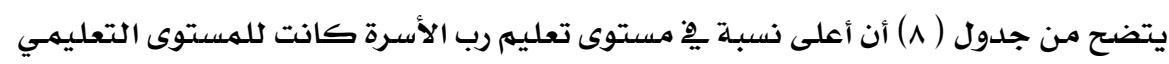

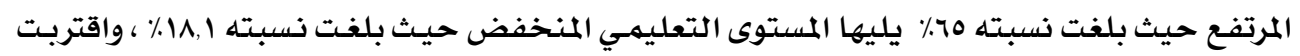

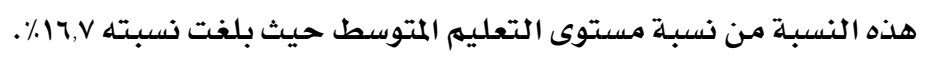

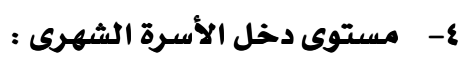

جدول ( (9) التوزيع النسبي لعينة الدراسة تبعًا لدخل الأسرة الشهري

\begin{tabular}{|c|c|c|}
\hline النسبة المئوية & العدد & دخل الأسرة الشُهري \\
\hline 17,1 & vy & مستوي دخل منخفض \\
\hline Ir,r & 7. & مستوي دخل متوسط \\
\hline 79,9 & HII & مستوي دخل مرتفع \\
\hline $1 \cdots$ & SOY & المجموع \\
\hline
\end{tabular}

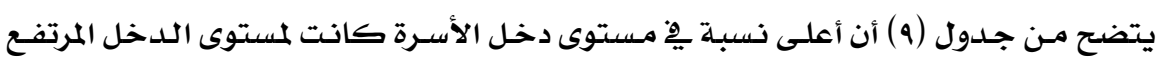

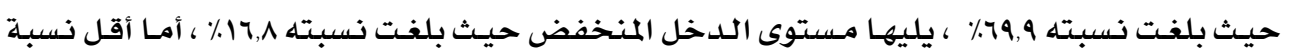

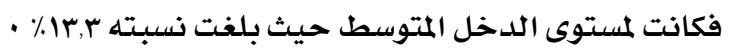

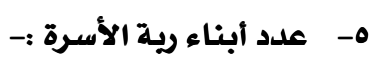

جدول ( ا ) التوزيع النسبي لعينة الدراسة تبعا لعدد الأبناء

\begin{tabular}{|c|c|c|}
\hline النسبة المئوية & العدد & علد الأبناs \\
\hline$r, Y$ & $\overline{T r}$ & ابز واحد \\
\hline$\llbracket \xi, 0$ & $r+1$ & ابنان \\
\hline$r \xi, 1$ & 1.9 & ثلاثة أبناء \\
\hline 18,9 & A1 & أربعة أبناء \\
\hline$\Lambda, \xi$ & $r \Lambda$ & خمسة أبناs \\
\hline$\cdot, 9$ & $\xi$ & ستة أبناء \\
\hline $1, r$ & 7 & سبعة أبناء \\
\hline$\cdot, r$ & 1 & ثمانية أبناء \\
\hline $1 \cdots$ & छor & المجموع \\
\hline
\end{tabular}

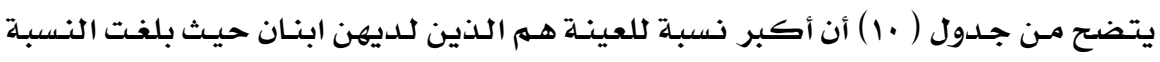

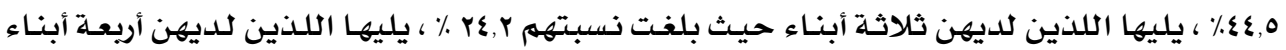




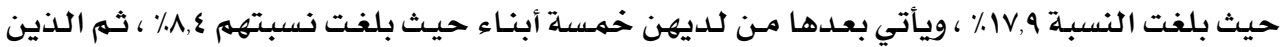

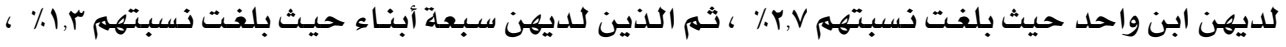

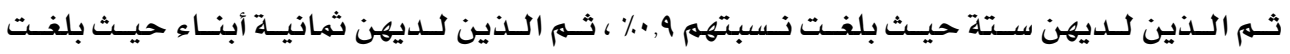

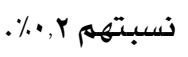

ـ دراسة مستوي الطاقة الإيجابية ِِِ المسكن:-

تم حسـاب مستوي الطاقـة الإيجابية يف المسكن عن طريق معرفة أقل درجـة حصلت عليها

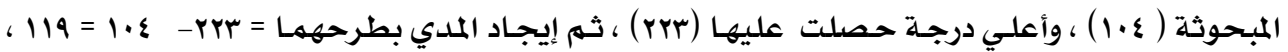

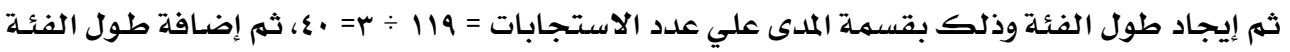

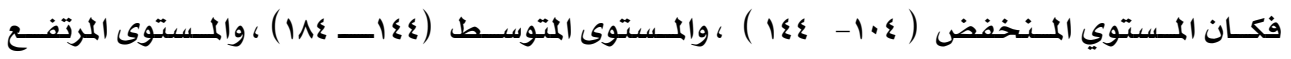
. (rrr $-1 \Lambda \varepsilon)$

جدول ( 11 ) التوزيع النسبي لعينة الدراسة تبعا لمستوى الطاقة الإيجابية يو المسكن

\begin{tabular}{|c|c|c|}
\hline النسبة & العدد العد & مستوي الطاقة الإيجابية في المسكن \\
\hline ro & 114 & مستوى منخفض ( \&־|_\{|| ) \\
\hline$\xi \Lambda, \xi$ & r19 & 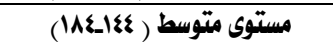 \\
\hline rq, & ire & مستوى مرتفع (YY_IA\&) \\
\hline $1 \cdots$ & sor & المجهوع \\
\hline
\end{tabular}

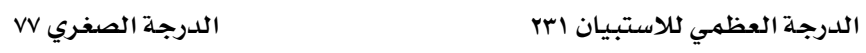

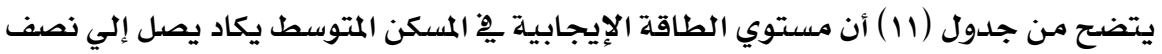

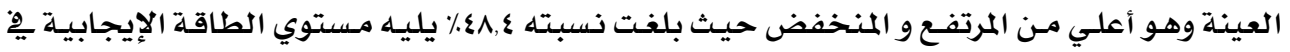

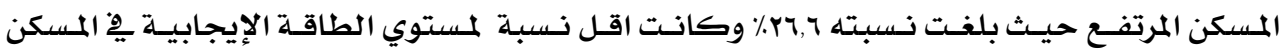

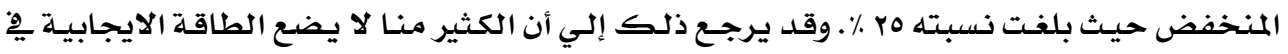

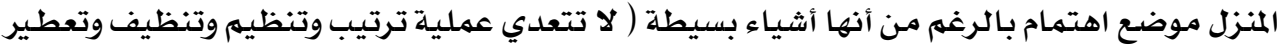

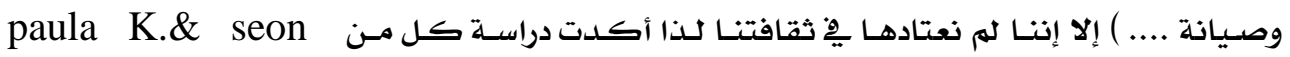

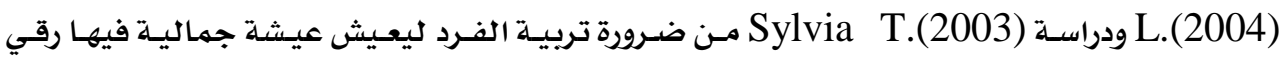
للمكان والبيئة.

\section{ـ دراسة مستوي الواجبات الأسرية.}

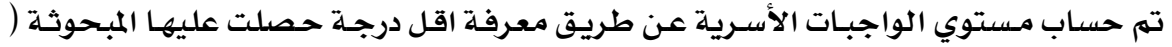

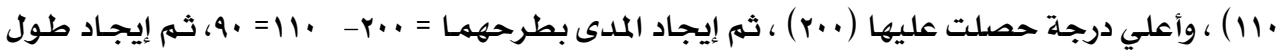

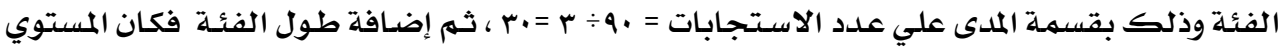

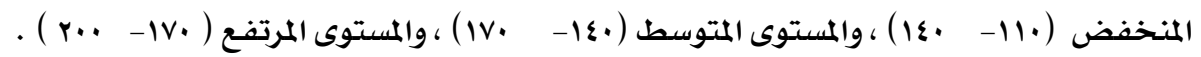




\section{جدول ( r ا ) التوزيع النسبي لعينة الدراسة تبعا لمستوى الواجبات الأسرية}

\begin{tabular}{|c|c|c|}
\hline النسبة & العدد & مستوي الواجبات الأسرية \\
\hline YI,Y & 91 & مستوى منخفض (•||-\&|) \\
\hline 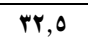 & $1 \leqslant V$ & مستوى متوسط (•lV_-1V) \\
\hline$\$ 0,1$ & $r \cdot r$ & مستوى مرتفع (•lV••Y) \\
\hline $1 \cdots$ & sor & المجموع \\
\hline
\end{tabular}

VY الدرجة الصغرى

الدرجة العظمي للاستبيان MIT

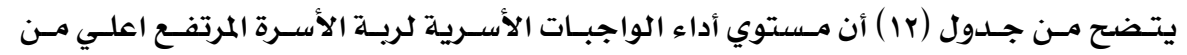

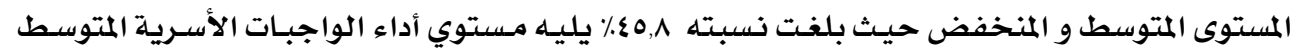

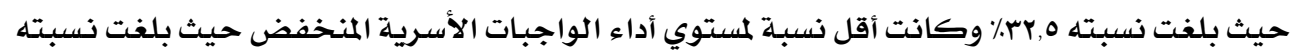

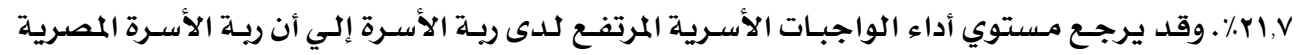

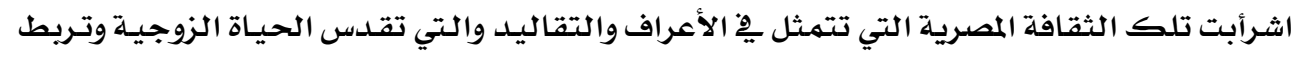

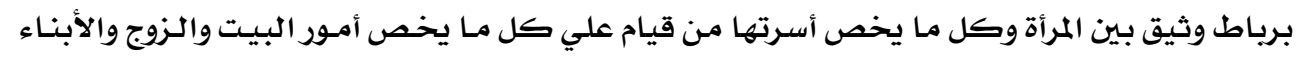

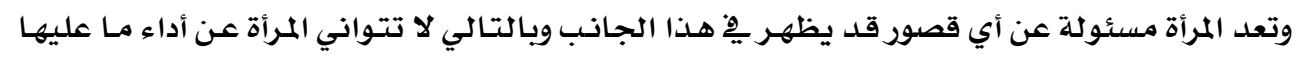

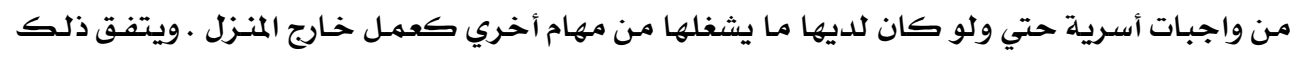

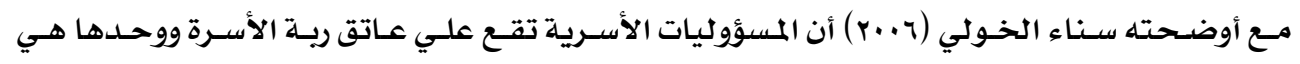

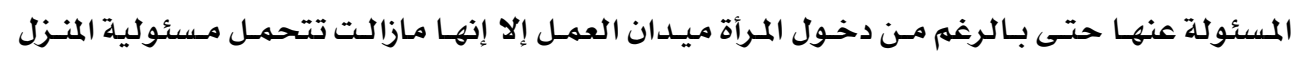
والعبء الأكبر من مسئوليات رعاية الأبناء . 
جدول ( ri ) توزيع استجابات عينة الدراسة تبعا للطاقة الايجابية يو المسكن

\begin{tabular}{|c|c|c|c|c|c|c|c|c|c|}
\hline \multicolumn{2}{|c|}{ 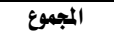 } & \multicolumn{2}{|c|}{$\mathbf{y}$} & \multicolumn{2}{|c|}{ إلى حلد ما با } & \multicolumn{2}{|c|}{ دائما } & \multirow{2}{*}{ العبارة } & \multirow{2}{*}{ a } \\
\hline نسبة & عدد & نسبة & عدد & 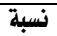 & عدد & 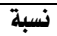 & عدد & & \\
\hline 1... & sor & 71,0 & rVA & $r \Lambda, 0$ & IV\& & - & - & 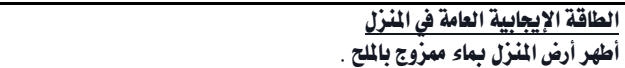 & 1 \\
\hline $1 \cdots$ & §or & $\cdot, r$ & 1 & $r \cdot, 0$ & $1+1$ & $79, r$ & rir & أنظف كل الأتربة الموجودة في المنزل يوميا خاصة الأتربة المخبأة في الأركان & $r$ \\
\hline 1.. & \&or & - & - & - & - & I... & §or & ارتفاع حوائط منزلي تتراوح من ثلاثة إلي خمسة أمتار & $r$ \\
\hline l*. & §or & 17,1 & VI & $1 \%, r$ & 7. & 79,9 & ri7 & أنظف كل خيوط العنكبوت الموجودة في المنزل خاصة المخباّة في الزوايا والأسقف & $\xi$ \\
\hline 1... & 乡or & $\xi r, 0$ & 194 & or,o & หq. & - & - & لا أضع أي ورود مجففه في المنزل . & 0 \\
\hline 1.. & §or & $\Delta 0, r$ & ro. & - & - & $\xi \xi, \vee$ & $r \cdot r$ & استخدم الكريستال المستدير ولا استخدم المدبب . & 7 \\
\hline 1.. & sor & $\cdot, r$ & 1 & $r q, 9$ & iro & 79,9 & ri7 & أقوم بتنظيف الحوائط التسخة أولاً بأول . & $\checkmark$ \\
\hline 1... & §or & $r 0, \xi$ & 110 & $r \cdot, 1$ & $1 \% 9$ & $\xi \xi, 0$ & $r \cdot 1$ & أقوم بطلاء الحوائط التسخة والتي يصعب تنظيفها & $\Lambda$ \\
\hline 1... & sor & iv & vY & $1 \%, r$ & १. & $79, Y$ & r10 & أتخلص من الكراكيب والأشياء التي لا أستخدمها بالمنزل أولا بأول، أو أتصلق بها & 9 \\
\hline 1.. & §or & 17,1 & VI & $r \Lambda, Y$ & ivo & $\$ \xi, 0$ & $r+1$ & أتخلص من الأشياء المعطلة بسرعة إصلاحها أو التخلص منها . & 1. \\
\hline $1 \cdots$ & 乡or & 17,1 & VI & $1 \%, 0$ & 71 & $79, Y$ & r10 & أتخلص من كل من الذكريات السيئة على الفور . & 11 \\
\hline $1 \cdots$ & sor & 17,1 & vq & $r \Lambda, \vee$ & ivo & $\$ \xi, 0$ & $r+1$ & الصور والأشياء الهامة احتفظ بها في علبة جميلة وأزيل الأتربة من عليها & ir \\
\hline 1.. & \$or & $r 9,7$ & Irs & $\begin{array}{c}, \xi \\
\end{array}$ & $r$ & 79,9 & ri7 & استخلم الألوان الزاهية لتزيين المنزل & it \\
\hline 1.. & §or & ro & IIT & - & - & vo & rra & لا احتفظ بنبات الصبار داخل البيت أو خارجه ه & iq \\
\hline $1 \cdots$ & \&or & iv & vV & 09,1 & rIY & $r r, q$ & $1 \cdot 1$ & أرتب الأثَاثُ بطريقة تسمح بوجود فراغ بين قطع الأثّاثٌ وبعضها & 10 \\
\hline $1 \cdots$ & \&or & iv & ry & $1 \%, Y$ & Tr & $79, r$ & rit & احرص على تشفيل وقراءة القران وخاصة سورة البقرة باستمرار في المنزل & 17 \\
\hline 1.. & \$or & $\cdot, r$ & 1 & $00, r$ & ro. & $\xi \xi, 0$ & $r+1$ & لا يوجد مكان خاص بي داخل المسكن يحقق لي الخصوصية & IV \\
\hline 1.. & sor & $r \cdot, 1$ & $1+7$ & $\cdot, r$ & 1 & $79, Y$ & r10 & أضع رناتات خلف باب المنزل & 11 \\
\hline l.. & §or & $r \cdot, 1$ & 1179 & - & - & 79,9 & ri7 & اقتنى قطع الأثُّث ذات الأطراف المنحنية وليس الحادة & 19 \\
\hline 1.. & \&or & $1 Y, 9$ & $\wedge 1$ & 01,0 & rrr & $r \cdot, 0$ & IrA & أوزع الورود والأزهار الطبيعية في أركان مختلفة في المنزل & r. \\
\hline 1... & \&or & $r \cdot, r$ & ITr & \{\rceil$, \vee$ & rII & rm & $1 . \xi$ & 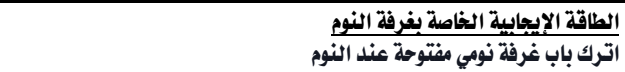 & 1 \\
\hline $1 \cdots$ & sor & 19,1 & vq & $r \varepsilon, 0$ & 107 & $\xi \Lambda, \mathrm{Y}$ & rr. & استخلام مفارش أنيقة للسرير & 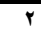 \\
\hline 1.. & \&or & 17,1 & VI & $\Delta 9, \mathrm{Y}$ & rre & $r r, 0$ & 1.7 & أعطر الجو في غرفة النوم برائحة الورد الخفيفة & $r$ \\
\hline $1 \cdots$ & 乡or & $r 9,7$ & Ir\& & $\cdot, 9$ & $\xi$ & 79,0 & ris & استعمل سريرًا من الخشب لا من المعلدن . & $\xi$ \\
\hline $1 \cdots$ & sor & $r q, 7$ & Irs & ro,r & 117 & $\xi \xi, \vee$ & $r \cdot r$ & توجد مرآة قبالة السرير تعكس صورته & 0 \\
\hline 1.. & \&or & $\cdot, \wedge$ & $\$ 9$ & $v \xi, 7$ & rry & $1 \xi, 7$ & 79 & لا أطفئ أنوار الفرفة عند النوم أو استعمل أنوارا هادئة & 7 \\
\hline 1.. & 乡or & $r \cdot, 0$ & IrA & - & - & 79,0 & ris & لا يوجدل بابان لفرفة نومي . & $\mathrm{v}$ \\
\hline 1... & §or & $\mathrm{Ir}, \Lambda$ & 01 & ro, $\mathrm{Y}$ & 117 & 71,0 & TrA & باب غرفة النوم قبالة المطبخ أو الحمام . & $\Lambda$ \\
\hline 1.. & \$or & 17,1 & Vq & $1 \%, r$ & 7. & 79,9 & riq & تنفذ أُشقة الشُمس بطريقة مباشُره في الفرفة & 9 \\
\hline $1 \cdots$ & sor & 17,1 & vi & $r \wedge, 0$ & IV\& & $\xi \xi, \vee$ & $r \cdot r$ & أزيل جيع الأجهزة من غرفة النوم كجهاز TV والهاتف المحمول . & 1. \\
\hline 1.. & \&or & $r q, 7$ & Irs & $\begin{array}{c}, \xi \\
\end{array}$ & $r$ & 79,9 & riq & السرير علي ارتفاع كبيز من الأرض . & 11 \\
\hline 1.. & 乡or & $r q, 7$ & Ir\& & - & - & V•,ई & rin & اترك باب دولاب الملابس مفتوحا بعد الاستخلام & ir \\
\hline $1 \cdots$ & \&or & $r q, 7$ & Irs & - & - & $\gamma \cdot, \varepsilon$ & rIA & توجد مساحة صفيرة أسفل السرير . & it \\
\hline 1.. & 乡or & 19,9 & 9. & $1 \xi, \Lambda$ & TV & 70,0 & r90 & أضع السرير مواجه لباب الفرفة . & $1 \varepsilon$ \\
\hline $1 \cdots$ & 乡or & $r, q$ & 99 & $\cdot, r$ & 1 & $\mathrm{VY}, \mathrm{q}$ & ror & أحرص على قراءة الأذكار قبل النوم وعند القيام منه & 10 \\
\hline 1... & sor & 1. & $\$ 0$ & $10, r$ & 79 & $r \xi, \Lambda$ & rra & استخدم ألوان هادئة لفرفة النوم كالأزرق و الرمادي الفاتح أو الأصفر الباهت .. & 17 \\
\hline $1 .$. & sor & $1 \xi, r$ & $7 \xi$ & $\cdot, \mathfrak{\varepsilon}$ & r & $\wedge 0, \xi$ & rat & تلدخل غرفة المعيشة إضاءة طبيعية ( أشعة الشمس الإستقبال المباشرة ) & 1 \\
\hline 1.. & §or & 9,0 & $\xi r$ & $\mathrm{rI}, \mathrm{Y}$ & 91 & $7 \Lambda, \Lambda$ & rII & أضع بعض النباتات الخضراء بغرفة المعيشة & r \\
\hline 1... & sor & VY, 9 & ror & rr,I & $1 \cdots$ & - & - & أعطر غرفة الميشة بالرقية الشرعية وبآيات الحفظ لي ولأسرتي . & $r$ \\
\hline $1 \cdots$ & sor & 1. & §o & $r, Y$ & 91 & $\uparrow \Lambda, \xi$ & $r .9$ & 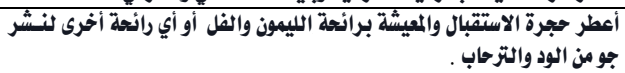 & $\xi$ \\
\hline l.. & \&or & $r, r$ & 91 & $\cdot, \xi$ & $r$ & $\mathrm{YY}, \mathrm{q}$ & ror & أستخدم في غرفة المعيشة أساس بخطوط منحنية أو مستديرة & 0 \\
\hline 1.. & \&or & $11, Y$ & or & 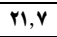 & 91 & 77,7 & $r+1$ & أحافظ علي مظهرها مرتبًا ومتزئًا & 7 \\
\hline 1.. & sor & $r, Y$ & 91 & ro,r & $11 \xi$ & or,1 & $r \xi$ & ينسجم الضوء مع ألوان الجدران والأرضية & v \\
\hline 1... & §or & - & - & $r \mid, Y$ & 91 & $V \Lambda, r$ & ro\& & لا يوجد بغرفة المعيشة أية كراكيب & $\Lambda$ \\
\hline
\end{tabular}


الطاقة الايجابية بإمالمسكن وعلاقتها باداء الواجبات الأسرية لرية الأسرة

\begin{tabular}{|c|c|c|c|c|c|c|c|c|c|}
\hline \multicolumn{2}{|c|}{ المجموع } & \multicolumn{2}{|c|}{$\bar{y}$} & \multicolumn{2}{|c|}{ إلى حلد ما } & \multicolumn{2}{|c|}{ دائها } & \multirow{2}{*}{ 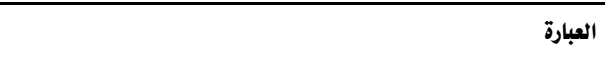 } & \multirow{2}{*}{ A } \\
\hline 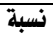 & 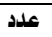 & 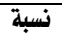 & عدد & 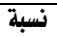 & علد & 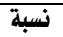 & عدد & & \\
\hline $1 \cdots$ & \&or & 17,1 & Vq & $0 \cdot, 9$ & rT. & rr,r & $1 \xi 7$ & أنظف الزرع الأخضر إن وجد من التراب بغسله أو مسحه & 9 \\
\hline $1 \cdots$ & \&or & 17,1 & V7 & $r \xi, 1$ & $10 \xi$ & $\$ 9,1$ & rrr & أتفادي الزوايا المظلمة في بيتي وأضيئها & $1 \cdot$ \\
\hline $1 \ldots$ & sor & $r 9,9$ & iro & - & - & $v \cdot, 1$ & riv & أضع مرآة كبيرة تعكس صورة الطعام والجالئسين الإبرة الطابية الطعام & 1 \\
\hline $1 \cdots$ & \&or & - & - & $T \gamma, r$ & r.६ & $r r, r$ & $1 \xi \Lambda$ & أزين غرفة الطعام بعناصر طبيعية كحوض السمك & r \\
\hline 1... & \&or & 11,1 & 10 & 10,0 & ve & $70, Y$ & ray & غرفة الطعام للدي قريبة جدا من المدخل الرئيسي للبيت & r \\
\hline 1... & 乌or & $\mathrm{IV}, \mathrm{r}$ & VA & 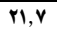 & 91 & 71,1 & rYq & عند وجود ركنة للطعام فإني أفصلها عن باقي أركان المنزل & $\xi$ \\
\hline $1 \cdots$ & \&or & $r q, 7$ & Irs & $\begin{array}{r}, \xi \\
\end{array}$ & $r$ & 79,9 & ri7 & طاولة الطعام ليست بها زوايا حادة فقد تكون بيضاوية الشكل أو مستديري & 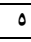 \\
\hline 1 1.. & sor & $r q, 7$ & itrs & $\Lambda, \Lambda$ & $\xi$ & 71,0 & rYA & كراسي غرفة الطعام للديّّ مجموع عددها زوجي . & 7 \\
\hline 1... & \$or & $r 9,7$ & IT\& & •, § & r & 79,9 & ri7 & أضع الكراسي والطاولة بعيدا عن مواجهة أي باب & $\mathrm{v}$ \\
\hline $1 .$. & \&or & $70, \mathrm{~V}$ & rav & $\Lambda, \Lambda$ & $\xi$ & 71,0 & rYA & ألوان الستائر مشرقة وجذابة . & $\Lambda$ \\
\hline 1... & 乌or & $r 9,7$ & ITs & $\cdot, \xi$ & r & 79,9 & riq & ألوان طلاء غرفة الطعام للدي فاتحة كالأبيض أو السماوي ، أو الأخضر الفاتع . & 9 \\
\hline 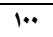 & sor & $r q, 7$ & itr & $\Lambda, \wedge$ & $\xi$ & 71,0 & rYA & عند وجود شعدلان بغرفة الطعام لابد أن يكون فيا شموع جميلة اللوز & 1. \\
\hline $1 .$. & \&or & $\mathrm{rq}, 7$ & Irs & $\cdot, \xi$ & $r$ & 79,9 & riq & نافذة غرفة الطعام تطل علي مظهر جميل . & 11 \\
\hline 1... & \&or & 19,1 & vi & 0,9 & r. & $r, r$ & $1 \leqslant 7$ & أنظف حمافي يوميتًا مرة أو أكثر الحمام & $\overline{1}$ \\
\hline $1 \cdots$ & \&or & $\xi \pi, \Lambda$ & 191 & $r \cdot, 1$ & $1+7$ & $\mathrm{rq,1}$ & 111 & أضع شييًا من الخل التفاح عند تنظيف الحعام & r \\
\hline $1 \cdots$ & gor & $\xi \cdot, r$ & IAY & $9, r$ & $\xi r$ & $0 \cdot, \varepsilon$ & rYA & أذكر اسم الله عند دخول الحمام . & $r$ \\
\hline 1... & 乌or & $r 9,1$ & $1 \mathrm{~A} \cdot$ & $r \xi, 1$ & $10 \xi$ & $r 7,1$ & 111 & أقدم رجلي اليسري قبل دخولي الحمام واليمني عند خروجي. & $\xi$ \\
\hline $1 .$. & \&or & 1,1 & 0 & $\$ 9, \wedge$ & rro & $\S 9,1$ & rrr & أغلق باب الحمام بعد الاستعمال . & 0 \\
\hline 1... & sor & 10,0 & v. & $\cdot, \xi$ & r & $\wedge \xi, 1$ & rA. & ألوان الحمام للدي الأزرق أو مشتقاته & 1 \\
\hline 1... & \&or & $r 9, \Lambda$ & in. & $r \xi, 1$ & $10 \xi$ & $\mathrm{r}, 1$ & 111 & أتخلص من الأواني والزجاجة المشروخ & 1 \\
\hline $1 \cdots$ & gor & $r \cdot, \Lambda$ & $9 \xi$ & $r A, 9$ & IV7 & $\xi \cdot, r$ & IAY & أتخلص من جميع الأواني القديعة أولا بأول & $r$ \\
\hline $1 \cdots$ & \&or & $\mathrm{IV}, \mathrm{r}$ & $r \wedge$ & $r \cdot, 1$ & $1+4$ & or,Y & rrA & لا أترك أواني متسخة بالمطبخ مهما كانت مشاغلي & r \\
\hline $1 \cdots$ & sor & - & - & $r \Lambda, 0$ & IY & 71,0 & rYA & أرتب أدوات المطبخ باستمرار . & $\xi$ \\
\hline 1... & 乌or & 17,1 & vy & $r \cdot, 1$ & $1+4$ & $r 0,1$ & r६. & أعيد كل الأجهزة والأدوات بعد استخدامها & 0 \\
\hline $1 \ldots$ & \&or & - & - & $r \Lambda, 0$ & IV\& & 71,0 & rYA & أتخلص من كل روائح المطبخ عن طريق الشفاط فقط & 7 \\
\hline 1... & 乡or & $r 9,7$ & Irs & $\mid \mathrm{i}, \mathrm{r}$ & YA & or, 1 & $r \xi$ & لا أترك بقايا أي أطعة بالمبخخ & $\mathrm{r}$ \\
\hline $1 \cdots$ & sor & $\mathbf{I r , \Lambda}$ & $\Delta \Lambda$ & $\{r, 0$ & 194 & $\$ \xi, Y$ & r.r & أتعهل الثلاجة وبقايا أجهزة المطبخ بالتنظيف والصيانة & $\Lambda$ \\
\hline $1 .$. & \&or & $\mathbf{I r , \Lambda}$ & $\Delta \Lambda$ & iv,r & $\mathrm{VA}$ & 79,9 & r17 & ثلاجتي لا يفوح منها روائح كريهة & 9 \\
\hline $1 \cdots$ & \&or & 19,1 & Vq & $r 9,7$ & Itrs & or, r & rEY & بعد الاستخدام أتأكلد من غلق جميع أبواب دواليب المطبخ & $1 \cdot$ \\
\hline $1 .$. & sor & $\mathbf{I r}, r$ & 7. & - & - & $\wedge \uparrow, \vee$ & rar & 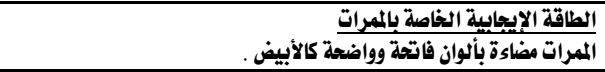 & 1 \\
\hline $1 .$. & \&or & $I^{\prime r}, \Lambda$ & $0 \Lambda$ & - & - & $\Delta v, r$ & raq & الأبواب الموجودة في الممرات مفتوحة دائمًا & $\bar{r}$ \\
\hline $1 \cdots$ & sor & $r \cdot, \Lambda$ & 179 & - & - & $79, r$ & TIT & ممرات بيتي طويلة وضيقة & $r$ \\
\hline $1 \cdots$ & sor & 17,1 & Vy & $r \Lambda, 0$ & IV乏 & $\xi \xi, Y$ & $r \cdot r$ & أضع نباتات طبيعية علي جانبي الممرات & $\xi$ \\
\hline
\end{tabular}

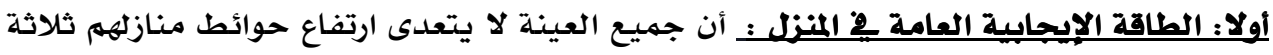

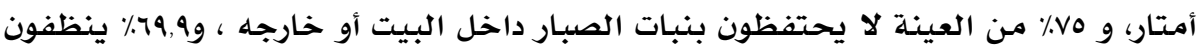

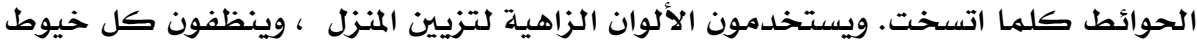

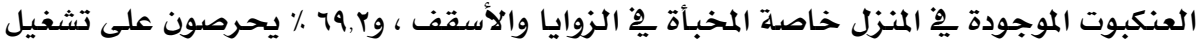

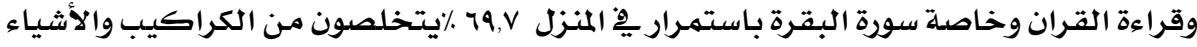

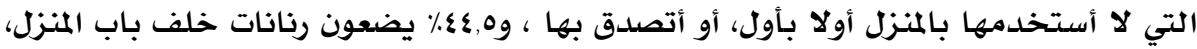




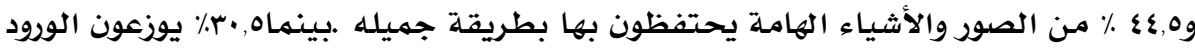

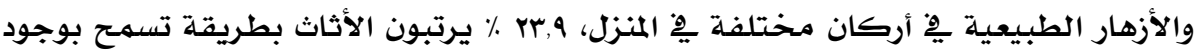

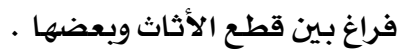
ثانيا : الطاقة الإيجحابية الخاصة بغرفة النوم ؛ VV,q٪ يحرصون على قراءة الأذكار قبل النوم وعند

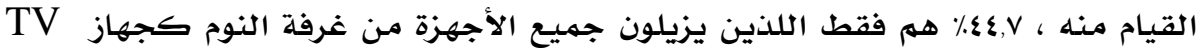

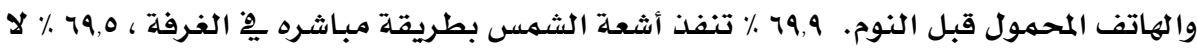

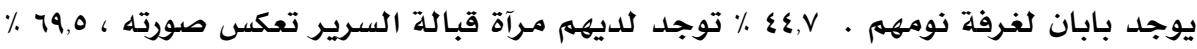

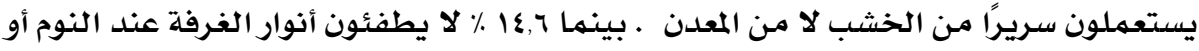

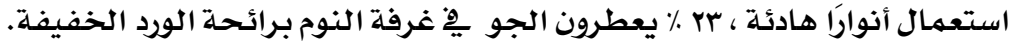

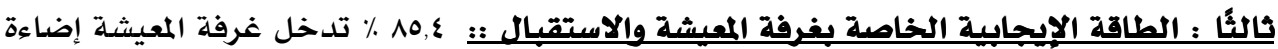

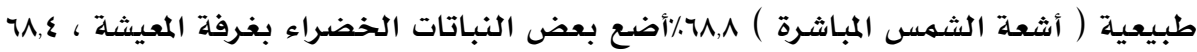

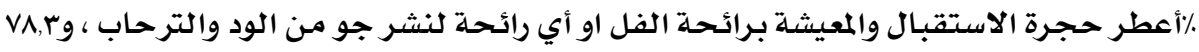

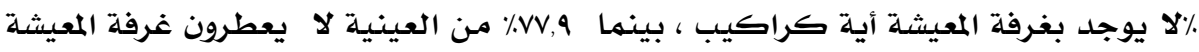

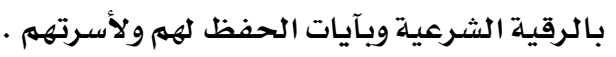

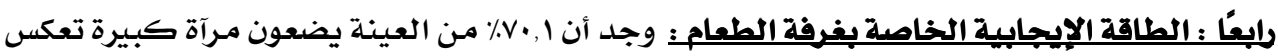

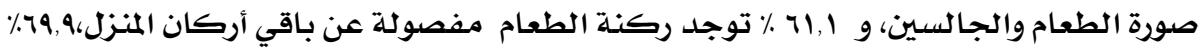

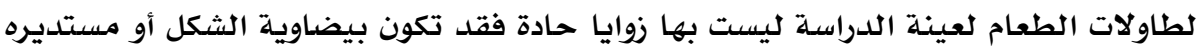

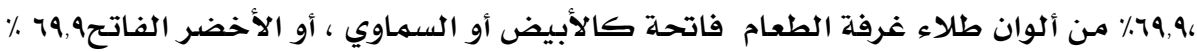

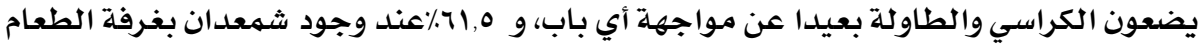

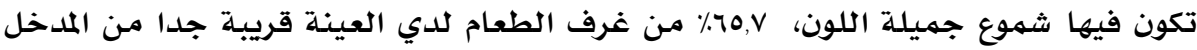

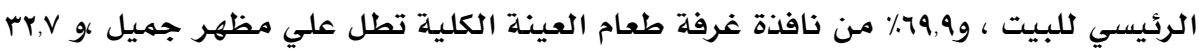

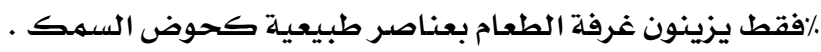

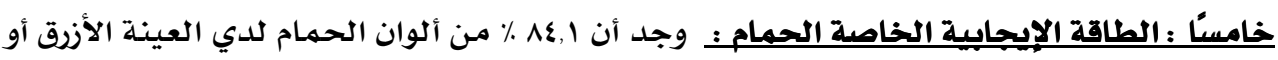

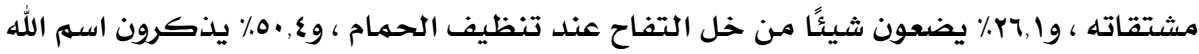

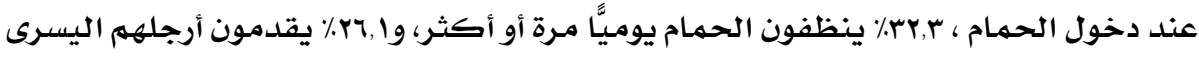

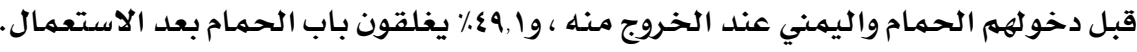

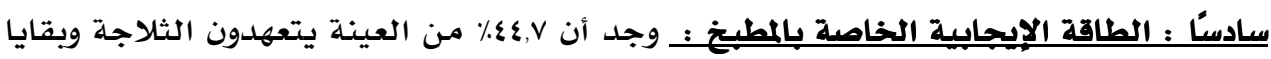

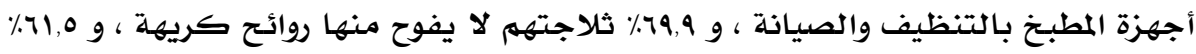

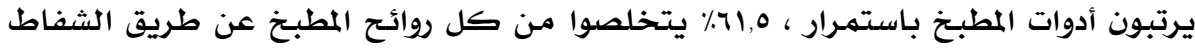

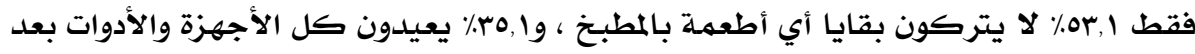

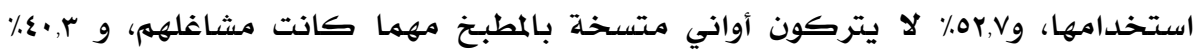




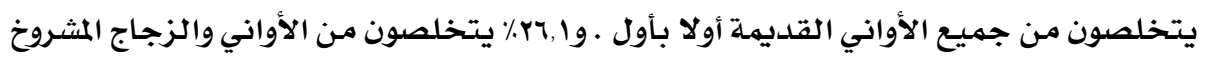

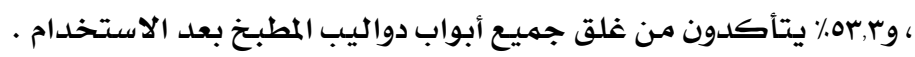

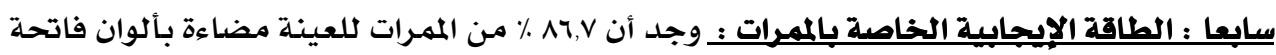

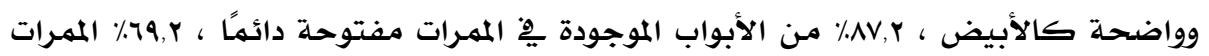

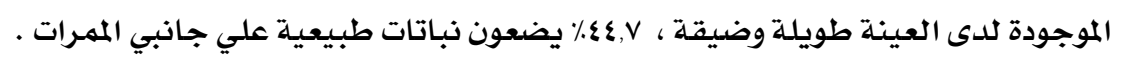

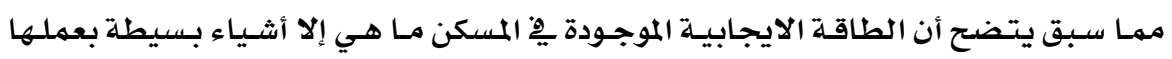

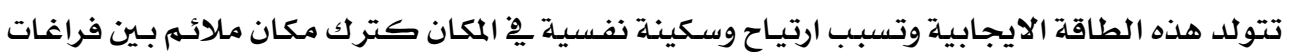

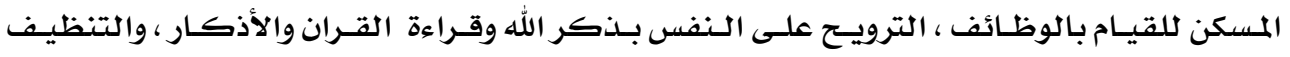

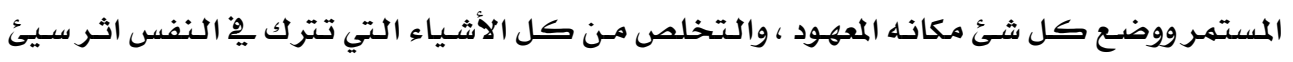

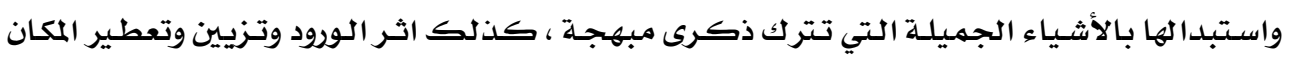

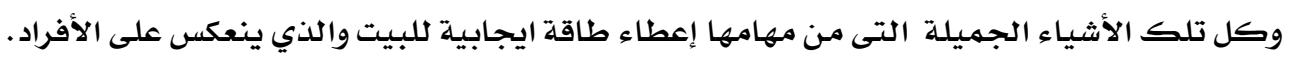

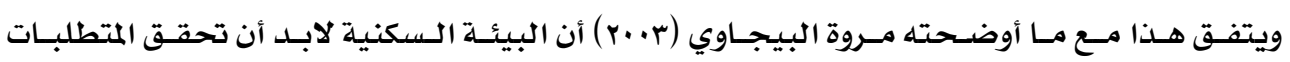

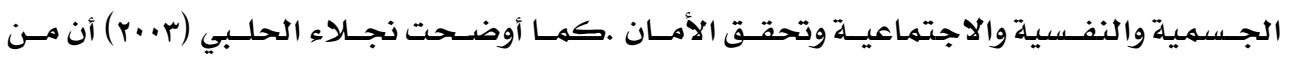

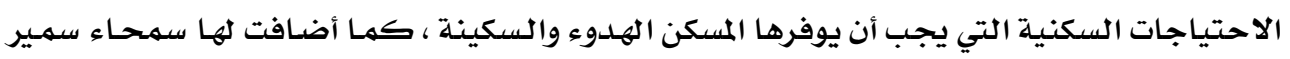

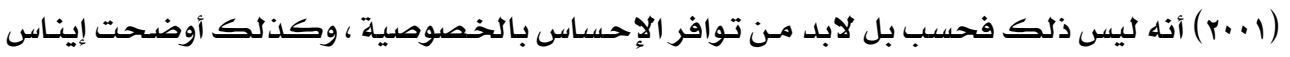

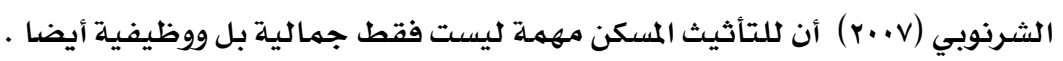


جدول (\&) ) توزيع استجابات عينة الدراسة تبعا للواجبات الأسرية لرية الأسرة

\begin{tabular}{|c|c|c|c|c|c|c|c|c|c|}
\hline \multicolumn{2}{|c|}{ المجموع } & \multicolumn{2}{|c|}{ 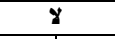 } & \multicolumn{2}{|c|}{ إلي حلَِّ ما } & \multicolumn{2}{|c|}{ 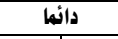 } & \multirow{2}{*}{ 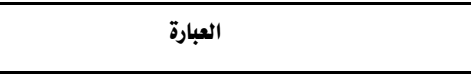 } & \multirow{2}{*}{ ค } \\
\hline | نسبة & علد & |نسبة & عدد عد & نسبة & عدد & نسبة & عدد & & \\
\hline $1 \cdots$ & \&or & $r q, \Lambda$ & $11 \cdot$ & $9, r$ & $\varepsilon r$ & $0 ., 9$ & rr. & أعمل علي حل المشكلات والأزمات : الواجبات الزوجية إذا وجية & 1 \\
\hline $1 \cdots$ & \&or & $\mathrm{rq}, \mathrm{Y}$ & IT\& & $r q, 1$ & $11 \wedge$ & $\boldsymbol{\xi \varepsilon , r}$ & r.. & أحرص علي أن أكون جميلة وجذابة أمام زوجي & $r$ \\
\hline $1 \cdots$ & §or & 17,1 & VY & $r \cdot, 1$ & 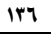 & or,1 & Y६. & أقف بجوارزوجي في جميع أزماته & $r$ \\
\hline $1 \cdots$ & \&or & $\mathbb{i r}, \Lambda$ & $\Delta \Lambda$ & ro, 7 & 117 & 71,0 & rVA & مهما يكن الخلاف بيني وبين زوجي لا ألجا للهجر والخصام & $\xi$ \\
\hline $1 \cdots$ & §or & 17,1 & vi & $i r, r$ & 7. & 79,9 & ril & أحرص علي مشاركة زوجي جميع مناسباته المختلفة & 0 \\
\hline $1 \cdots$ & \&or & $\mathbb{I r}, \Lambda$ & $\Delta \Lambda$ & rq, 7 & ITE & or, Y & rq. & أعامل زوجي بالحسني . & 7 \\
\hline $1 \cdots$ & §or & 17,1 & vi & IT,Y & ar & 79,0 & MIE & أحرص علي أن يظهر زوجي بصورة لائقة أمام الآخرين & 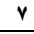 \\
\hline $1 . \cdot$ & sor & $\mathbf{I r , \Lambda}$ & $\Delta \wedge$ & - & - & $\Lambda V, r$ & ras & أتسامع مع زوجي إذا حدث بيننا مشكلة & $\wedge$ \\
\hline $1 .+$ & \&or & $17, \wedge$ & VY & $\mathbb{I r}, \Lambda$ & $\Delta \Lambda$ & $V \cdot, \xi$ & rin & أكثر من الثناء علي زوجي أمام الآخرين & 9 \\
\hline $1 \cdots$ & \&or & $\mathbb{I r}, \Lambda$ & $\Delta \Lambda$ & rv, 7 & iv. & $\$ 9,7$ & TYE & أشعر زوجي بأنه أهم شخص في حياتي . & 1. \\
\hline $1 .+$ & \&or & 17,1 & VY & Ir, r & 7. & 79,9 & riq & استقبل زوجي بالكلم الطيب عند دخوله المنزل . & 11 \\
\hline $1 \cdots$ & §or & 18,7 & 79 & $r \wedge, q$ & IVY & $\leqslant 7,0$ & M. & أهتم بتوفير الخصوصية بيني وبين زوجي . & ir \\
\hline $1 \cdots$ & sor & $r r, O$ & 1.7 & $r r, I$ & $1 \cdots$ & $0\}, \xi$ & 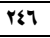 & أحرص دائمًا ألا يشم مني زوجي إلا الرائحة الجميلة & ir \\
\hline $1 \cdots$ & sor & 17,1 & VY & $r \cdot 1$ & Iry & or,l & r\&. & أسامح زوجي إذا اخطأ في حقي . & 18 \\
\hline $1 \cdots$ & sor & $r q, \Lambda$ & 1A* & $r 1, Y$ & 91 & rA,O & IVE & أظهر الاهتمام عند العلاقة الجنسية لإرضاء زوجي . & 10 \\
\hline $1 \cdots$ & sor & 17,1 & VY & $r \cdot, 1$ & Iry & or,l & Y\&. & أقدر احتياجات زوجي للعاطفة وأقدمها له متي شاء & 17 \\
\hline $1 \cdots$ & 乡or & 17,1 & VY & $r \xi, 0$ & $19 r$ & $\varepsilon \cdot, \bigvee$ & IA\& & حسن المحاشرة متوفر بيني وبين زوجي . & IV \\
\hline $1 .+$ & \&or & 17,1 & VY & Ir,Y & Ir & 79,0 & MIE & يعرف زوجي عني أدق تفاصيل حياتي . & 11 \\
\hline 1. & sor & - & - & $r 1, Y$ & 91 & $V \wedge, r$ & ros & ألا أبالغ في غيرتي علي زوجي & 19 \\
\hline $1 \cdots$ & \&or & 17,1 & VY & Ir, r & 7. & 79,9 & FIY & أتبادل الهلدايا أنا وزوجي في مناسباتنا الخاصة & $r \cdot$ \\
\hline $1 \cdots$ & sor & 17,1 & VY & $\mathrm{rI}, \mathrm{Y}$ & 91 & 71,0 & rYA & أقدر رغبات زوجي الشخصية & $M$ \\
\hline $1 \cdots$ & sor & or, $Y$ & rrA & $r \mid, r$ & 97 & $r 7,1$ & 111 & لا أناقش شيئا سييًا مع زوجي في غرفة نومي & rr \\
\hline $1 \cdots$ & sor & ir,o & 71 & $19, Y$ & 19 & 77,1 & $r+r$ & أتخير أطيب الكلام في حديثي مع زوجي & rr \\
\hline $1 \cdots$ & \&Or & $r r, 7$ & $10 \mathrm{r}$ & $r r, \Lambda$ & $10 \%$ & $r r, O$ & $1 \leqslant Y$ & أحرص علي وجود مكان لزوجي يتمتع فيه بالخصوصية الأسرية المنية & 1 \\
\hline $1 \cdots$ & sor & $\mathbb{i r}, \Lambda$ & $\Delta \Lambda$ & iv,r & V^ & 79,9 & HIT & أحرص علي أن يجد زوجي ما يأكله إذا جاع . & r \\
\hline $1 \cdots$ & sor & 17,1 & VY & rq, 7 & ITE & or,o & rir & أحرص علي عمل الأصناف التي يحبها زوجي من آن لآخز & $r$ \\
\hline $1 \cdots$ & sor & ir,0 & 71 & $19, \mathrm{Y}$ & 19 & 77,1 & $r+r$ & أحافظ علي نظافة أولادي ليراهم زوجي دائمًا في أحسن صورة . & $\varepsilon$ \\
\hline $1 \cdots$ & sor & $\mathrm{rq}, \Lambda$ & 1A* & $\mathrm{rA}, 0$ & IV₹ & rI, Y & 91 & أحاول أن اجعل البيت هاديًا مريحًا عند عودة زوجي من العمل . & 0 \\
\hline $1 . \cdot$ & ६or & $\mathbb{} \mid \boldsymbol{\Lambda}, \Lambda$ & $0 \wedge$ & IV,r & V^ & 79,9 & MII & اشترك مع زوجي في وضع القرارات المالية & 7 \\
\hline $1 \cdots$ & sor & 17,1 & vi & rA, 0 & IVร & $\mathfrak{\xi \varepsilon , Y}$ & $r+r$ & أنا من أضع بنود الإنفاق المختلفة & $\checkmark$ \\
\hline $1 \cdots$ & sor & Ir, 1 & $\Delta \wedge$ & IV,r & VA & 79,9 & ril & اشتري بديلات الأطعمة للتفلب علي ارتفاع الأسعار & $\wedge$ \\
\hline $1 \cdots$ & \&or & $17, \wedge$ & VY & $\mathrm{rA}, 0$ & IVร & $\xi \xi, Y$ & $r \cdot r$ & أحلد أولوياتي عند الشراء الأهم فالمهم . & 9 \\
\hline $1 \cdots$ & \&or & or,1 & r\&. & $r \varepsilon, 1$ & $10 \varepsilon$ & Ir, 1 & $\Delta \wedge$ & اشتري كل ما أرغب في شرائه من ملابس . & 1. \\
\hline $1 \cdots$ & sor & 17,1 & VY & rA,0 & IV乏 & $\boldsymbol{\xi \varepsilon , Y}$ & $r+r$ & أهتم بموازنة الدخل المالي للأسرة مع الاحتياجات المتعددة & 11 \\
\hline $1 \cdots$ & sor & $\mathbf{I r}, \Lambda$ & $\Delta \wedge$ & $0\}, 9$ & $r \leqslant \Lambda$ & rr, r & $1 \leqslant 7$ & أتجنب حلوثُ قصور في ميزانية الأسرة . & ir \\
\hline $1 \cdots$ & sor & rq, 7 & IT\& & ry,l & 111 & $\boldsymbol{\varepsilon \varepsilon , r}$ & $r+$. & اقتصد في وجوه الإنفاق المختلفة . & it \\
\hline $1 . \cdot$ & \&or & $\| r, \Lambda$ & $0 \wedge$ & $r \&, 1$ & $10 \varepsilon$ & or, I & r६. & أضع في ميزانية الأسرة بندًا للترفيه . & 18 \\
\hline $1 \cdots$ & sor & $r q, 7$ & IT\& & 17,1 & V7 & Or,o & rir & أضع بندا للطوارئ من ميزانية الأسرة . & 10 \\
\hline $1 \cdots$ & \&or & - & - & $\{\eta, 0$ & ri. & or,o & rEY & أضع بندَ في الميزانية للادخار. & 17 \\
\hline $1 \cdots$ & \&or & - & - & $r q, 7$ & ITE & $v \cdot, \xi$ & rin & أقوم بالأعمال المنزلية من غسل وطبخ وتنظيف .... & iv \\
\hline $1 \cdots$ & \&or & $1, \Lambda$ & $\Lambda$ & rq, 7 & ITE & $7 \wedge, 7$ & r. & أخصص جزيًا من وقتي لتبادل الحديثُ مع أفراد أسرتي & 11 \\
\hline $1 .$. & sor & 17,1 & vi & Ir, $\mathrm{Y}$ & ar & 79,0 & MI & 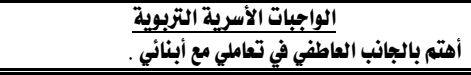 & 1 \\
\hline $1 \cdots$ & sor & $\cdot, r$ & 1 & $\Delta 9,0$ & r79 & $\varepsilon \cdot$, & iAr & أخرج للتنزه والترفيه مع أسرتي كلما سنحت الظروف . & r \\
\hline $1 \cdots$ & sor & 17,1 & VY & IT,0 & 71 & $79, V$ & rio & أهتم برعاية وتوجيه أبنائي . & $r$ \\
\hline $1 \cdots$ & sor & - & - & $\Delta 9, r$ & rqA & $\xi \cdot, Y$ & IAE & أوافق زوجي في طريقة تأديب أبنائنا . & $\varepsilon$ \\
\hline
\end{tabular}




\begin{tabular}{|c|c|c|c|c|c|c|c|c|c|}
\hline \multicolumn{2}{|c|}{ 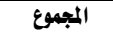 } & \multicolumn{2}{|c|}{$\mathbf{y}$} & \multicolumn{2}{|c|}{ 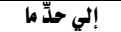 } & \multicolumn{2}{|c|}{ دائما } & \multirow{2}{*}{ 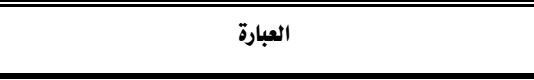 } & \multirow{2}{*}{ A } \\
\hline 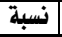 & علد & 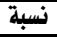 & عدد & نسبة & علد & 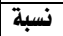 & علدد & & \\
\hline $1 \cdots$ & sor & 17,1 & VI & $\mid \mathrm{Ir}, \mathrm{Y}$ & Ir & 79,0 & riई & أتشارك أنا وزوجي في مناقشة مشاكل الأبناء وحلها & 0 \\
\hline $1 \cdots$ & \&OY & - & - & $\checkmark \vee, 1$ & r\$ะ & $r r, q$ & $1+1$ & أتدلدل في اختيار أصدقاء أبنائي . & 7 \\
\hline $1 \cdots$ & \&or & 17,1 & VI & Ir,Y & Ir & 79,0 & ris & أعاقب أبنائي علي مختلف الأخطاء . & 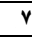 \\
\hline $1 \cdots$ & sor & - & - & $v q, 1$ & r\$ะ & $r r, q$ & $1+1$ & أعطي لأبنائي الحرية الكاملة في التعبير عن آرائهم . & $\Lambda$ \\
\hline $1+\cdots$ & \&or & $1 r, \Lambda$ & $0 \wedge$ & $r \xi, 1$ & $10 \xi$ & or,1 & r\&. & أتابع سلوك أبنائي باهتمام في المواقف المختلفة . & 9 \\
\hline 1... & \&or & - & - & $\mathrm{VY,1}$ & $r \leqslant \xi$ & $r r, q$ & $1 \cdot 1$ & أشارك كأبنائي مختلف ألعابهم وأنشطتهم . & 1. \\
\hline $1 \ldots$ & \&or & $r q, 1$ & 1A. & $r \cdot, 0$ & IrA & $r q, 7$ & Irs & أعطي لأبنائي الهلايا المختلفة لتشجيعهم علي المذاكرة . & 11 \\
\hline $1 . \cdot$ & sor & rr & 1.8 & $\$ 7,0$ & ri. & $r \cdot, 0$ & IrA & يسمع أبنائي مشاكلي مع زوجي . & ir \\
\hline 1... & sor & 17,1 & vy & $r q, 7$ & ITE & or,o & rar & أساعد أبنائي في اتخاذ القرارات الخاصة بهـ . & it \\
\hline $1 \cdots$ & \&or & - & - & $\$ 7,0$ & $r$ r. & or,o & rst & يساعدني أبنائي في الأعمال المنزلية علي حسب أعمارهم . & 18 \\
\hline 1... & \&or & 19,1 & 19 & $r q, 7$ & IT\& & or,o & TEY & أحرص علي تناول جميع أفراد الأسرة للطعام بعضهم مع بعض & 10 \\
\hline $1 \cdots$ & \&or & $1, \wedge$ & $\Lambda$ & $r q, 7$ & Irs & 71,7 & ri. & أشُارك أبنائي مذاكرة الدروس وكتابة الواجبات المدرسية . & 17 \\
\hline $1 \cdots$ & sor & $\mathbf{i v , r}$ & VA & $r \wedge, 0$ & IV\& & $\xi \xi, r$ & r.. & اشرح لأبنائي ما يصعب عليهم في المقررات الملدرسية . & iv \\
\hline $1 \cdots$ & sor & - & - & $\$ 7,9$ & rIT & or,1 & $r \xi$ & أعطي أبنائي دروسًا خصوصية . & 11 \\
\hline $1 \cdots$ & \&or & 17,1 & VI & $\xi Y, 0$ & $19 r$ & $\xi \cdot, \mathrm{Y}$ & IA乏 & أجيب عن أسئلة أبنائي الكثيرة في مختلف النواحي . & 19 \\
\hline $1 \cdots$ & sor & - & - & $r \cdot, 0$ & ira & 79,0 & ris & أبسط لأبنائي بعض الأمور المعقدة لفهم الكون . & $r \cdot$ \\
\hline $1 \cdots$ & \&or & 17,1 & vq & $\xi r, 0$ & $19 r$ & $\xi \cdot, Y$ & IA乏 & أدلل أبنائي وألبي جميع ما يطلبونه & ri \\
\hline $1 \cdots$ & sor & - & - & $r \cdot, 0$ & ira & 79,0 & riई & اصطحب أبنائي في زياراتي للأقارب . & rr \\
\hline $1 \cdots$ & sor & $i r, \Lambda$ & $\Delta \wedge$ & ro,r & 117 & 71,0 & trA & أوجه أبنائي إلي إتباع الطرق الصحيحة في العناية الشخصية . & rr \\
\hline $1 \cdots$ & sor & 17,1 & vi & $\xi r, 0$ & $19 r$ & $\xi \cdot, \vee$ & IA\& & أعطي لأولادي ما يكفيهم من مصروف & ro \\
\hline $1 \cdots$ & sor & - & - & $r \cdot, 0$ & ira & 79,0 & riई & أحاول أن أكوز صلديقة لأبنائي . & rq \\
\hline $1 \cdots$ & \&or & $r 9,7$ & Irs & $r \cdot, \Lambda$ & $9 \xi$ & $\S 9,7$ & rrs & أوبخ وأعاقب أبنائي أمام الآخرين . & rr \\
\hline 1.. & sor & Ir,A & $0 \wedge$ & $\mid V, r$ & VA & $V \cdot, \boldsymbol{z}$ & riq & أتلفظ بألفاظ ساقطة أمام أبنائي . & rA \\
\hline $1 \cdots$ & \&or & Ir,A & $\Delta \wedge$ & 17,1 & Vy & $v \cdot, \boldsymbol{\varepsilon}$ & $\mathrm{MIN}$ & اهتم بتوجيه أبنائي فيما يشاهدونه في التلفزيوذ . & ra \\
\hline 1... & sor & 17,1 & vi & $\mathbb{I r}, \mathrm{A}$ & $0 \wedge$ & $\boldsymbol{v}, \boldsymbol{\varepsilon}$ & rin & أتابع مع الملدرسة والدرس مستوى أبنائي . & r. \\
\hline $1 \cdots$ & \&or & - & - & $r o, r$ & 109 & $7 \varepsilon, 1$ & rar & أحث أبنائي علي المداومة علي الصلاة والشكر والذكر الرضا والقناعة. & ri \\
\hline $1 \cdots$ & \&or & $r q, r$ & 178 & ro,r & 117 & $r \wedge, 1$ & IVY & أعلم أبنائي أتجنب مناقشة مختلف أزماتنا الأسرية أمام أبنائنا & rr \\
\hline
\end{tabular}

$$
\text { يتضح من جدول (ع ا ) : }
$$

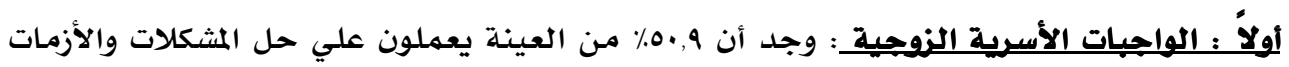

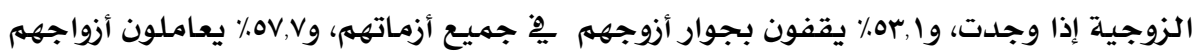

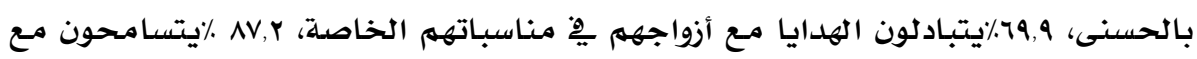

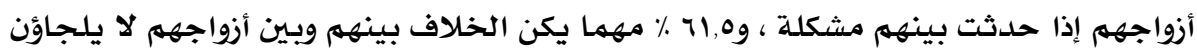

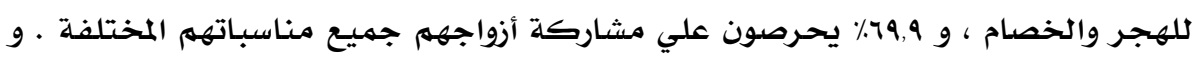

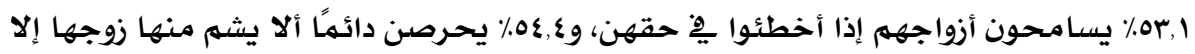

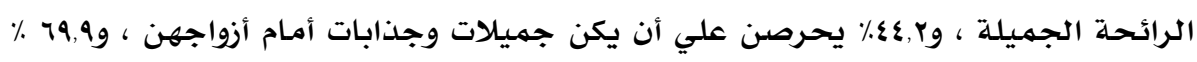

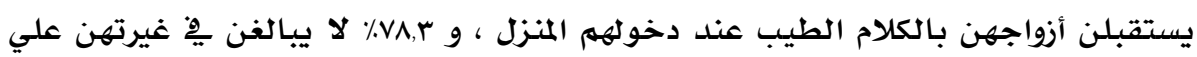

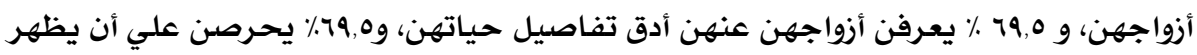

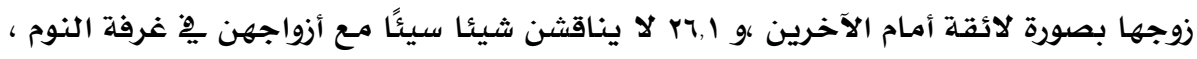

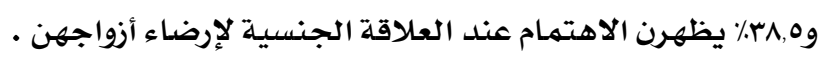

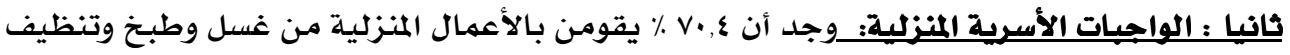

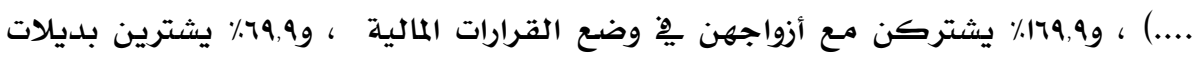




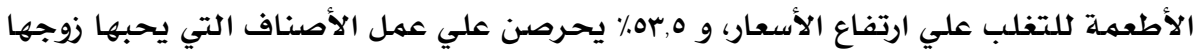

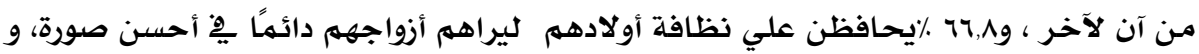

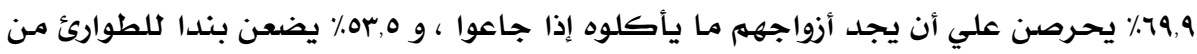

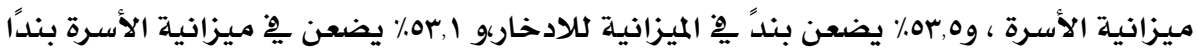

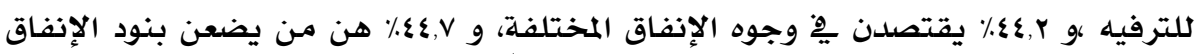

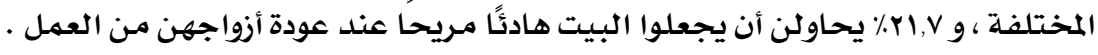

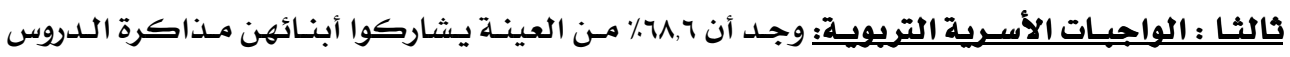

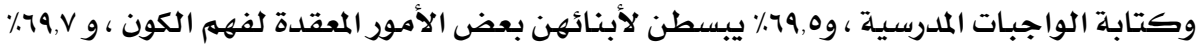

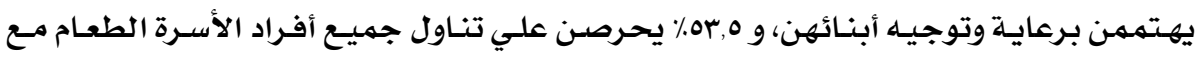

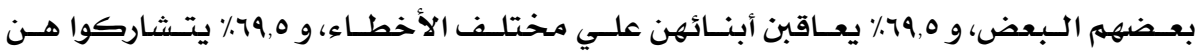

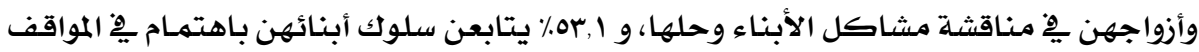

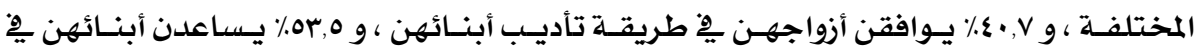

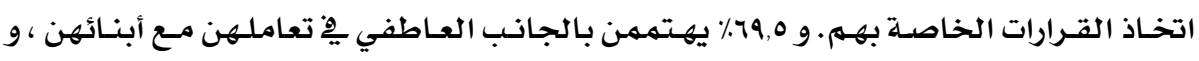

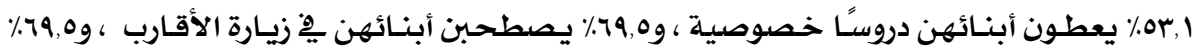

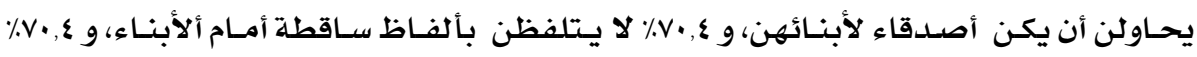

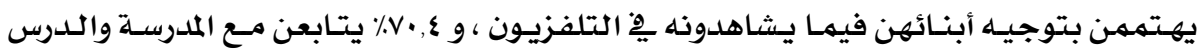

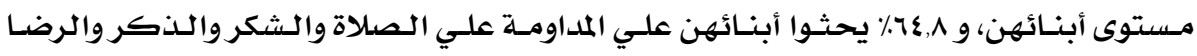
والقناعة.

مها سبق يتضح أن الواجبات الزوجية تتمثل يِّ التسامح والتعامل بالحسنى وإرضـاء النزوج

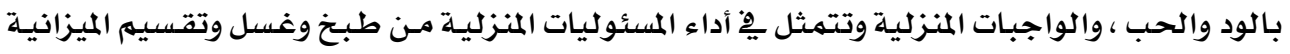

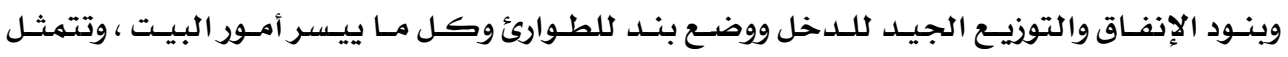

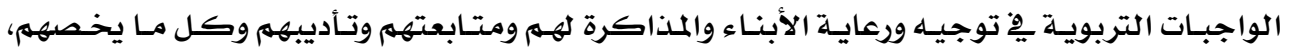

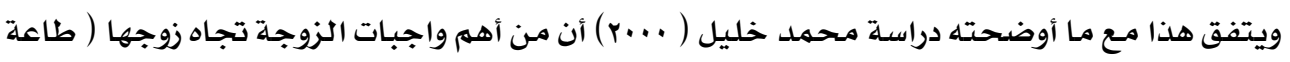

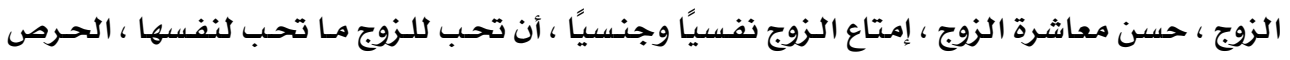

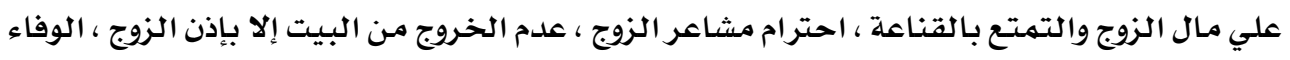

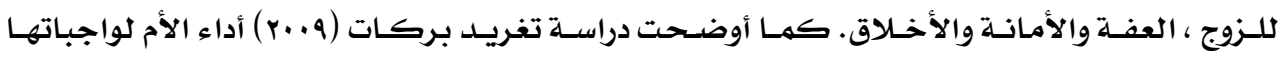

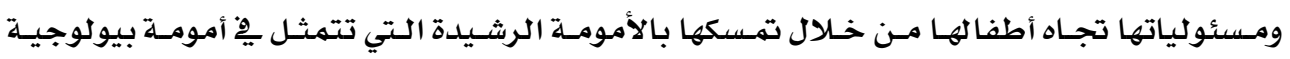

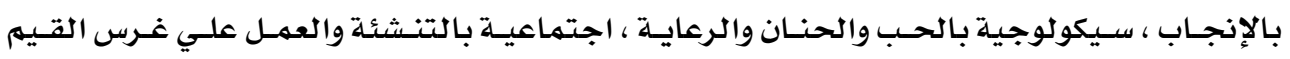

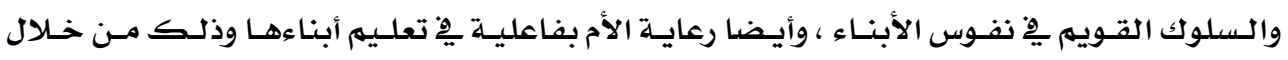

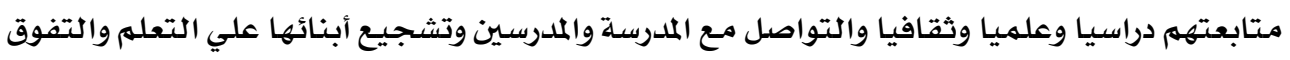

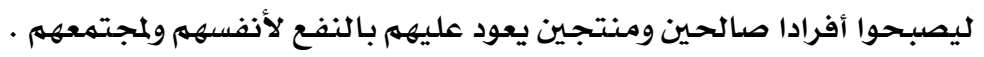




\section{بـ الطاقة الايجابية مِامسكن وعلاقتها باداء الواجبات الأسرية لرية الأسرة \\ ثانيًا : مناقشة الفروض البحثية : \\ الفرض الأول :- ينص الفرض الأول علي أنه :}

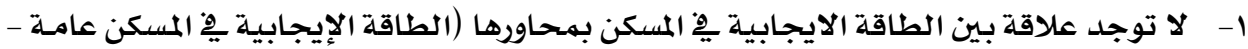

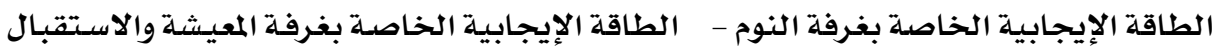

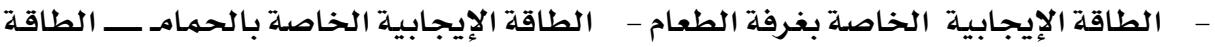

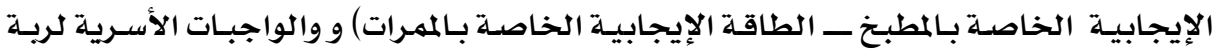

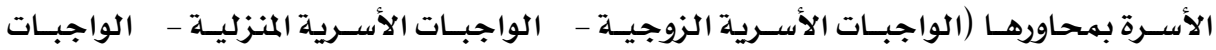
الأسـرية التربوية).

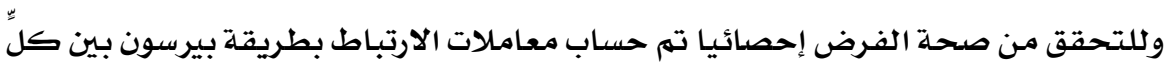

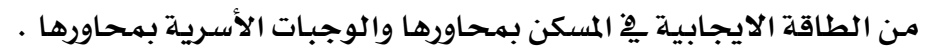

جدول ( 10 ) معاملات الارتباط بيرسون بين الطاقة الإيجابية للمسكن والواجبات الأسرية لعينة الدراسة

\begin{tabular}{|c|c|c|c|c|}
\hline مجموع الواجبات & 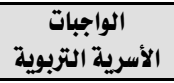 & الأسرية المنزلية & الزواجبات الأسرية & الطاقة الإيجابية في المسكن \\
\hline$* * .909$ & $* * .90 r$ & $* * .971$ & $* * 9 \cdot 1$ & الطاقة الإيجابية في المنزل عامة \\
\hline$* * .9 \% 1$ & $* * .9 r \leq$ & $* * . \wedge 99$ & $* * .91 \leq$ & الطاقة الإيجابية الخاصة بغرفة النوم \\
\hline$* * .9 \ldots$ & $* * . \wedge 9 \%$ & 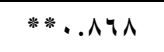 & $* * . \wedge \wedge 0$ & الطاقة الإيجابية الخاصة بغرفة المعيشة والاستقبال \\
\hline$* * .9 \vee 0$ & $* * .9 \vee 7$ & $* * .91 \%$ & $* * .9 \vee \leqslant$ & الطاقة الإيجابية الخاصة بغرفة الطعام \\
\hline$* * . \Delta r V$ & $* * .000$ & $* * . r \Delta y$ & $* * .71 \mathrm{~V}$ & الطاقة الإيجابية الخاصة بالحعام \\
\hline$* * .997$ & $* * .994$ & $* * .979$ & $* * .9 \vee$. & الطاقة الإيجابية الخاصة بالمطبخ \\
\hline$* * .9 .0$ & $* * . \wedge \vee 1$ & $* * .91 \mathrm{~V}$ & $* * . \wedge \wedge q$ & الطاقة الإيجابية الخاصة بالممرات \\
\hline$* * .9 \wedge \wedge$ & $* * .9 \wedge r$ & $* * .90 \leqslant$ & $* * .979$ & المجموع \\
\hline
\end{tabular}

• • دال عند مستوى ا+., دال عند مستوى ه., بلدون نجوم غير دال

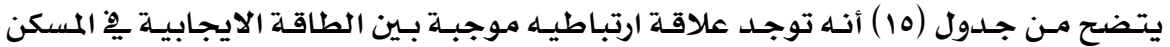
بمسحاورهـا (الطاقة الإيجابيـة يخ المسكن عامسة - الطاقـة الإيجابيـة الخاصسة بغرفة النـوم - الطاقـة الإيجابية الخاصسة بغرفة المعيشة والاستقبال - الطاقة الإيجابية الخاصسة بغرفة الطعام - الطاقة

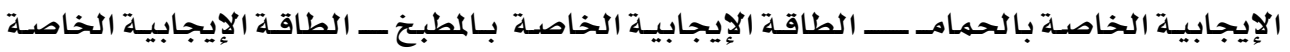
بـالممرات) وبـين الواجبـات الأسـريـة لربـة الأســرة بمحاورهـا (الواجبـات الأسـريـة الزوجيـة - الواجبـات الأسـرية المنزليـة - الواجبـات الأسـرية التربوية) عند مستوى معنويـة ا +. • ، وهذا يعني انه كلهـا زادت

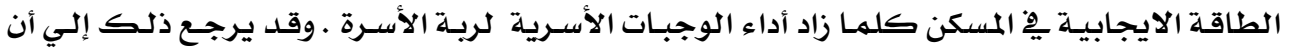

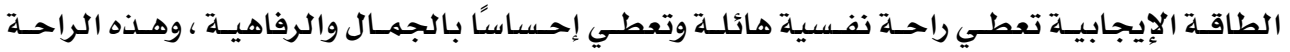
والسكينـة تتأتي من أسبـاب عدة لنظافة المسكن وترتيبـه الجيد ورائحته العطرة وتطييبـه بخير الكلام - 


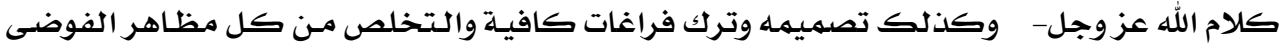

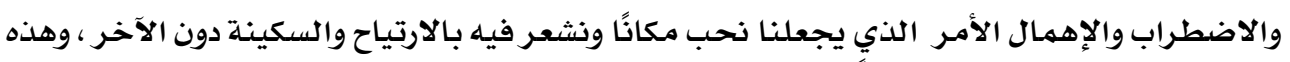

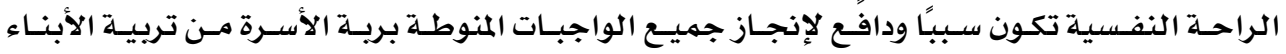

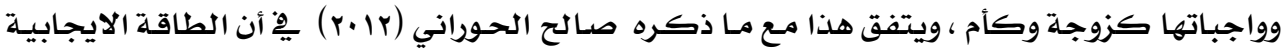

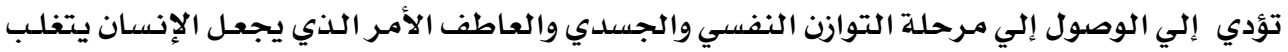

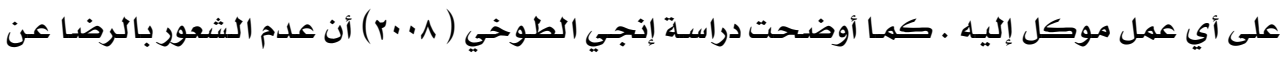

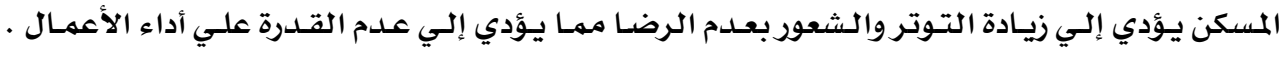

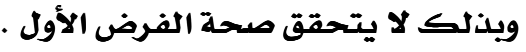

الفرض الثاني :- ينص الفرض الثاني علي أنه :

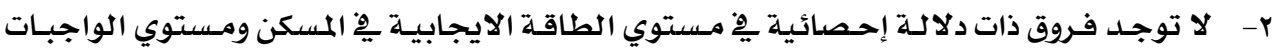

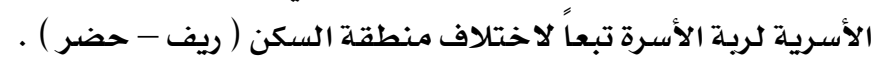

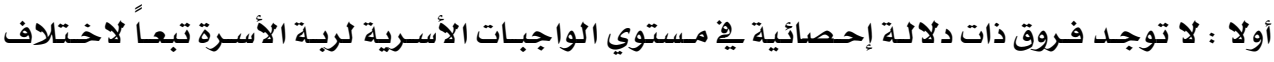

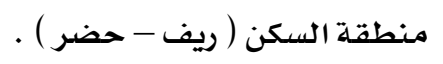

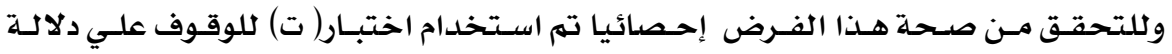

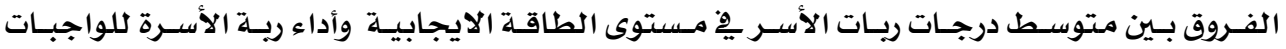

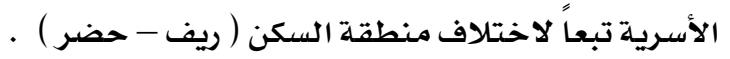

جدول (17) دلالة الفروق بين متوسط درجات الطاقة الإيجابية للمسكن

\begin{tabular}{|c|c|c|c|c|c|c|}
\hline \multirow{2}{*}{ مستوى } & \multirow[b]{2}{*}{ 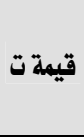 } & TIV $=\dot{j}$ & حضر & $1 r 0=\dot{3}$ & ريف & \multirow{2}{*}{ الطاقة الإيجابية في المسكن } \\
\hline & & الانعراف & المتوسط & الانعراف & 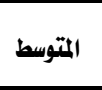 & \\
\hline$\cdot, \cdot 0$ & 18,900 & $1 \cdot, 901 \times 0$ & O1,•VYq & A, TrIV & ro,rryr & الطاقة الإيجابية في المنزل عامة \\
\hline$\cdot,+1$ & 10,991 & $\Lambda, 1.9 \mathrm{r}$. & $\{r, \bullet \wedge$ & $1 \cdot, \cdot \cdots 1 \wedge \xi$ & TV, TA1q & الطاقة الإيجابية الخاصة بغرفة النوم \\
\hline$\cdot, \cdot 1$ & $r, r r$ & r,\&719 & $r Y, Y \leqslant \varepsilon O$ & 0,01700 & $19, v \varepsilon \cdot v$ & الطاقة الإيجابية الخاصة بغرفة الميشة والاستقبال \\
\hline$\cdot, \cdot 1$ & $\mathbb{I r , A \leqslant r}$ & r, *rrro & ra,orqA & $\Lambda, 7011$. & IA, YAOY & الطاقة الإيجابية الخاصة بغرفة الطعام \\
\hline., 0 & $r, 0 \wedge \xi$ & r, HEAYr & $1 \%, 909$. & 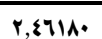 & $1 r, \cdot 110$ & الطاقة الإيجابية الخاصة بالحصام \\
\hline$\cdot,+1$ & 10,001 & $\varepsilon,\{\xi \% 01$ & ro,\&O\&r & $\xi$, \&\&ITq & $1 A, \wedge 97 \mathrm{r}$ & الطاقة الإيجابية الخاصة بالمطبخ \\
\hline$\cdot,+1$ & 19,057 & 1, rrovy & $11, r 1 \leqslant 0$ & $r, 07 \lambda \cdot \Lambda$ & V,TrYr & الطاقة الإيجابية الخاصة بالممرات \\
\hline$\cdot,+1$ & 17,014 & $r r, 790 . \%$ & 199,994 & $\{\bullet, A \vee \cdot \xi \eta$ & $\mid \varepsilon_{\bullet}, \& \xi$ & مجموع الطاقة الإيجابية في المسكن \\
\hline
\end{tabular}

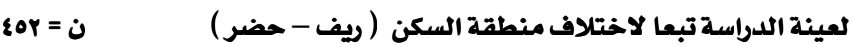

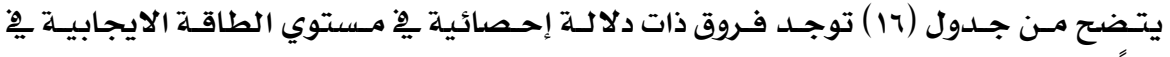

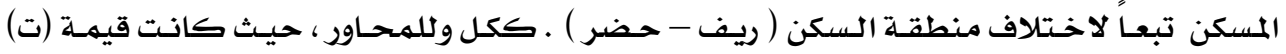

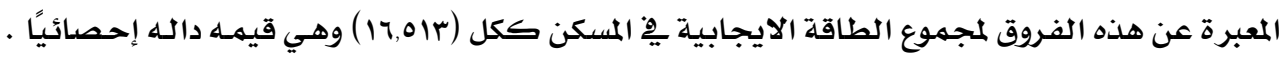

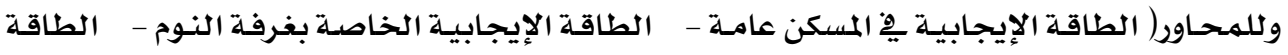


الإيجابية الخاصدة بغرفة المعيشة والاستقبال - الطاقة الإيجابية الخاصة بغرفة الطعام - الطاقة

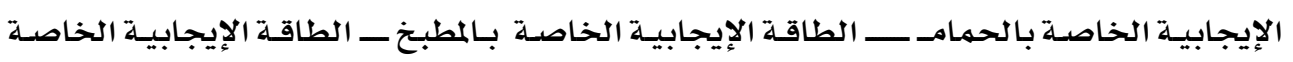

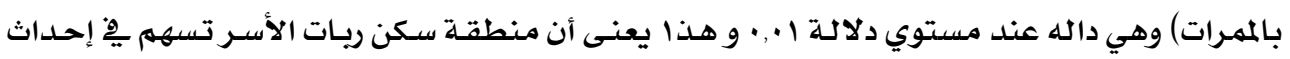

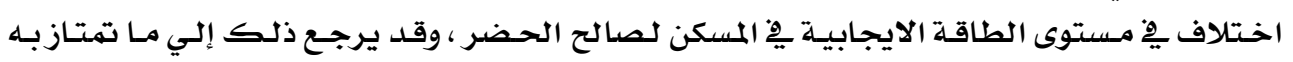

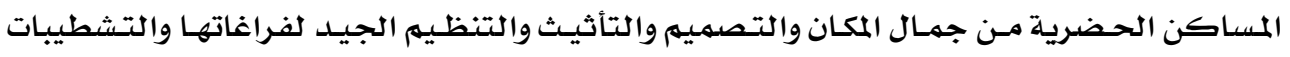

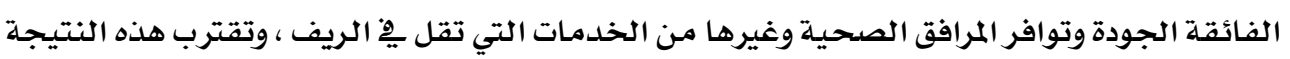

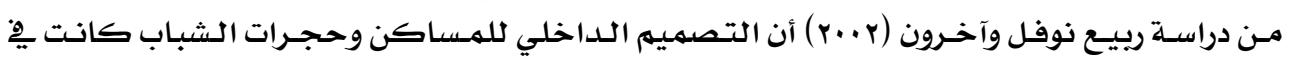

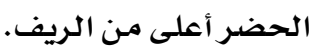

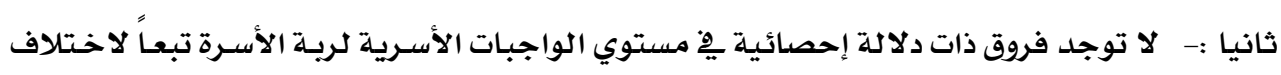

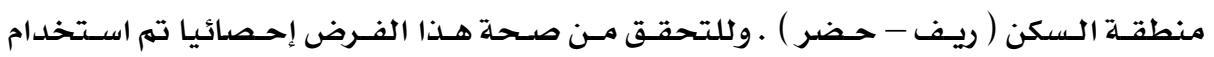

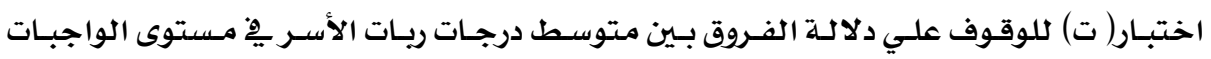

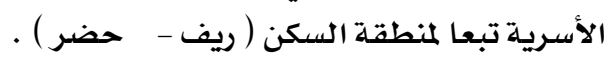

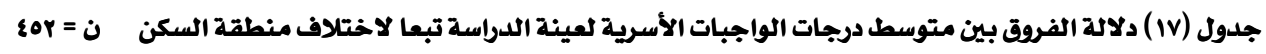

\begin{tabular}{|c|c|c|c|c|c|c|}
\hline \multirow{2}{*}{ مستوى الدلاية } & \multirow{2}{*}{ قيمة ت } & \multicolumn{2}{|c|}{ riv = } & \multicolumn{2}{|c|}{ ريف } & \multirow{2}{*}{ الواجبات الأسرية } \\
\hline & & الانحراف الميعياري & المتوسط & الانحراف المعياري & المتوسط & \\
\hline$\cdot, \cdot+1$ & $1 \%, 7 \wedge \Lambda$ & A,rYrrr & $\Delta 0$, ArqY & $11, \cdot 4999$ & 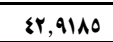 & الواجبات الأسرية الزوجية \\
\hline غير دالة & $19,\{A r$ & $\Lambda, \cdot 717 \varepsilon$ & 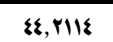 & $7,91 \mathrm{rVH}$ & rA, YMAO & الواجبات الأسرية المنزلية \\
\hline$\cdot, \cdot 1$ & 17,019 & Ir,IEATr & $\wedge 0,0 \vee \leqslant 1$ & 10,57 rVY & 77,117 & الواجبات الأسرية التربوية \\
\hline$\cdot,+1$ & $10,\{\xi 1$ & rA, YA० & $1 \wedge 0,7 r \cdot r$ & rry & Irr,Ar+r & مجموع أداء الواجبات الأسرية \\
\hline
\end{tabular}

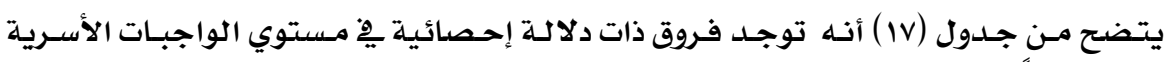

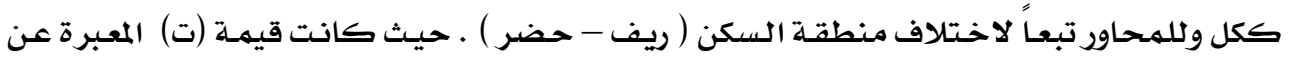

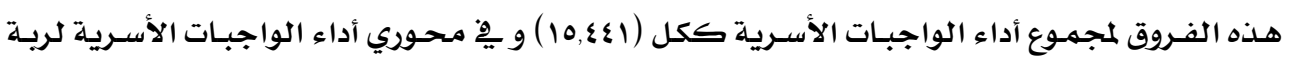

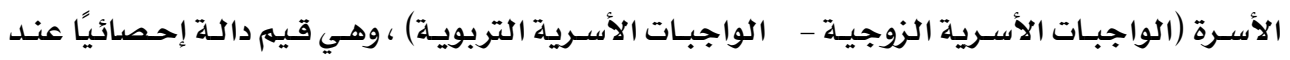

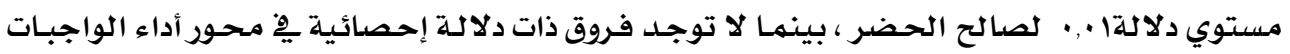

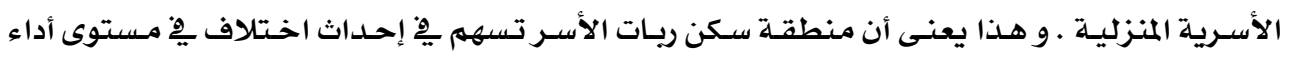

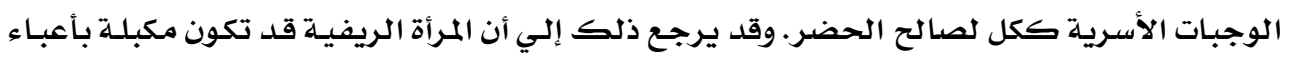

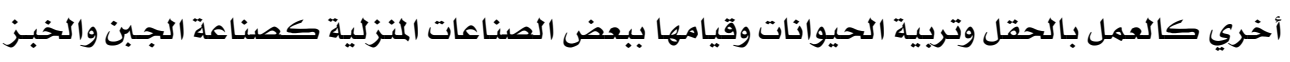

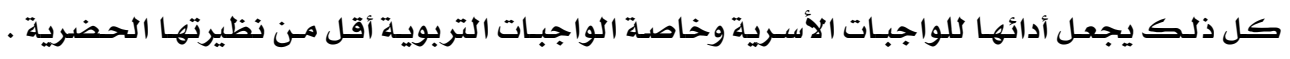

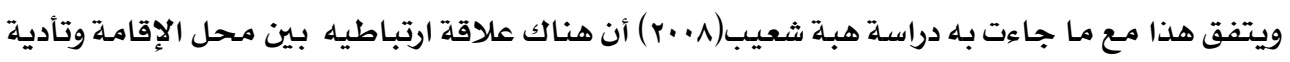

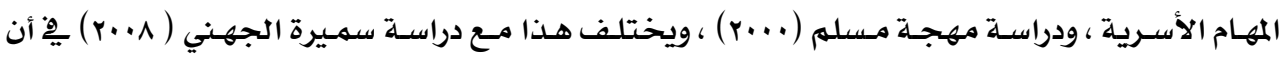

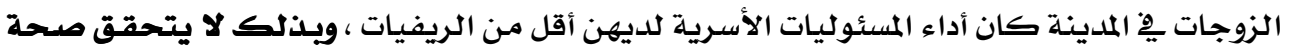
الفرض الثاني • 


$$
\text { الفرض الثالث :- ينص الفرض الثالث على : }
$$

r- - لا توجد فروق ذات دلالة إحصائية بين كل من الطاقة الايجابية يِّ المسكن و والواجبات الأسـريـة

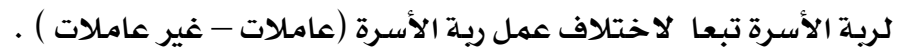

أولا: لا توجد فروق ذات دلالة إحصائية بين كل من الطاقة الايجابية ِِّ المسكن ة تبعا لاختلاف عمل

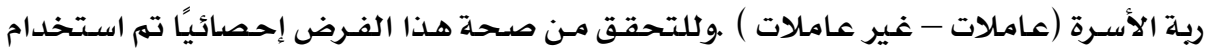

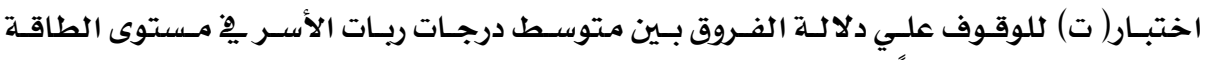

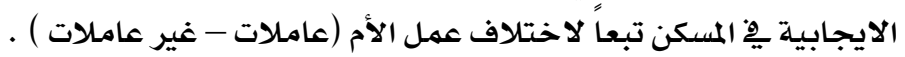

\begin{tabular}{|c|c|c|c|c|c|c|}
\hline \multirow{2}{*}{ مستوى } & \multirow[b]{2}{*}{ 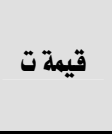 } & \multicolumn{2}{|c|}{ عاملات = ع } & \multicolumn{2}{|c|}{ غير عاهلات = ب00 } & \multirow[b]{2}{*}{ الطاقة الإيجابية في المسكن } \\
\hline & & الالانحراف & المتوسط & الالانعراف & المتوسط & \\
\hline 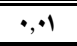 & r\&O,IAr & $1 \%, 0 \leqslant 0 \leqslant 0$ & rY, Irqई & $7, \cdot 1197$ & or,.97v & الطاقة الإيجابية في المنزل عامة \\
\hline$\cdot, \cdot 1$ & rqr,rqI & $1 \cdot$, ATAr. & rq,IrIA & $\varepsilon, r+1 \cdot r$ & $\{\xi$, rqๆ & الطاقة الإيجابية الخاصة بغرفة النوم \\
\hline$\cdot, \cdot 1$ & $\mid r q 1,7 A r$ & $0,8 \% \cdot 79$ & rI,rArq & $1,\{r \cdot \xi \eta$ & $r \Lambda,\{q \xi 1$ & الطاقة الإيجابية الخاصة بغرفة المعيشة والاستقبال \\
\hline$\cdot, \cdot 1$ & 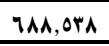 & $9, Y 9 \mid \leqslant \wedge$ & $|9, \cdot v| \mid$ & r,rrVY. & rI, q1Vq & الطاقة الإيجابية الخاصة بغرفة الطعام \\
\hline$\cdot, \cdot 1$ & ovy, r\&Y & $1, \cdot 177 \mathrm{~V}$ & $1 \cdot, 905 \%$ & r, rirra & $|\xi, \bullet \xi T|$ & الطاقة الإيجابية الخاصة بالحهام \\
\hline$\cdot, \cdot 1$ & VOI, TYA & 0, ro.r. & $19,811 Y$ & 1, YAOA1 & rq,701. & الطاقة الإيجابية الخاصة بالطبخ \\
\hline$\cdot, \cdot 1$ & r19,rrq & $r, Y 0.1 A$ & $\Lambda, r \Lambda \cdot V$ & $\cdot$, , tirar & $11,0 . r$. & الطاقة الإيجابية الخاصة بالمررات \\
\hline$\cdot, \cdot 1$ & VIr,VYr & $\{0, \vee 90 \leqslant 7$ & $1 \leqslant 0, \wedge 7 r$ & $11, r+4$ & $r \cdot, \cdot V r$ & مجموع الطاقة الإيجابية للمسكن \\
\hline
\end{tabular}

جدول ( 11) دلالة الفروق بين متوسط درجات الطاقة الإيجابية يو المسكن

يتضح من جدول (1) أنه توجـد فروق ذات دلالـة إحصائية بـين متوسط درجـات ريـات الأسـر

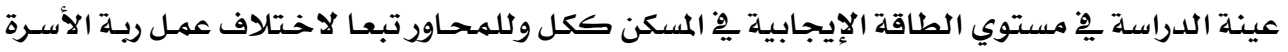

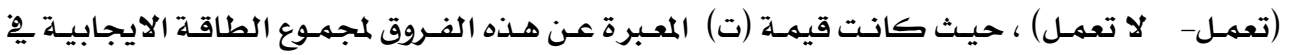

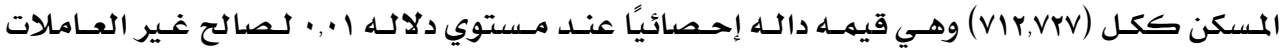

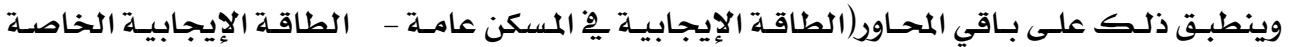

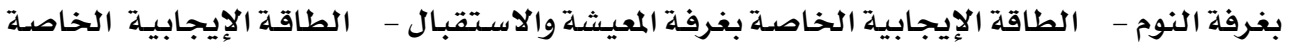

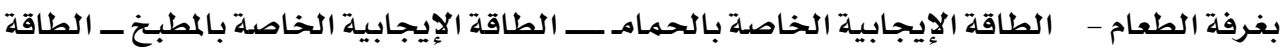

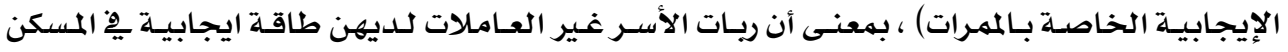

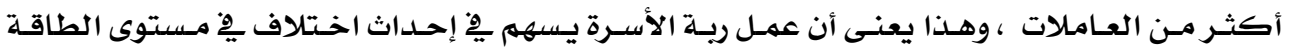

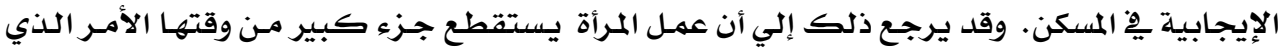

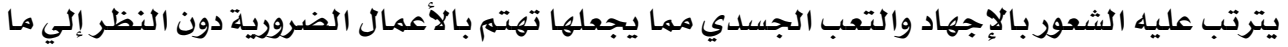

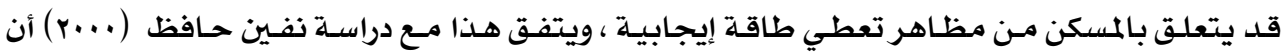

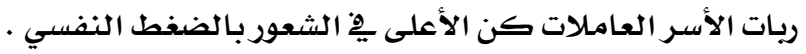




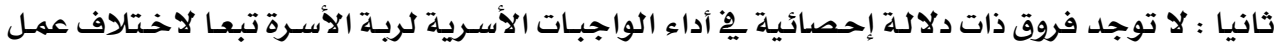

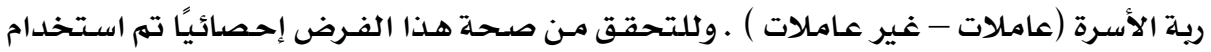

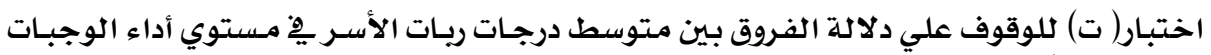

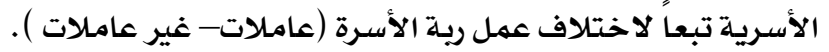
جدول ( 19 ) دلالة الفروق بين متوسط درجات الواجبات الأسرية
EOY $=0$
لعينة الدراسة تبعا لاختلاف عمل ربة الأسرة (عاملات - غير عاملات ) دلاتل

\begin{tabular}{|c|c|c|c|c|c|c|}
\hline \multirow{2}{*}{ مستول } & \multirow{2}{*}{ ق قيمة ت } & \multicolumn{2}{|l|}{$19 v=j$} & \multicolumn{2}{|c|}{ 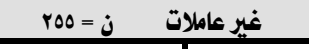 } & \multirow{2}{*}{ الواجبات الأسرية } \\
\hline & & الانحراف المعياري & 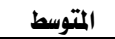 & الانعراف المعياري & التتوسط & \\
\hline$\cdot,+1$ & IrTY,ovT & 11,07041 & \&r,lor & r,IEATY & $O \Lambda, Y \wedge E T$ & الواجبات الأسرية الزوجية \\
\hline$\cdot, \cdot 1$ & $\{r q, A r A$ & $11, r Y A \cdot \eta$ & $r r, r \xi=1$ & $\{, \wedge \leqslant \vee 10$ & $\{0,1 A \cdot \xi$ & الواجبات الأسرية المنزلية \\
\hline$\cdot, \cdot 1$ & 190,991 & 17, vorrer & $79, \cdot 77$. & r,EYVIT & $9 \cdot, \Gamma \wedge E T$ & الواجبات الأسرية التربوية \\
\hline$\cdot, \cdot 1$ & $1 \cdot 77, v \cdot v$ & $r 9,879147$ & $181,07 \mathrm{r}$ & $7,+Y A Y A$ & $19 \xi$, ror & مجموع الواجبات الأسرية \\
\hline
\end{tabular}

ـ يتضح من جدول (19) أنه توجد فروق ذات دلالة إحصائية بين متوسط درجـات ريـات الأسـرة

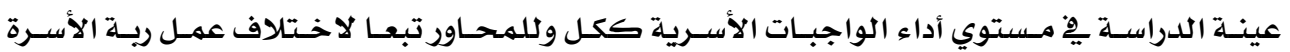

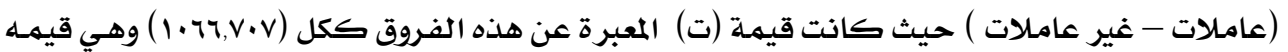

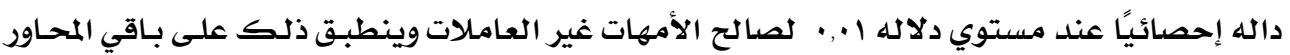

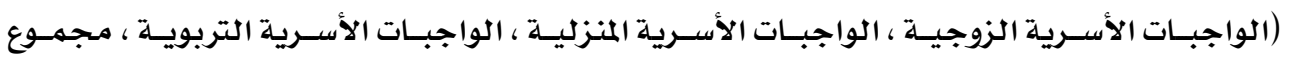

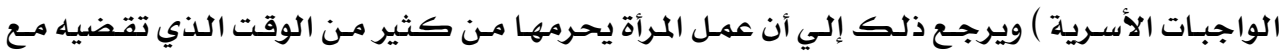

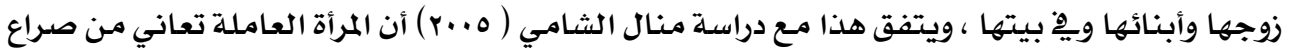

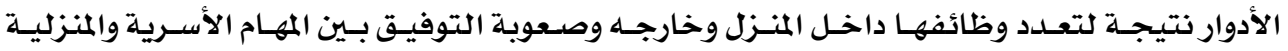

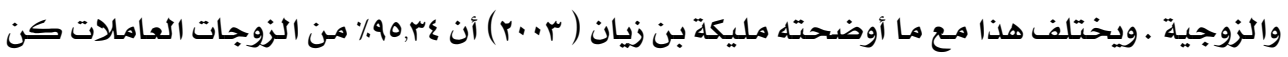

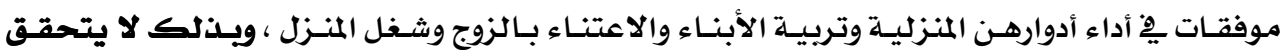
صحمة الفرض الثالث . موفة أدوارهن

$$
\text { الفرض الرابع :- ينص الفرض الرابع على: }
$$

ع- لا توجد فروق ذات دلالة إحصائية بين كل من الطاقـة الايجابيـة يِ المسكن والواجبـات الأسـريـة

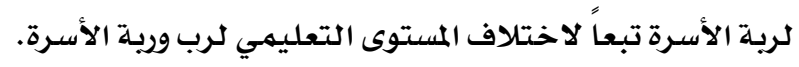

أولا : لا توجد فروق ذات دلالة إحصائية يِّ مستوى الطاقة الايجابية يِّ المسكن و والواجبـات الأسـريـة

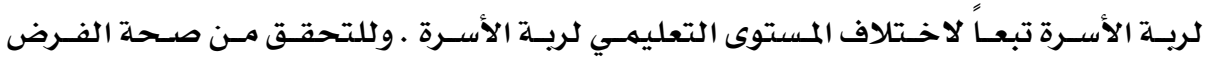
إحصائيا تم استخدام اختبـار تحليل التبـاين فى اتجـاه واحد

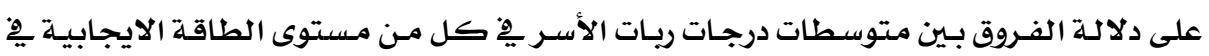

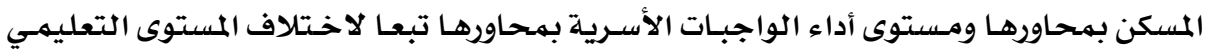
لرية الأسرة . 


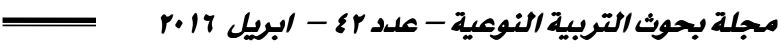

جدول ( r ) ) تحليل التباين يِ اتجاه واحد لمستوى الطاقة الإيجابية مِ المسكن

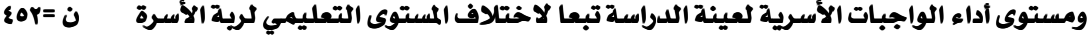

\begin{tabular}{|c|c|c|c|c|c|c|}
\hline مستوى & قيمة ف & متوسط المربعات & درجات الحرية & مجموع المربعات & مصلدر التباين & الطاقة الإيجابية فى المسكن \\
\hline$\cdot, \cdot 1$ & $9 A r, 7 . r$ & $\begin{array}{l}\text { ralqr,rqr } \\
\text { ra, To\& }\end{array}$ & $\begin{array}{l}r \\
\leqslant \leqslant 9 \\
\leqslant 01\end{array}$ & $\begin{array}{l}\text { OATrE, VYT } \\
\text { IrTIE,\&AY } \\
\text { MIY\&, rI. }\end{array}$ & داخل المجنموعات المجموعات & الطاقة الإيجابية في \\
\hline$\cdot, \cdot 1$ & $1 \& \vee q, r$ & $\begin{array}{c}r \cdot r \cdot \varepsilon, 970 \\
|r, Y r|\end{array}$ & $\begin{array}{c}r \\
\leqslant \leqslant 9 \\
\leqslant 01\end{array}$ & $\begin{array}{l}\xi \cdot 7 \cdot 9,94 . \\
7170, \cdot 0 . \\
\xi 7 r Y \xi, 91 .\end{array}$ & داخل المجمبوعات المجوعات & الخاصة بغرفة الإيجابية \\
\hline$\cdot, \cdot 1$ & V\&V, qVr & $\begin{array}{c}\{7 \leqslant 1,0 \leqslant 7 \\
7, Y+7\end{array}$ & $\begin{array}{c}r \\
\leqslant 29 \\
\leqslant 01\end{array}$ & $\begin{array}{l}\text { 9rAr,・9r } \\
\text { rYAY,rrI } \\
\text { Ir.79,rqr }\end{array}$ & داخل المجلموعات المجوعات & الماقيشة الخاصة بإيجابية \\
\hline$\cdot, \cdot 1$ & llvr,r & $\begin{array}{l}\text { 10r71, } 991 \\
17, \cdot \varepsilon V\end{array}$ & $\begin{array}{c}r \\
\leqslant \leqslant 9 \\
\leqslant 01\end{array}$ & $\begin{array}{l}\text { r.Vrr, } 190 \\
\text { OAOr, 9r9 } \\
\text { rYOA•, IrE }\end{array}$ & داخل المجمهوعات المجوعات & الخاصة الطغرفة الإبجابة \\
\hline$\cdot, \cdot 0$ & $9 Y, 94 r$ & $\begin{array}{l}r 99,171 \\
\xi, \cdot v \varepsilon\end{array}$ & $\begin{array}{l}r \\
\leqslant \leqslant 9 \\
501\end{array}$ & 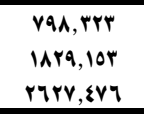 & داخل المجمموعات المجموعات & الطاصة الإيجابية \\
\hline$\cdot, \cdot 1$ & $1799, r$ & $\begin{array}{c}01 \leqslant \varepsilon, v 1 \cdot \\
r,+r A\end{array}$ & $\begin{array}{c}r \\
\$ \leqslant 9 \\
\leqslant 01\end{array}$ & $\begin{array}{l}\text { 1.rAq,\&r| } \\
\mid r 09,0 r . \\
117 \& \wedge, 991\end{array}$ & داخل المجمموعات المجوعات & الطاقة الإيجابية \\
\hline$\cdot, \cdot 1$ & $\mid \xi \Lambda \cdot, r$ & $\begin{array}{c}1100, \text { rrA } \\
\cdot, \mathrm{rAI}\end{array}$ & $\begin{array}{c}r \\
\$ \leqslant 9 \\
\$ 01\end{array}$ & 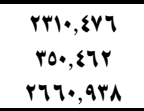 & داخل المجلموعات المجموعات & الخاصة بالمايجراتية \\
\hline$\cdot, \cdot 1$ & $i r \cdot v, r$ & 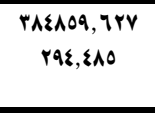 & $\begin{array}{l}r \\
\leqslant \leqslant 9 \\
\leqslant 01\end{array}$ & $\begin{array}{l}\text { VIAYI9, YOS } \\
\text { IFrYYr, OOY } \\
9 \cdot 19 \leqslant Y, A \cdot 0\end{array}$ & داخل المجنموعات المجموعات & الإيجابية للمسكوع الطاقة \\
\hline$\cdot, \cdot 1$ & riro,r & $\begin{array}{l}\text { rEYqI, IAE } \\
11, \text { rYq }\end{array}$ & $\begin{array}{c}r \\
\leqslant \leqslant 9 \\
\leqslant 01\end{array}$ & $\begin{array}{l}\text { \&AOAY, rTY } \\
01 \cdot 9, r 1 \varepsilon \\
\text { Orन91, 7A1 }\end{array}$ & داخل المجمموعات المجوعات & الزواجبات الأسرية \\
\hline$\cdot, \cdot 1$ & $v 71, \cdot 9$. & $\begin{array}{l}19187,8 \cdot 0 \\
r 0,197\end{array}$ & $\begin{array}{c}r \\
\leqslant \leqslant 9 \\
\leqslant 01\end{array}$ & $\begin{array}{l}\text { rATOY,Al. } \\
\text { llrIr,990 } \\
\text { \$9790,1.0 }\end{array}$ & داخل المجمبوعات المجموعات & المواجبات الأسرية \\
\hline$\cdot, \cdot 1$ & rETo,r & $\begin{array}{l}\text { OOAOV,Arr } \\
r Y, 9 A 1\end{array}$ & $\begin{array}{r}r \\
\$ \leqslant 9 \\
\$ 01\end{array}$ & 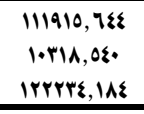 & داخل المجزموعات المجموعات & التواجبات الأسرية \\
\hline$\cdot, \cdot 1$ & $199, \xi 4$ & $\begin{array}{l}\text { YA.OHI, OrA } \\
\text { THIA., YVY } \\
\text { TrEYST,ASY }\end{array}$ & $\begin{array}{r}r \\
\leqslant \leqslant 9 \\
\$ 01 \\
\end{array}$ & 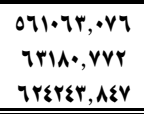 & داخل المجزموعات المجموعات & مجموع الأواجبات \\
\hline
\end{tabular}




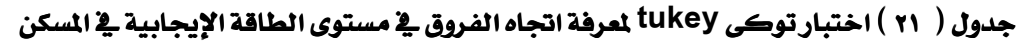
ومستوى أداء الواجبات الأسرية لعينة الدراسة تبعا لاختلاف المستوى التعليمي لرية الأسرة

\begin{tabular}{|c|c|c|c|}
\hline \multicolumn{3}{|c|}{ اختبار Tukey } & \multirow[t]{2}{*}{ المتفيرات } \\
\hline مستوي مرتفع & مستوي متوسط & مستوي منخفض & \\
\hline or,910r & $r 0,09 \cdot 9$ & ro,AYY\& & الطاقة الإيجابية في المسكن عامة \\
\hline$\{\xi, \cdot 17 r$ & $r \xi,\{\cdot 91$ & rr, 1019 & الطاقة الإيجابية الخاصة بغرفة النوم \\
\hline rA,§OAY & $19, r \leqslant 11$ & $|A, 1 \cdot 7|$ & الطاقة الإيجابية الخاصة بغرفة المعيشة والاستقبال \\
\hline rI,9FI7 & $17,7 \cdot 71$ & Ir, Tr.r & الطاقة الإيجابية الخاصة بغرفة الطعام \\
\hline 14,0 OYA & $11, \leqslant \wedge \leqslant \wedge$ & 1., YYAO & الطاقة الإيجابية الخاصة بالحمام \\
\hline rq, YrYq & $|A, 1+7|$ & $10, \xi 1 \mathrm{VY}$ & الطاقة الإيجابية الخاصة بالمبخخ \\
\hline II,TYYI & $\Lambda, 11 r q$ & 0,7111 & الطاقة الإيجابية الخاصة بالممرات \\
\hline$r \mid \cdot, r q r$ & ITI,OAY & $\| \xi, \Lambda \cdot r$ & مجموع الطاقة الإيجابية للمسكن \\
\hline$\Delta 9, \cdot \xi Y r$ & ra,010r & $r \xi, q 11 \xi$ & الواجبات الأسرية الزوجية \\
\hline$\{0,9|r|$ & rq, 79r. & ro, Y090 & الواجبات الأسرية المنزلية \\
\hline $9 \cdot, r 9 \cdot 9$ & Tr, rVYr & or,rari & الواجبات الأسرية التربوية \\
\hline 190, ror & Irq,EAr & $11 \%, \cdot \xi \cdot r$ & مجموع الواجبات الأسرية \\
\hline
\end{tabular}

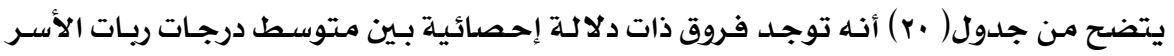

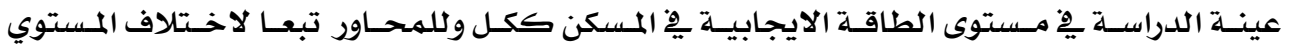

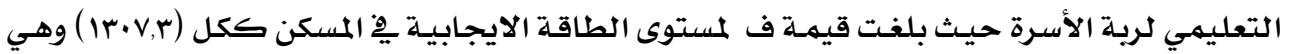

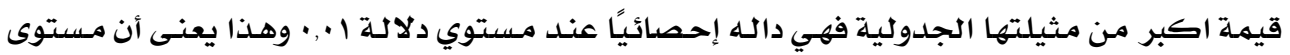

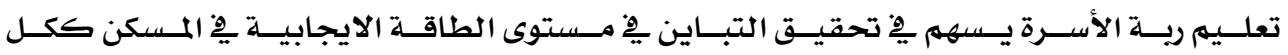
ولجميع المحاور.

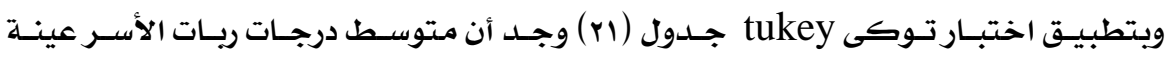

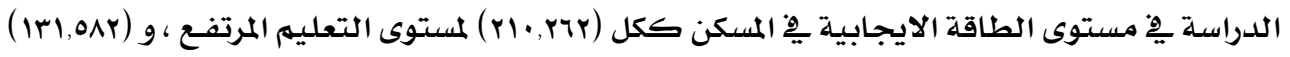

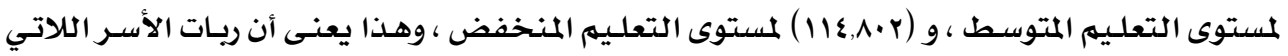

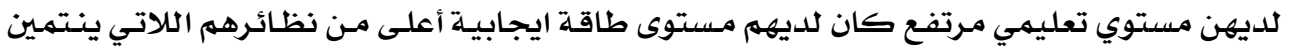

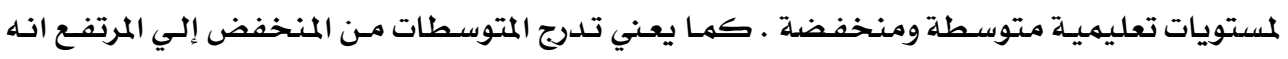

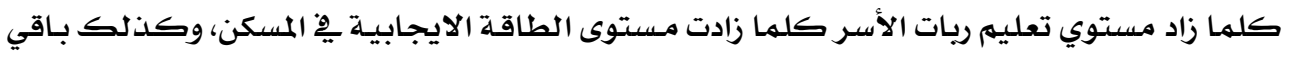

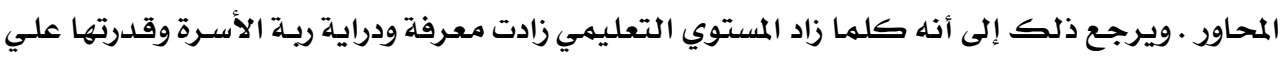

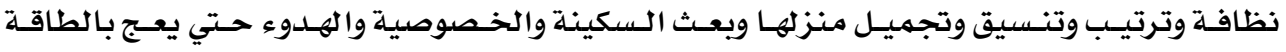

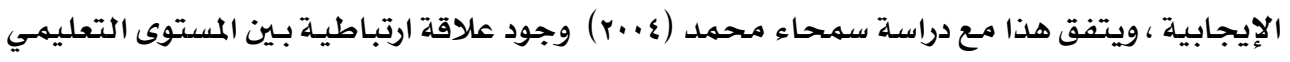

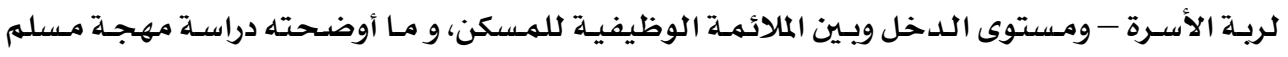

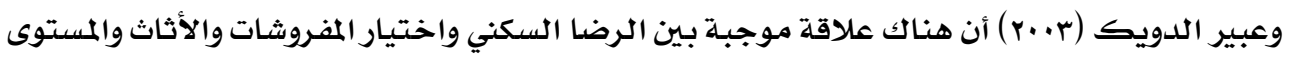

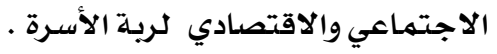

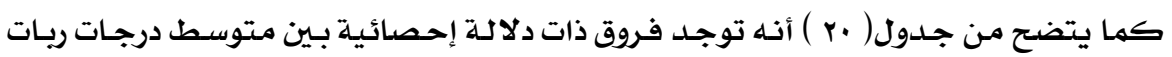

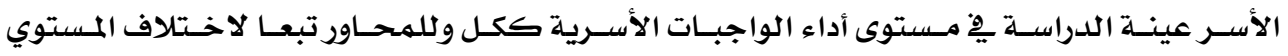




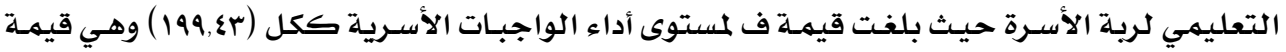

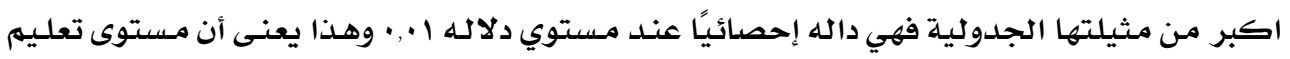

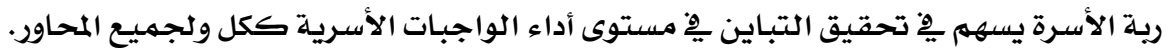

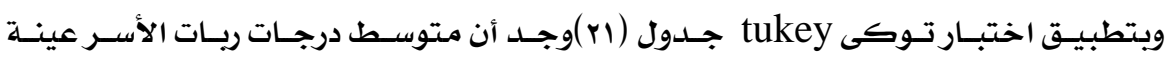

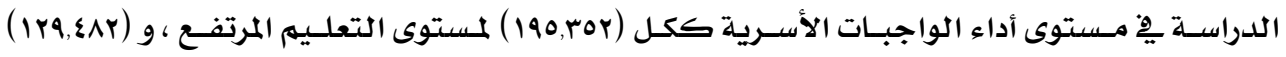

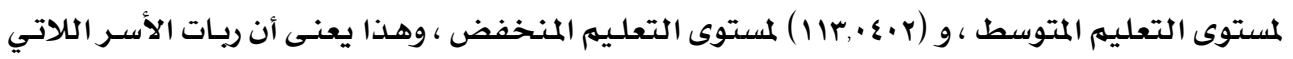

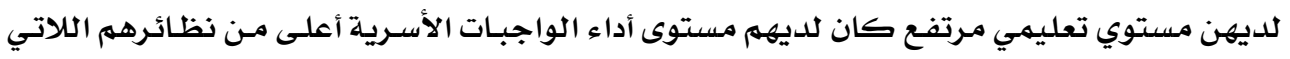

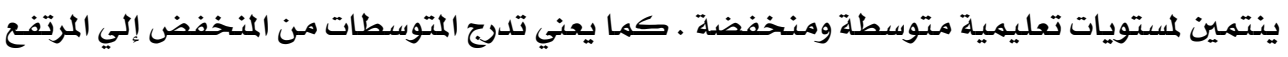

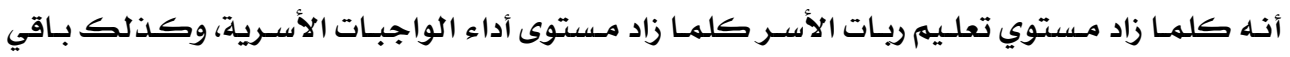

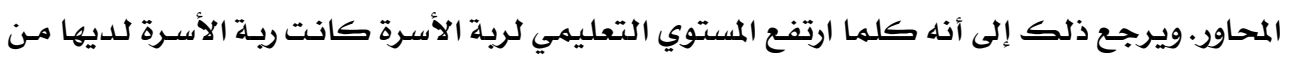

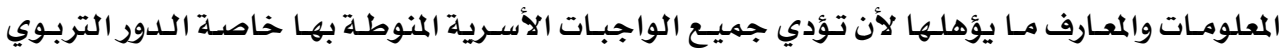

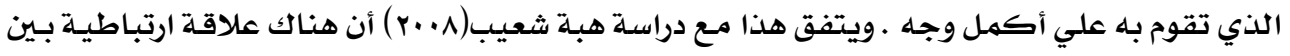

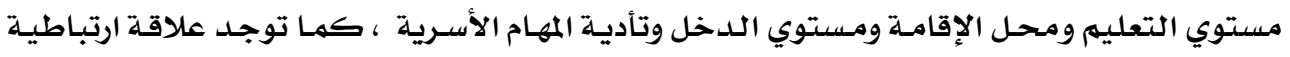

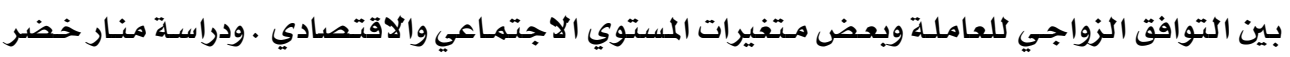

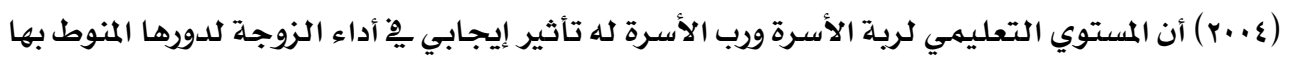

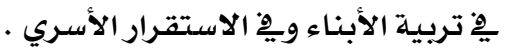

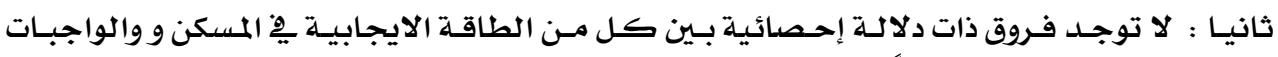

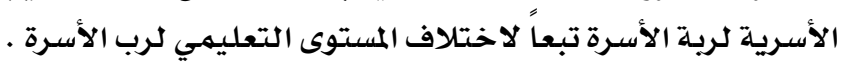

وللتحقق مـن صدحة الفـرض إحصائيا تم استخدام اختبـار تحليـل التبـاين فى اتجـاه واحسد

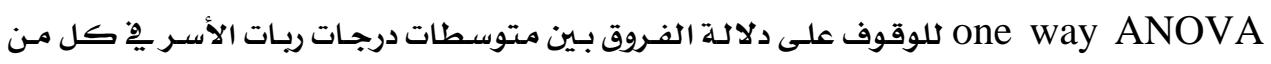

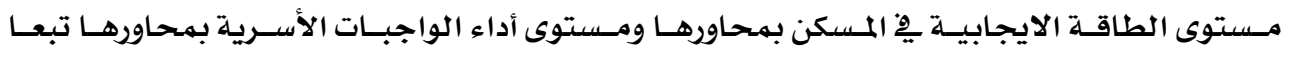

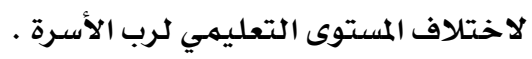


جدول ( r ) ) تحليل التباين يِ اتجاه واحد لمستوى الطاقة الإيجابية ـِ المسكن

ومستوى أداء الواجبات الأسرية لعينة الدراسة تبعا لاختلاف المستوى التعليمي لرب الأسرة

\begin{tabular}{|c|c|c|c|c|c|c|}
\hline مستوى & قيمة ف & متوسط المربعات & درجات الحرية & مجموع المربعات & مصدر التباين & الطاقة الإيجابية \\
\hline$\cdot, \cdot 1$ & $7 \xi 1, Y+\Lambda$ & $\begin{array}{c}\text { ryors, rVY } \\
\text { \$I, rar }\end{array}$ & $\begin{array}{l}r \\
\leqslant \leqslant 9 \\
\leqslant 01\end{array}$ & 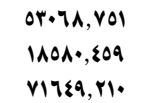 & داخل المجمموعات المجوعات & في المسكن عامة الإيجابية \\
\hline$\cdot,+1$ & Vrr, +11 & $\begin{array}{c}\mid r q \cdot \varepsilon, \cdot \varepsilon q \\
r \varepsilon, \varepsilon r o\end{array}$ & $\begin{array}{l}r \\
\leqslant \leqslant 9 \\
\leqslant 01\end{array}$ & $\begin{array}{l}r 01 \cdot 1, \cdot 99 \\
1.977,11 \% \\
\text { \&7YY\&,91. }\end{array}$ & داخل المجموعات المجموعات & الخاصة بغرفة الإيجابية \\
\hline$\cdot, \cdot 1$ & «॥, YO. & $\begin{array}{c}\xi \cdot r \cdot, \wedge \vee v \\
\wedge, q \gamma \cdot\end{array}$ & $\begin{array}{c}r \\
\leqslant \leqslant 9 \\
\leqslant 01\end{array}$ & $\begin{array}{l}A \cdot \xi 1, Y 0 \xi \\
\xi \cdot r v, 7 \cdot \Lambda \\
1 r \cdot 7 q, r q r\end{array}$ & داخل المجمعوعات المجوعات & الالخاقة الإيجابية الماية والاستقبة \\
\hline$\cdot, \cdot 1$ & $7 \wedge v, r \leq \varepsilon$ & $\begin{array}{c}\text { IrrAY,97r } \\
r \cdot, \cdot 01\end{array}$ & $\begin{array}{l}r \\
\leqslant \leqslant 9 \\
\leqslant 01\end{array}$ & $\begin{array}{l}\text { rrorr, 9rE } \\
9 \cdot+7,19 . \\
\text { r90A•, IrE }\end{array}$ & داخل المجمموعات المجموعات & الطاقة الإيجابية \\
\hline$\cdot,+1$ & A\&, rTO & $\begin{array}{l}\text { rOA, } \$ \xi 1 \\
\xi, r 00\end{array}$ & $\begin{array}{c}r \\
\$ \leqslant 9 \\
\leqslant 01\end{array}$ & $\begin{array}{l}\text { Y1Y,A11 } \\
191 \cdot, 090 \\
\text { rYrV, EYY }\end{array}$ & داخل المجمعوعات المجوعات & الخاصة الإيجابية \\
\hline$\cdot,+1$ & $\wedge \neg 1$, YVq & $\begin{array}{c}\varepsilon q r_{+}, r_{\cdot \bullet} \\
0, r q \varepsilon\end{array}$ & $\begin{array}{l}r \\
\leqslant \leqslant 9 \\
\leqslant 01\end{array}$ & $\begin{array}{l}9 Y \varepsilon \cdot, r 99 \\
r \varepsilon \cdot \Lambda, 09 r \\
117 \xi \Lambda, 991\end{array}$ & داخل المجمعوعات المجموعات & الخاصة الإيجابية بالمطبخ \\
\hline$\cdot,+1$ & Y^o, YY. & $\begin{array}{l}\text { l.er,rir } \\
\text { I,s7r }\end{array}$ & $\begin{array}{l}r \\
\leqslant \leqslant 9 \\
\leqslant 01\end{array}$ & 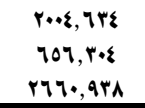 & داخل المجمعوعات المجوعات & الطاصة الإيجابية \\
\hline$\cdot, \cdot 1$ & 519,570 & 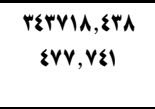 & $\begin{array}{l}r \\
\leqslant \leqslant 9 \\
\leqslant 01\end{array}$ & 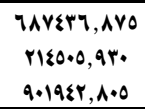 & داخل المجمموعات المجموعات & الإيجابية للمسكن الطاقة \\
\hline$\cdot,+1$ & $1 \cdot \cdot 0, r$ & 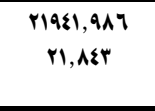 & $\begin{array}{l}r \\
\leqslant \leqslant 9 \\
\leqslant 01\end{array}$ & 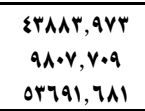 & داخل المجنموعات المجموعات & الزواجبات الأسرية \\
\hline$\cdot, \cdot 1$ & $0 \cdot \cdot, V 19$ & $\begin{array}{c}\text { IrISO,OAN } \\
r \xi, r \leqslant Y\end{array}$ & $\begin{array}{l}r \\
\leqslant \leqslant 9 \\
\leqslant 01\end{array}$ & $\begin{array}{l}\text { r\&rq1, Irr } \\
\text { lorrs, 7rA } \\
\$ 9770, \Lambda \cdot 0\end{array}$ & داخل المجمعوعات المجوعات & الواجبات الأسرية \\
\hline$\cdot, \cdot 1$ & $1.77, r$ & $\begin{array}{l}0 .\{\Lambda 1,1+\Lambda \\
\{V, r V Y\end{array}$ & $\begin{array}{l}r \\
\leqslant \leqslant 9 \\
\leqslant 01\end{array}$ & $\begin{array}{l}\text { l..997r, rIT } \\
\text { rIrrI,97Y } \\
\text { IrrrYs, IAE }\end{array}$ & داخل المجمموعات المجموعات & التواجبات الأسرية \\
\hline$\cdot, \cdot 1$ & $9 \leqslant 9, \leqslant 77$ & $\begin{array}{l}\text { rorsrE, IAO } \\
\text { rYo,Ar. }\end{array}$ & $\begin{array}{l}r \\
\leqslant \leqslant 9 \\
\leqslant 01\end{array}$ & 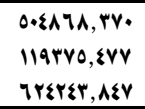 & داخل المجمموعات المجموعات & مجموع الواجبات \\
\hline
\end{tabular}




\begin{tabular}{|c|c|c|c|}
\hline \multicolumn{4}{|c|}{ 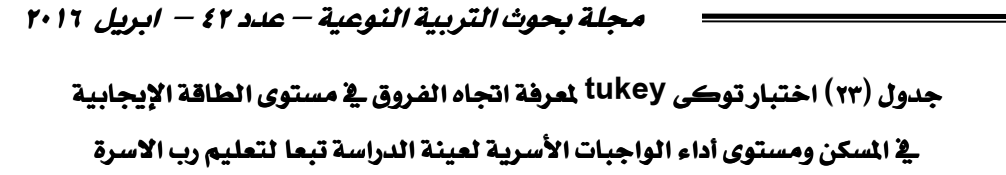 } \\
\hline \multicolumn{3}{|c|}{ اختبار Tukey } & \multirow[t]{2}{*}{ المتفيرات } \\
\hline مستوي مرتفع & مستوي متوسط & مستوي منخفض & \\
\hline Or,QEYY & rV, Tav\& & $r Y, \cdot \wedge 0 \Sigma$ & الطاقة الإيجابية في المسكن عامة \\
\hline$\{\xi, \cdots$ & $79,97.0$ & $r \xi, \cdots \cdot \cdots$ & الطاقة الإيجابية الخاصة بغرفة النوم \\
\hline$r A,\{\& 07$ & 19,YYIY & $19,\{7.0$ & الطاقة الإيجابية الخاصة بغر فة المعيشة والاستقبال \\
\hline rI,qrr. & $1 \wedge, 0 \vee \wedge 9$ & $14, r 909$ & الطاقة الإيجابية الخاصة بغرفة الطعام \\
\hline $1 T, 00 \leqslant \varepsilon$ & $11,94 I 1$ & $1 \cdot, r \leqslant 10$ & الطاقة الإيجابية الخاصة بالحمام \\
\hline rq,VMIT & $19,19 y \varepsilon$ & $10, \wedge \vee \wedge$. & الطاقة الإيجابية بالمطبخ \\
\hline II, TrYY & $\Lambda$, roYI & $7, \xi \cdot \vee 9$ & الطاقة الإيجابية الخاصة بالممرات \\
\hline YI., YEY & $|\xi|, 7 \mid r$ & $11 \mathrm{~A}, \mathrm{TIr}$ & مجموع الطاقة الإيجابية للمسكن \\
\hline$\Delta 9, \cdot 71 \cdot$ & sr,PYr & ro,YoYI & الواجبات الأسرية الزوجية \\
\hline$\$ 0, १ \leqslant q$. & $r \wedge, 99.0$ & $r 7,7 \cdot 91$ & الواجبات الأسرية المنزلية \\
\hline q., rvvq & $77, \times 190$ & Or, Aorr & الواجبات الأسرية التربوية \\
\hline $190, \mathrm{rar}$ & IrV, YAr & 117, YYY & مجموع الواجبات الأسرية \\
\hline
\end{tabular}

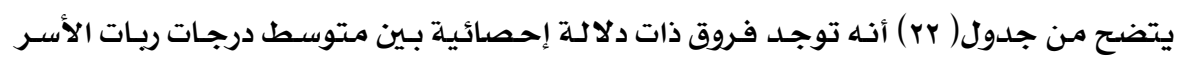

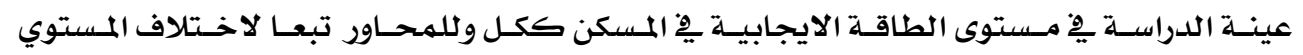

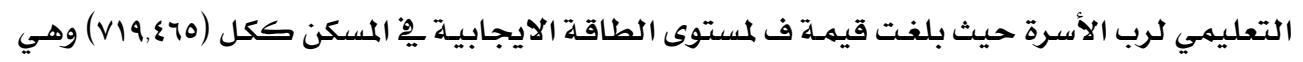

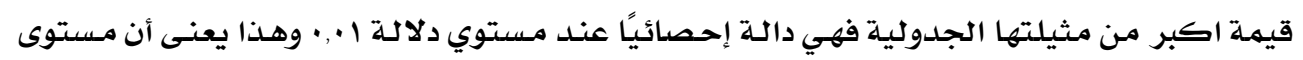

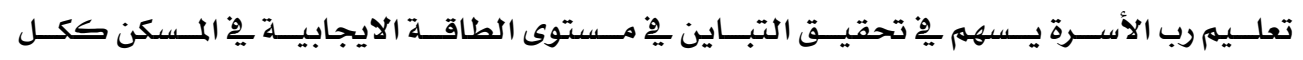

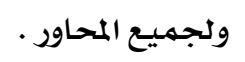

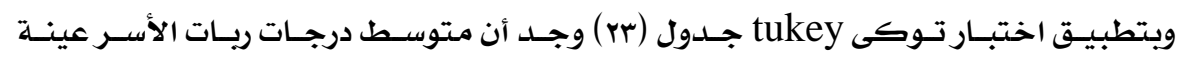

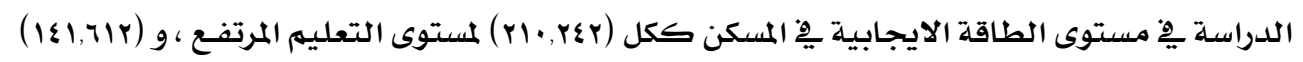

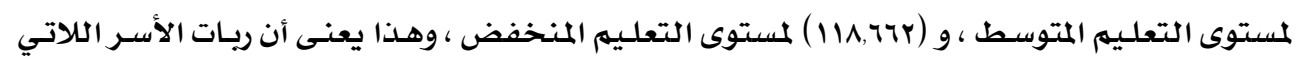

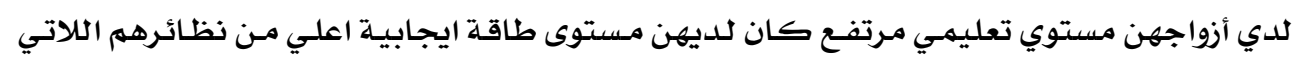

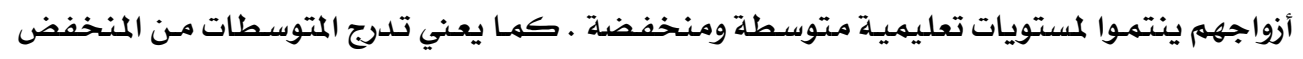

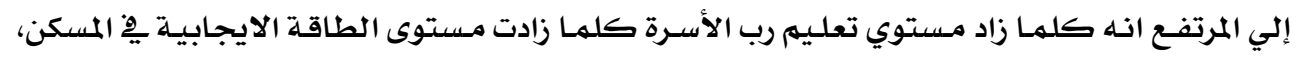

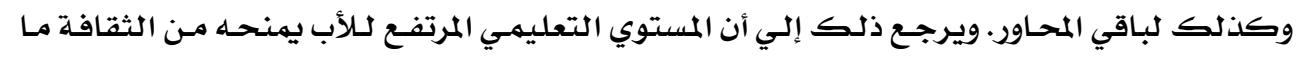

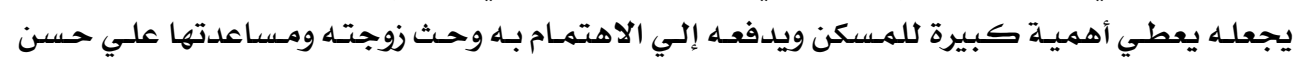
العناية بـه حتى ينبض بالطاقة الإيجابية .

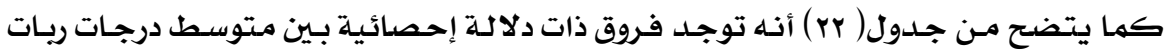

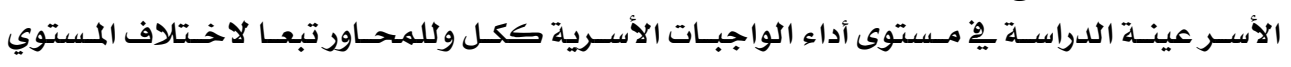

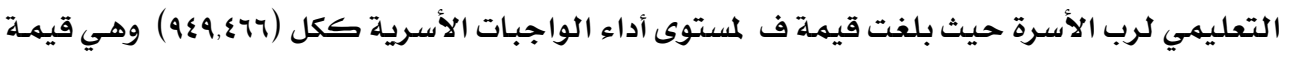

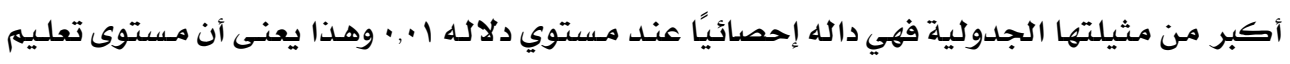




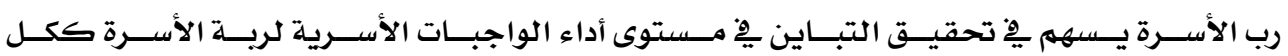
ولجميع المحاور.

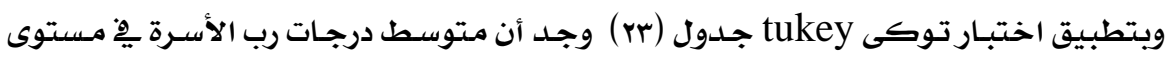

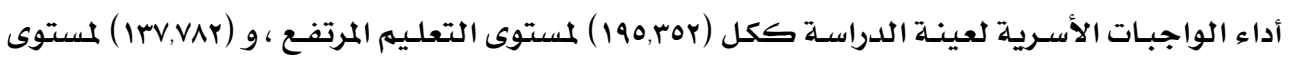

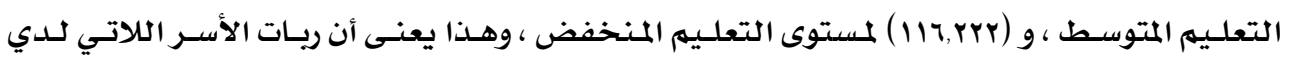

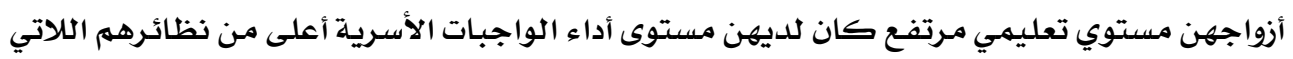

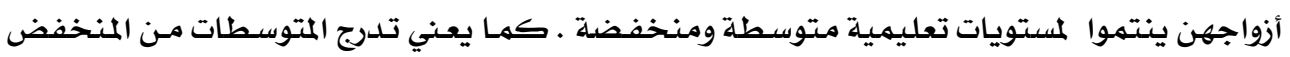

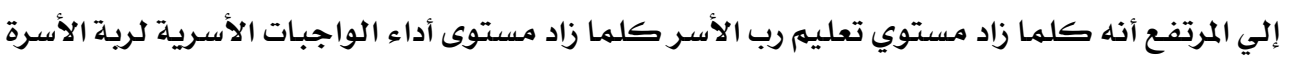

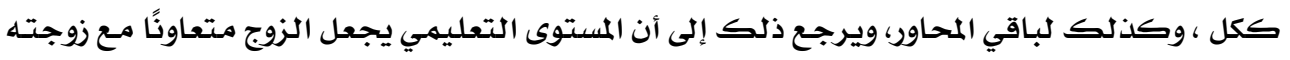

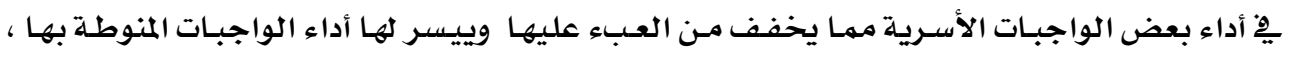

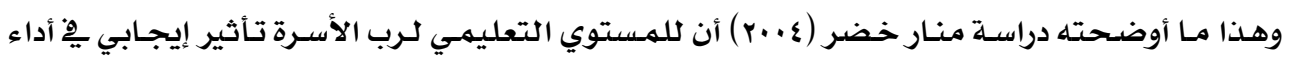

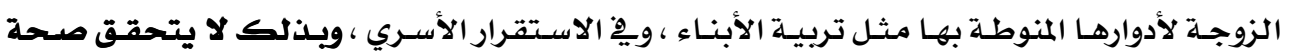

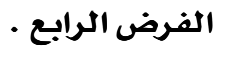

الفرض الخامس : ينص الفرض الخرص الخامس

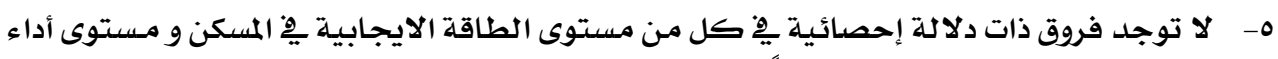

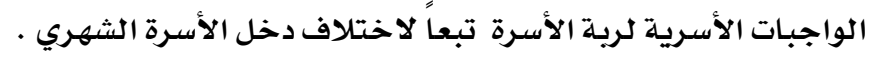

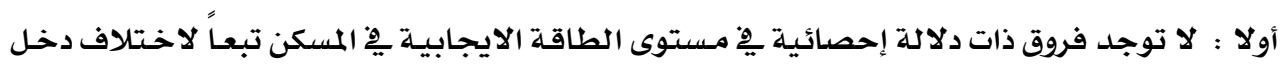

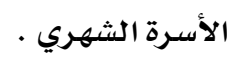

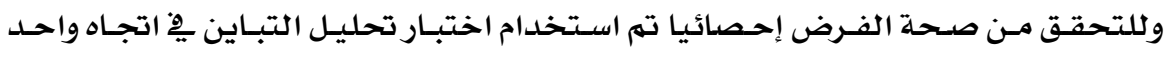
one way ANOVA

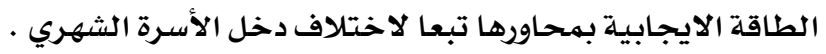


جدول ( r ) تحليل التباين ِّ اتجاه واحد لمستوى الطاقة الإيجابية

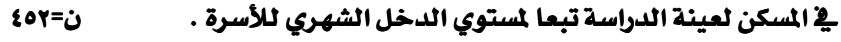

\begin{tabular}{|c|c|c|c|c|c|c|}
\hline مستوى & قيمة ف & متوسط المربعات & درجات الحرية & مجموع المربعات & مصدر التباين & الطاقة الإيجابية \\
\hline$\cdot,+1$ & $1 r 99, r$ & $\begin{array}{l}r \cdot r r v, \cdot r o \\
r r, \varepsilon \wedge \varepsilon\end{array}$ & $\begin{array}{r}r \\
\leqslant \leqslant 9 \\
\leqslant 01\end{array}$ & $\begin{array}{l}71005, \cdot 0 . \\
10.90,171 \\
117 \leqslant 9, r 1 .\end{array}$ & داخل المجموعات المجوعات & الطاقة الإيجابية في \\
\hline$\cdot,+1$ & $1194, r$ & $\begin{array}{l}\text { rrorr,EYA } \\
1 \Lambda, 91 \wedge\end{array}$ & $\begin{array}{l}r \\
\leqslant \leqslant 9 \\
\leqslant 01\end{array}$ & $\begin{array}{l}\$ 01 r r, \wedge 00 \\
\text { Aะqะ, rrq } \\
\text { OrYrY, } 190\end{array}$ & داخل المجموعات المجوعات & الخاصة بغرفة النوم الإيجابية \\
\hline$\cdot,+1$ & $91 \mathrm{r}, \mathrm{rq0}$ & $\begin{array}{l}\{91\}, \cdot 0 . \\
0, \cdot \cdot 1\end{array}$ & $\begin{array}{l}r \\
\leqslant \leqslant 9 \\
\leqslant 01\end{array}$ & 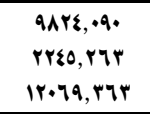 & داخل المجمموعات المجموعات & 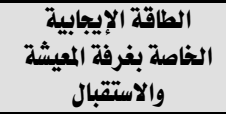 \\
\hline$\cdot,+1$ & $r r \cdot \Lambda, r$ & $\begin{array}{l}\text { |riry, Ir| } \\
0, \mid r A\end{array}$ & $\begin{array}{l}r \\
\leqslant \leqslant 9 \\
\$ 01\end{array}$ & $\begin{array}{l}\text { rETOO, r\&I } \\
\text { rrTE,AAT } \\
\text { rYOA•, IrE }\end{array}$ & داخل المجموعات المجوعات & الخاصة بغرفة الطاقيجام الطابية \\
\hline$\cdot, \cdot 1$ & 1179,110 & $\begin{array}{c}\xi 97, \cdot r r \\
r, 7 \leqslant r\end{array}$ & $\begin{array}{l}r \\
\leqslant \leqslant 9 \\
\leqslant 01\end{array}$ & $\begin{array}{l}99 r, \cdot 77 \\
17 r 0,8 \cdot 9 \\
\text { rqrr, \&r7 }\end{array}$ & داخل المجمعوعات المجموعات & الطاقة الإيجابية بالحمام \\
\hline$\cdot, \cdot 1$ & $\varepsilon r q 0, r$ & $\begin{array}{c}00 \leqslant 1,\{r Y \\
1, r 71\end{array}$ & $\begin{array}{l}r \\
\leqslant \leqslant 9 \\
\leqslant 01\end{array}$ & $\begin{array}{l}11+\wedge r, \wedge V \varepsilon \\
077,11 Y \\
117\{\wedge, 991\end{array}$ & داخل المجمموعات المجموعات & الطاقة الإيجابية \\
\hline$\cdot,+1$ & rAYA,r & $\begin{array}{c}\text { Irrs, r+A } \\
\cdot, \text { Irq }\end{array}$ & $\begin{array}{l}r \\
\leqslant \leqslant 9 \\
\$ 01\end{array}$ & 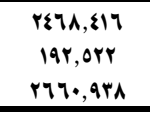 & داخل المجمعوعات المجوعات & الخاصة الإيجابية \\
\hline$\cdot,+1$ & rVIT,r & $\begin{array}{l}\text { srossq, VrA } \\
\text { IIr, TAr }\end{array}$ & $\begin{array}{l}r \\
\leqslant \leqslant 9 \\
\leqslant 01\end{array}$ & $\begin{array}{l}10 \cdot 199, \& 09 \\
01 \cdot \varepsilon r, r \leqslant 9 \\
9.19 \varepsilon r, 1.0\end{array}$ & داخل المجموعات المجوعات & مجموع الطاقة الإيجابية \\
\hline
\end{tabular}

\section{جدول (ro ) اختبار توكى tukey لمعرفة اتجاه الفروق}

2ِّ2 مستوى الطاقة الإيجابية ـِ المسكن تبعا لدخل الأسرة الشهري

\begin{tabular}{|c|c|c|c|}
\hline \multicolumn{3}{|c|}{ اختبار Tukey } & \multirow[t]{2}{*}{ المتفيرات } \\
\hline مستوي مرتفع & مستوي متوسط & مستوي منخفض & \\
\hline Or,ArOq & rr,qrrr & ro, ,... & الطاقة الإيجابية في المسكن عامة \\
\hline 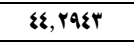 & rr, TIIY & rr,ZYII & الطاقة الإيجابية الخاصة بغرفة النوم \\
\hline rA, rq0 & $19, \cdot Y \wedge 9$ & IV, YATY & الطاقة الإيجابية الخاصة بغرفة المعيشة والاستقبال \\
\hline$r r, \cdot 1 r r$ & $1 \xi,\{77 Y$ & $\mid r, \cdots \cdot \cdot$ & الطاقة الإيجابية الخاصة بغرفة الطعام \\
\hline $1 \%, 7 \leqslant 17$ & $11,1 \cdots$ & $1 \cdot, \cdots$ & الطاقة الإيجابية الخاصة بالحمام \\
\hline YY,YIAE & IV, YATY & $10, \cdots$ & الطاقة الإيجابية بالمطبخ \\
\hline 11,0911 & $\Lambda, \cdots \cdots$ & $0, r I 7 r$ & الطاقة الإيجابية الخاصة بالممرات \\
\hline rI.,々9Y & $|r|, q \cdot Y$ & $111,0 . r$ & مجموع الطاقة الإيجابية للمسكن \\
\hline
\end{tabular}

يتضح من جدول( ع) أنه توجـد فروق ذات دلالـة إحصائية بـين متوسط درجـات ريـات الأسـر

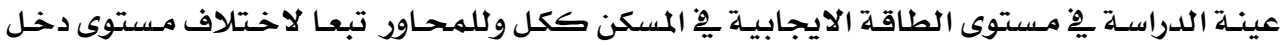




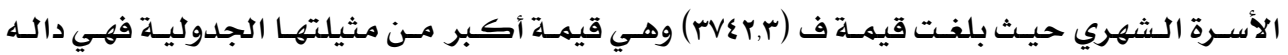

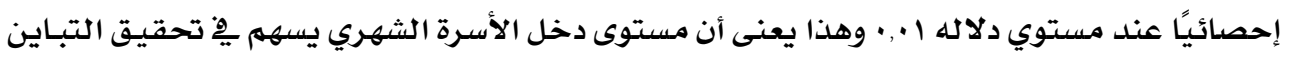

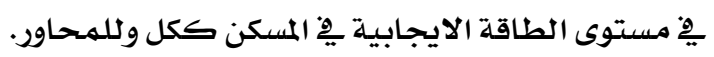

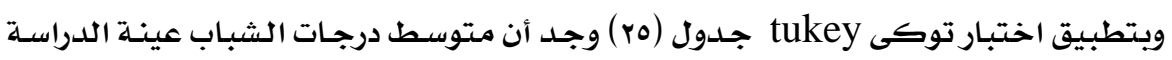

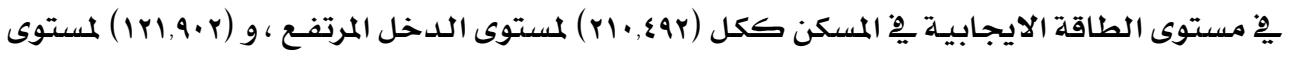

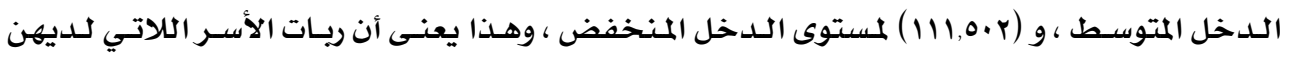

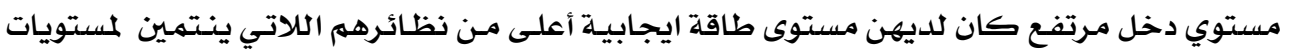

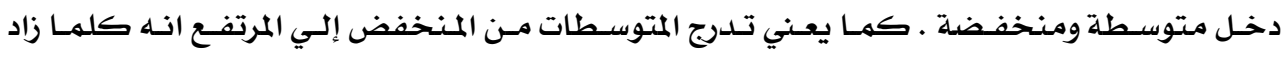

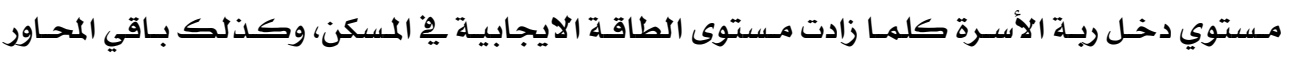

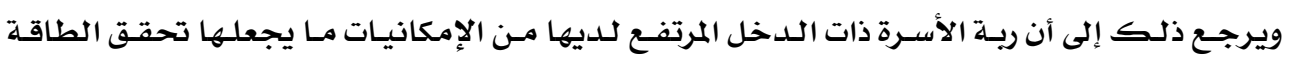

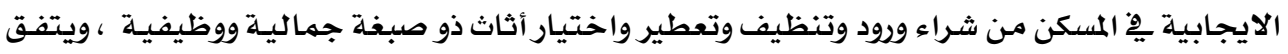

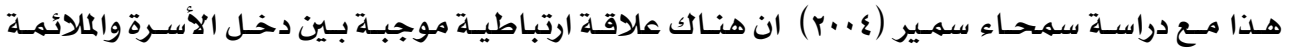

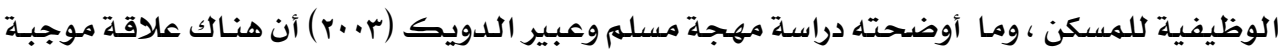

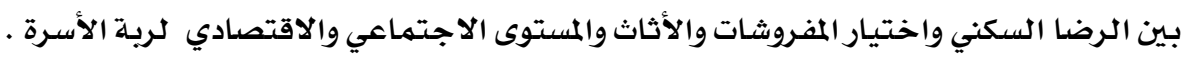

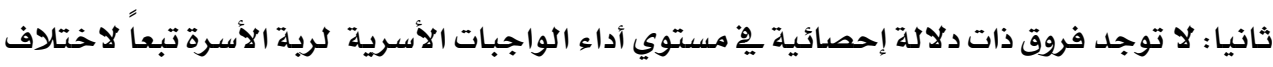

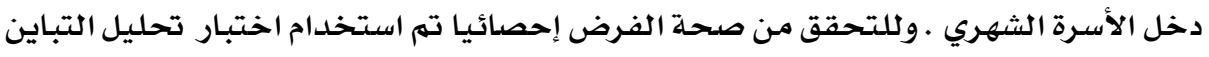

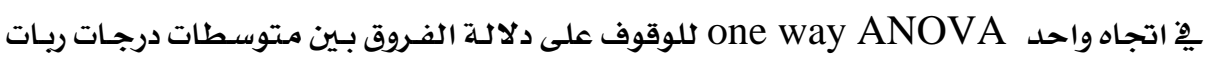

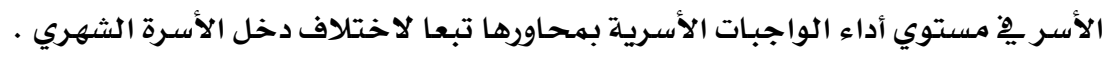

جدول (rr) تحليل التباين يِ اتجاه واحد لمستوى الواجبات الأسرية

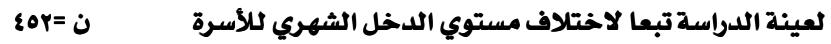

\begin{tabular}{|c|c|c|c|c|c|c|}
\hline مستوى & قيمة ف & متوسط المربعات & درجات الحرية & مجموع المربعات & مصدر التباين & الواجبات الأسرية \\
\hline$\cdot,+1$ & $11 \cdot 1,8$ & $\begin{array}{c}r q r \cdot q, r r r \\
r, r q .\end{array}$ & $\begin{array}{l}r \\
\leqslant \leqslant 9 \\
\leqslant 01\end{array}$ & $\begin{array}{l}\text { orglA, 7or } \\
1 \cdot V r, \cdot r A \\
\text { orgal, } 711\end{array}$ & داخل المجموعات المجموعات & الزواجبات الأسرية \\
\hline$\cdot,+1$ & IrEY, r & $\begin{array}{l}Y 1 \cdot\{0,\{T \xi \\
\mid 7, A Y 1\end{array}$ & $\begin{array}{l}r \\
\leqslant \leqslant 9 \\
\leqslant 01\end{array}$ & $\begin{array}{l}\text { \&r.q., qrq } \\
\text { VOV\&, ArY } \\
\$ 9770,1 \cdot 0\end{array}$ & داخل المجمهوعات المجموعات & الواجبات الأسرية \\
\hline$\cdot, \cdot 1$ & $1 .+7,8$ & $\begin{array}{c}\text { OQYAY, YQY } \\
0,9 \& Y\end{array}$ & $\begin{array}{l}r \\
\leqslant \leqslant 9 \\
\leqslant 01\end{array}$ & $\begin{array}{l}119070,094 \\
\text { Y7YA,091 } \\
\text { IYrYYE, IAE }\end{array}$ & داخل المجموعات المجوعات & التواجبات الأسرية \\
\hline$\cdot, \cdot 1$ & $v \leqslant 10, r$ & $\begin{array}{c}r \cdot r q \leqslant q, Y Y O \\
\varepsilon \cdot, \wedge 07\end{array}$ & $\begin{array}{l}r \\
\leqslant \leqslant 9 \\
\leqslant 01\end{array}$ & 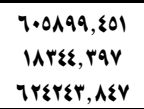 & داخل المجموعات المجوعات & مجموع الواجبات \\
\hline
\end{tabular}


جدول (rv) اختبارتوكى tukey لمعرفة اتجاه الفروق مِّ مستوى الواجبات الأسرية لربة الأسرة تبعا لدخل الأسرة الشهري

\begin{tabular}{|c|c|c|c|}
\hline \multicolumn{3}{|c|}{ اختبار Tukey } & \multirow[t]{2}{*}{ المتفيرات } \\
\hline مستوي مرتفع & مستوي متوسط & مستوي منغفض & \\
\hline $09,+r Y r$ & $r v, 717 v$ & $r \xi, \cdots \cdots$ & الواجبات الأسرية الزوجية \\
\hline$\$ 0,9) \leqslant 7$ & $r o, \cdots \cdot \cdot$ & $Y \&, V \backslash T V$ & الواجبات الأسرية المنزلية \\
\hline $9 \cdot, \pi 1 \cdot 1$ & $7 \cdot, \wedge 17$ Y & $01, \cdots \cdot \cdot$ & الواجبات الأسرية التزبوية \\
\hline 190, ror & IrT, IOr & $11 \cdot, \cdots r$ & مجموع الواجبات الأسرية \\
\hline
\end{tabular}

• يتضح من جدول( بـ ) أنه توجد فروق ذات دلالة إحصائية بـين متوسط درجـات ريـات الأسـر

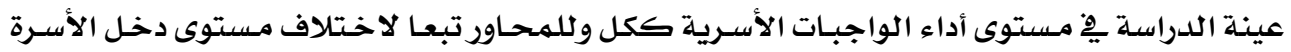

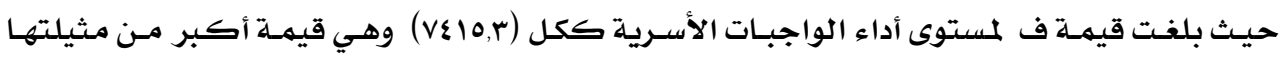

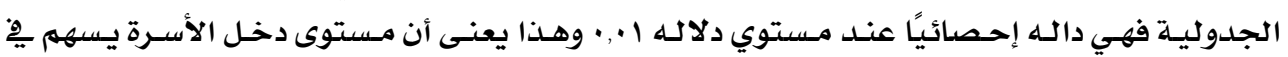

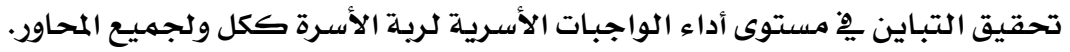

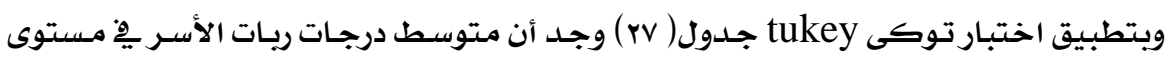

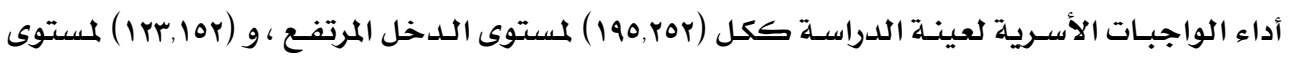

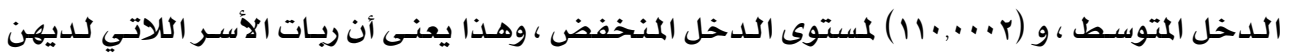

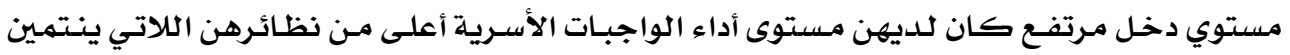

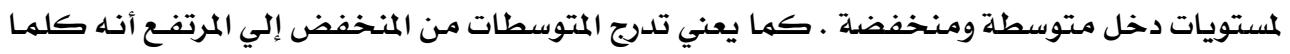

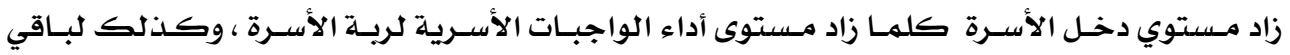

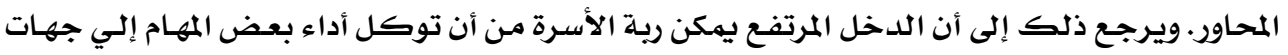

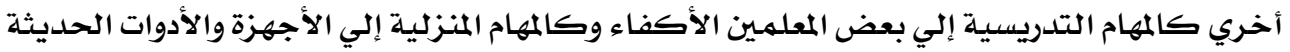

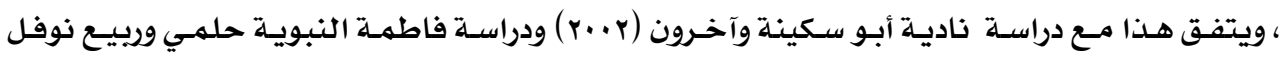
(Y...)

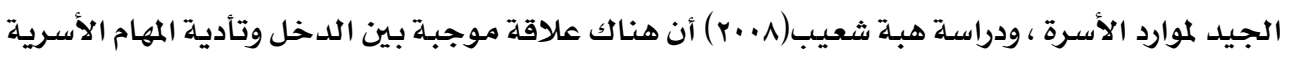

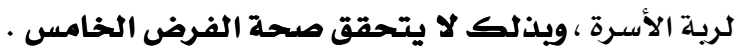
الفرض السادس : ينص الفرض على :

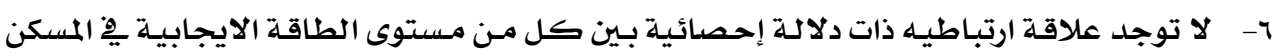

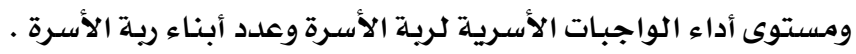

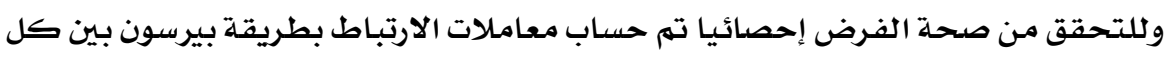

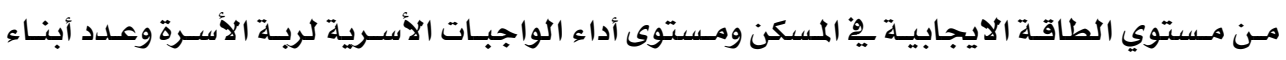
ريبة الأسرة مـن مستوي 
جدول ( YN ) معاملات الارتباط بيرسون بين مستوى الطاقة الإيجابية

ومستوى أداء الواجبات الأسرية وعدد أبناء رية الأسرة

\begin{tabular}{|c|c|}
\hline عدد الأبناء & المتفيرات \\
\hline$* * .7 \leq 0-$ & الطاقة الإيجابية في المسكن عامة \\
\hline ***. .レリ1- & الطاقة الإيجابية الخاصة بغرفة النوم \\
\hline$* * \cdot \vee \cdot 9-$ & الطاقة الإيجابية الخاصة بغرفة المعيشة والاستقبال \\
\hline **. . $\vee \diamond \diamond-$ & الطاقة الإيجابية الخاصة بغرفة الطعام \\
\hline$* \% .019-$ & الطاقة الإيجابية الخاصة بالحمام \\
\hline$* * . V r r-$ & الطاقة الإيجابية بالمطبخ \\
\hline$* * . \wedge \mid \vee-$ & الطاقة الإيجابية الخاصة بالممرات \\
\hline$* * \cdot . \vee \leq 0-$ & مجموع الطاقة الإيجابية للمسكن \\
\hline$* * . . \vee 9 \leq-$ & الواجبات الأسرية الزوجية الوجية \\
\hline$* * . \vee V M 1-$ & الواجبات الأسرية المنزلية \\
\hline *\%*. . Vนฯ & الواجبات الأسرية التربوية \\
\hline 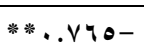 & مجموع الواجبات الأسرية \\
\hline
\end{tabular}

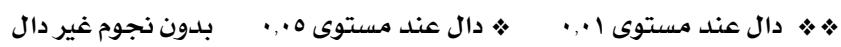

$$
\text { - }
$$

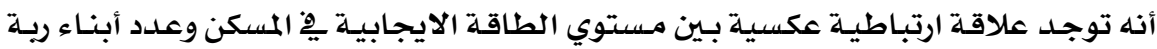
الأسـرة ككل عند مستوى معنوية ا •. • وهذا يعني أنه كلما زاد عدد الأبناء كلما قل مستوي الطاقة

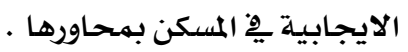

كهـا توجـد علاقـة ارتبـاطيـه عكسيـة بـين مستتوى أداء ريـة الأسـرة للواجبـات الأسـريـة وعـدد

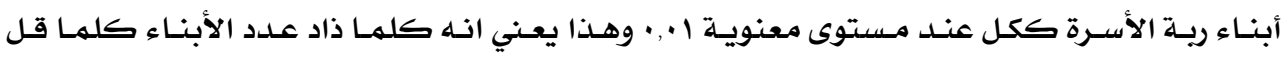

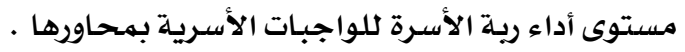

وقد يرجـ ذلك إلى أنه كلما زاد عدد أبناء ريلة الأسـرة زاد الضغط على ريسة الأسـرة لتحقيق

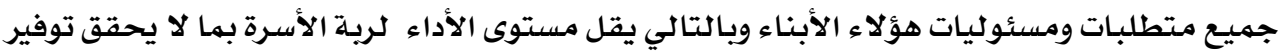

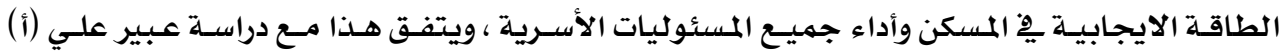
( ع +r) كلما زاد علدد الأبنـاء كلما قل الدور الذي تقـوم بـه الأم تجـاه أولادهـا ( الواجبـات التربويـة ) ،

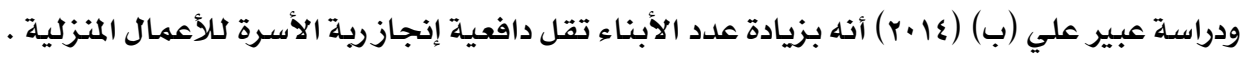
التتوهسات

ضرورة الاهتمام بتعليهم المرأة ورفع مستواها التعليهي حيث أن ارتفاع المستوي التعليهي لها يزيـد معرفة ودرايـة ريسة الأسـرة وقدرتها علي ترتيب وتنسيق وتجميل منزلها وبعث السكينـة والخصوصيـة 
والهدوء حتي يعج بالطاقة الإيجابية وتؤدي جميع الواجبات المنوطة بها بأريحية وإقبال .

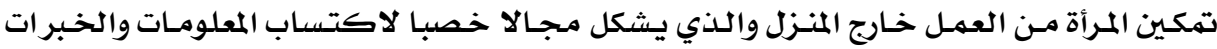

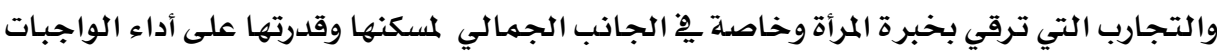

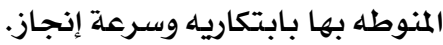

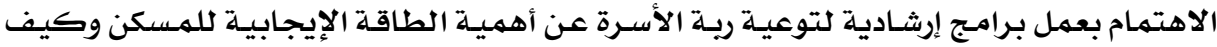

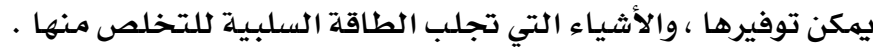

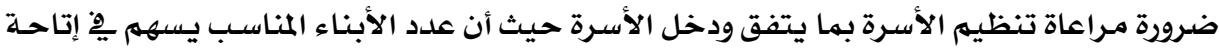

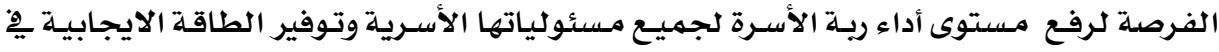

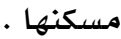
تسليط الإعلام الأضـواء علـي أهميـة الطاقـة الإيجابيـة ومـدي أهميتها وكيفيـة تحقيقها وبيان

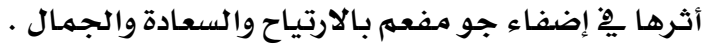

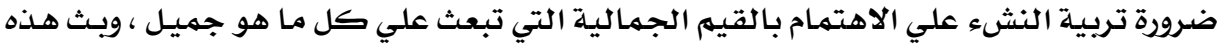

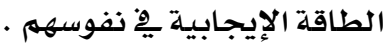

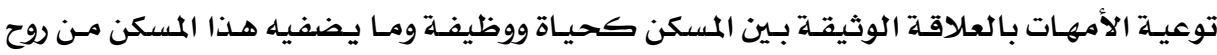

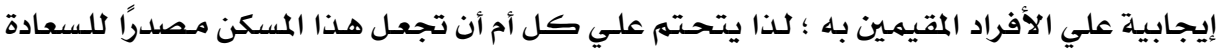

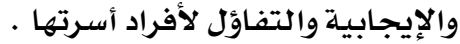

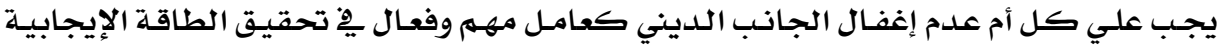

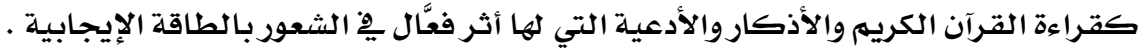

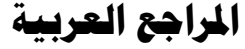

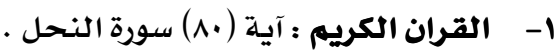

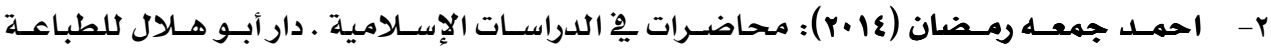
والنشر · المنيا

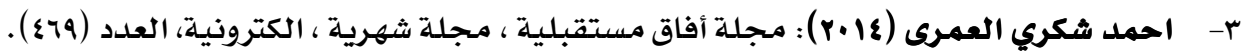

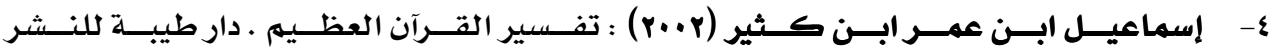

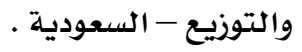

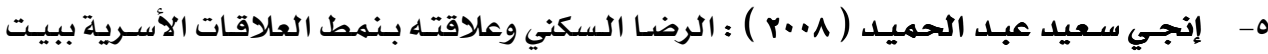

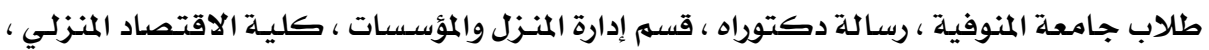

جامعة المنوفية .

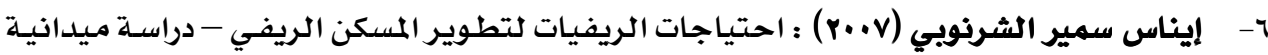

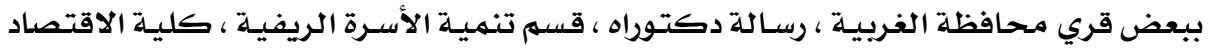

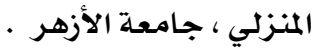




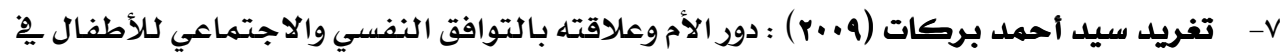

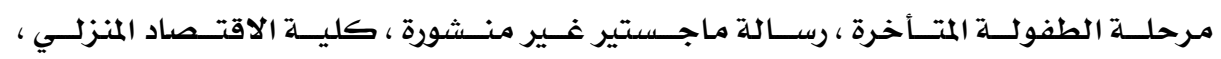
جامعة المنوفية .

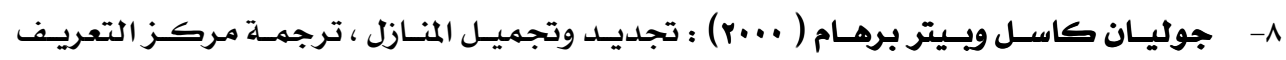

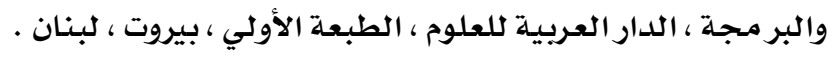

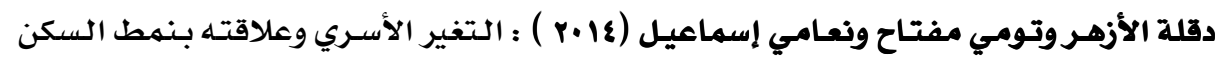

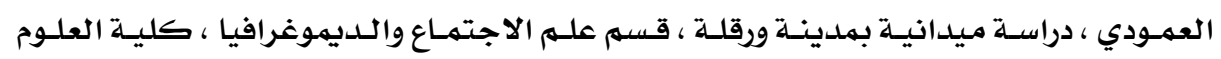

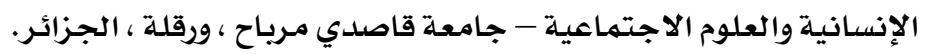

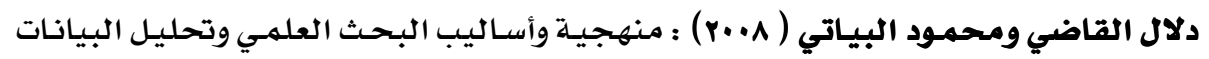

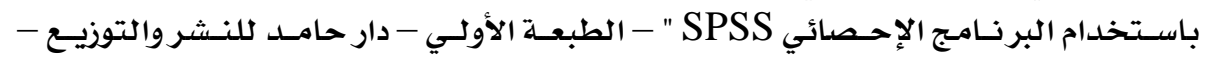
عمان - الأردن.

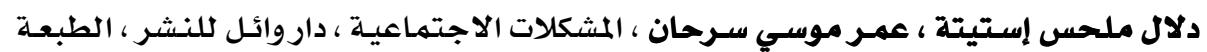

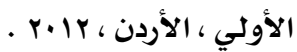

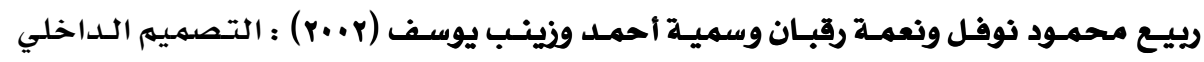
$-14$

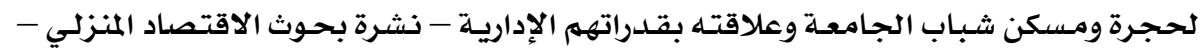

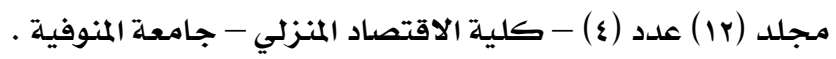

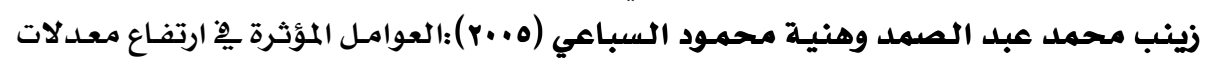

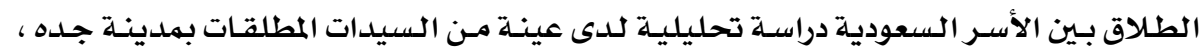

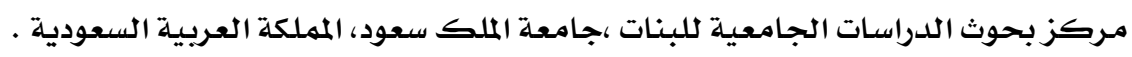

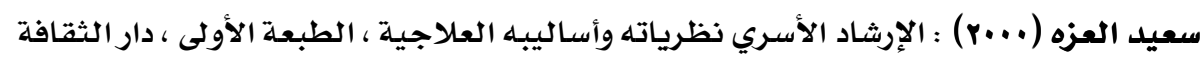

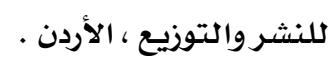

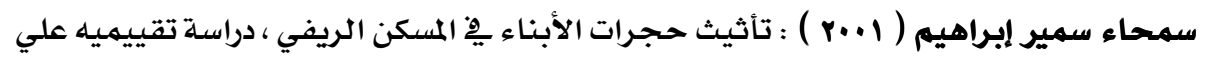

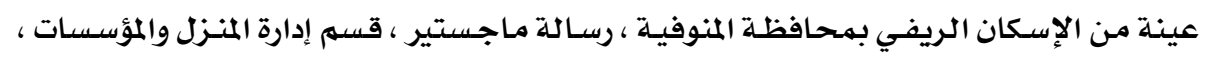

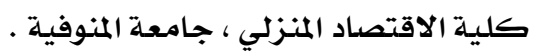

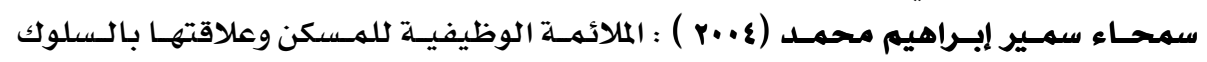

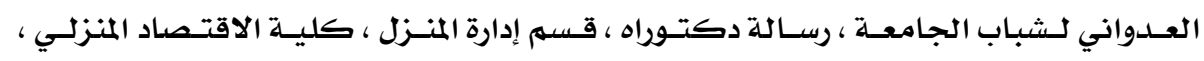
جامعة المنوفية .

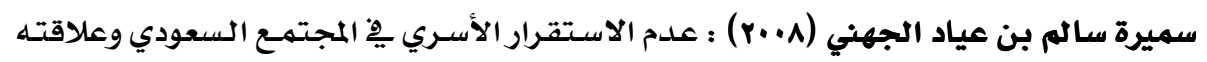

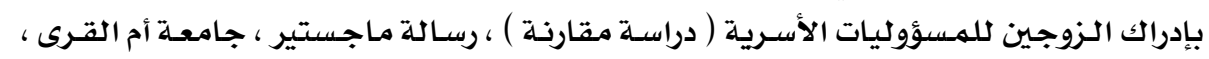

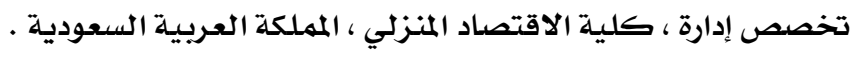

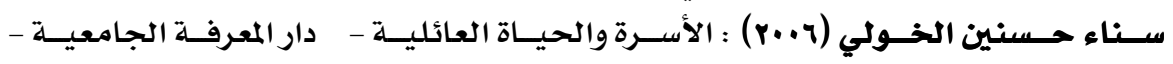
$-11$

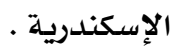
صالح الحوراني(r| -r) : طاقة الريكي أسرارومعرفة ، معلهم الريكي ، الأردن . $-1 \varepsilon$ $-10$ $-17$ 


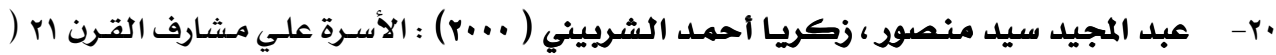

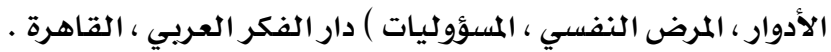

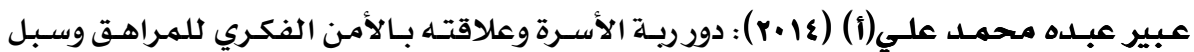

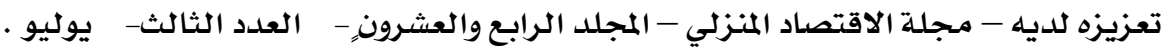

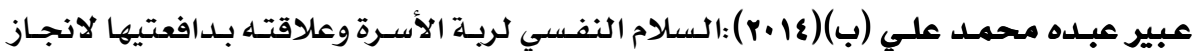

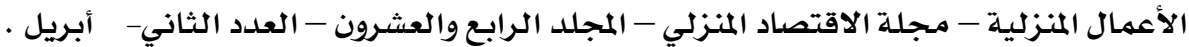

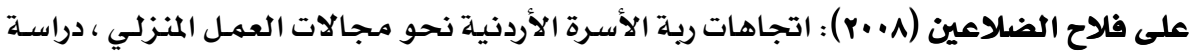

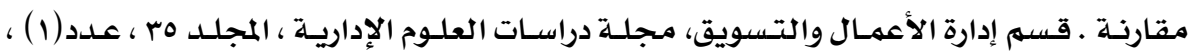
جامعة مؤتة ، الكرك ، مقارنة ، الأردن.

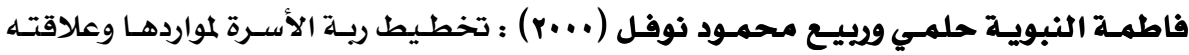
$-Y \varepsilon$

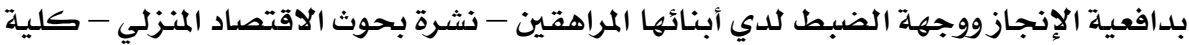

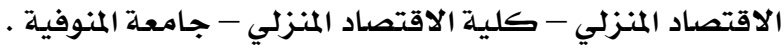

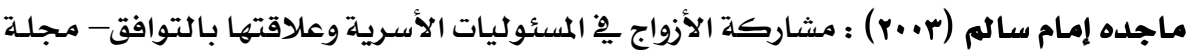

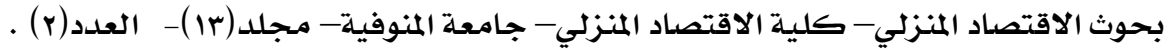

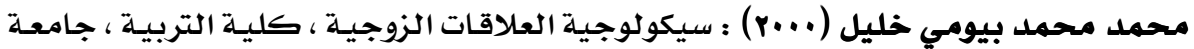

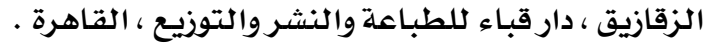

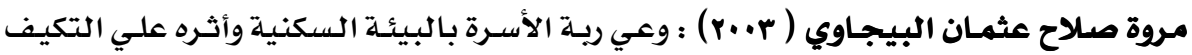

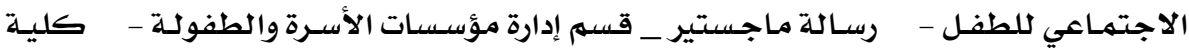

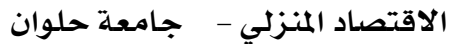

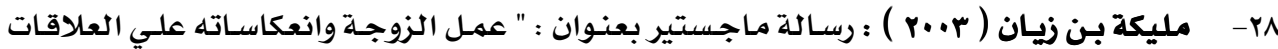

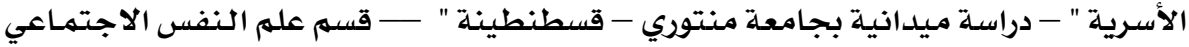

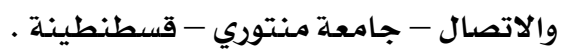

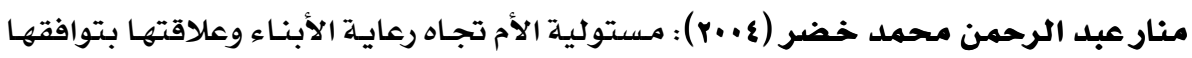

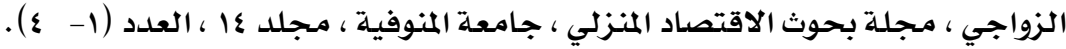

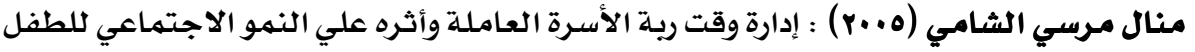

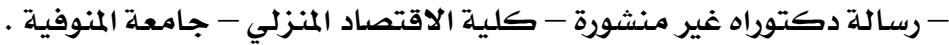

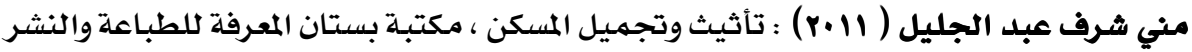

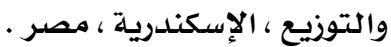

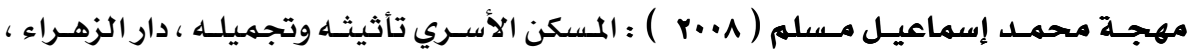
$-r r$

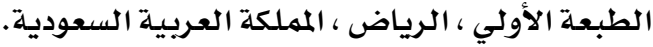

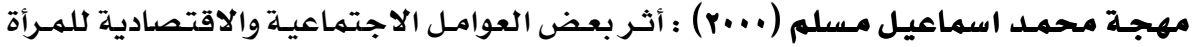
r

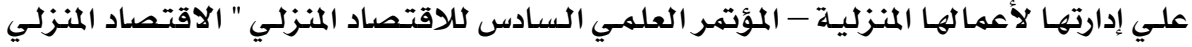

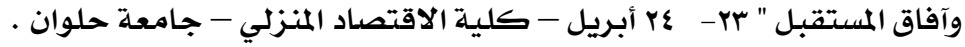




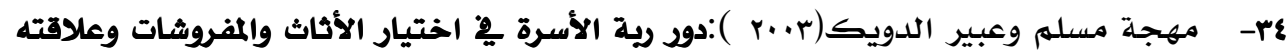

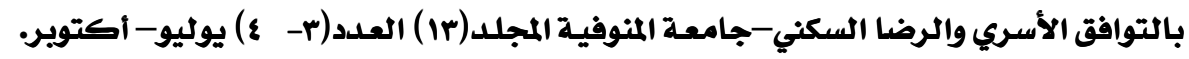

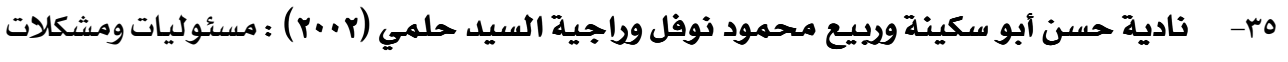

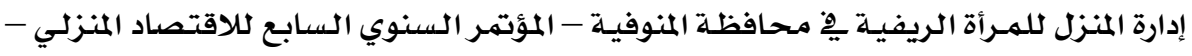

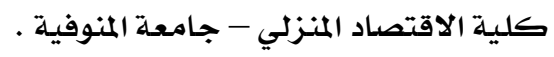

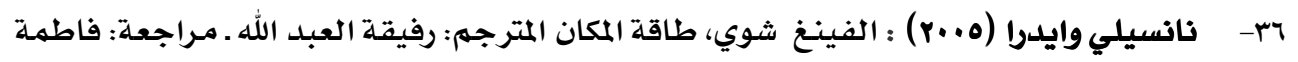

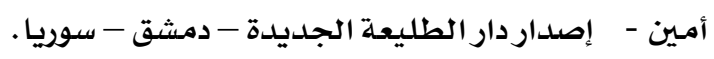

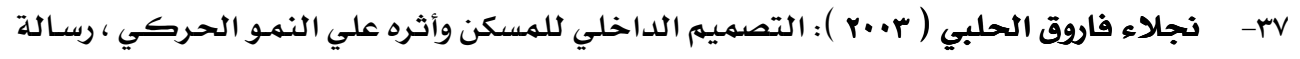

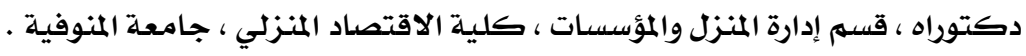

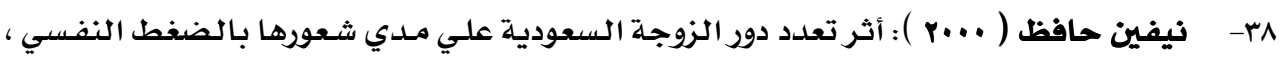

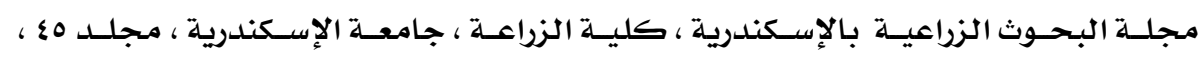

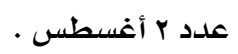

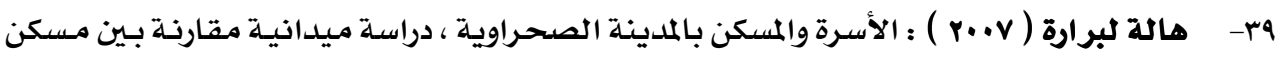

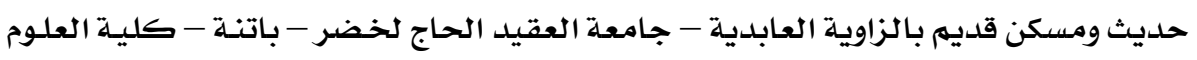

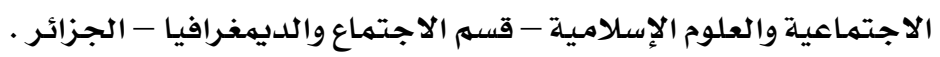

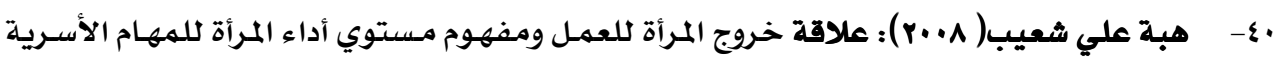

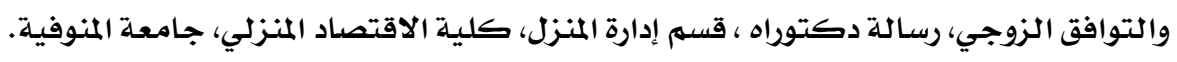

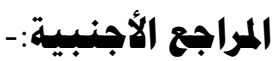

- Charles .C\& Jennifer. T. \& \& Richard. R :(2015)"Positive Psychology" The Scientific and Practical Explorations of Human Strengths Third Edition, SAGE, America.

- Donovan B.klieg.(2001): Creating a total object of Art, Arts \& Activities, Vol.133, February.p22.

- paula K.\& seon L.(2004): tha Role of participation in An-school and Qusidc - Activities in the Talnt Development of Gifted Student . journal of School Gifted Education, Vol.15.p107.

- Ralph A. Smith.(2002) : Recalling a Sense of purpose : The DRAE literature project-part One ,School Arts ,Vol.102,October.p 12 .

- Sylvia T. clark.(2003): cave kids: Pecos River-Style Art, Art \& Activities, Vol.132, January 32. .

- William C. Compton \& Edward Hoffman(2011): Positive Psychology: The Science of Happiness and Flourishing (PSY 255 Health Psychology) 2nd Edition, congress, USA. 


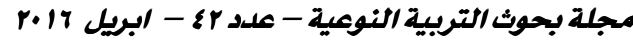

The positive energy in the dwelling and its relationship to the performance of family duties of head of the family

Preparation

Abeer Abdo Mohammed Ali

\section{Abstract}

Targeted research mainly study the relationship between the positive energy in the home and the level of performance of family duties of the head of the household, and identify positive energy level in housing and the level of performance of family duties of the head of the family, and the study of the differences between all of the positive energy level in housing and the level of performance of family duties according to ( housing area the work of head of the family - education level of head of the family - the family level of education of convergence - the level of monthly household income), and determine the relationship between the level of positive energy in the home and the level of performance of family duties and the number of children of head of the family. This study was conducted on a sample of 452 heads of household, and took a sample of rural and urban provinces (Western - Kafr el-Sheikh - Beni Suef), it was a way of psoriasis choice. The study tools and data collection represented in the data form for heads of household, and a questionnaire to measure the positive energy in housing Axes. (Positive energy in public housing - own positive energy bedroom - own positive energy the living room and reception - positive private dining room energy - positive energy bath positive energy cuisine own positive energy corridors), and a questionnaire to measure family meals Axes

(family duties marital - family homework - educational family duties) . it the most important results that there are positive correlation between the positive energy in the dwelling relationship and the level of performance of family duties of the head of the family, and there are significant differences between all of the positive energy in the home and the level of performance of family duties of the head of the household depending on the different housing area (rural - urban), There are also significant differences between all of the positive energy in the home and the level of performance of family duties of head of the household

*Family and childhood institutions management - College of Home Economics 
depending on the different level of education the Lord and head of the family and the level of monthly household income in favor of the higher levels of education and income. There is also a positive correlation between the positive energy in the home and the level of performance of family duties of head of the household and the number of children of head of the family,

\section{It was the most important recommendations:}

- The need for attention to women's education and raising the educational level as the high educational level of it increases the knowledge and expertise of head of the family and their ability to arrange and coordinate and beautify her home and sent tranquility, privacy and tranquility so full of positive energy and perform all duties assigned to them.

- Enable women to work outside the home, which is a fertile ground for the acquisition of information, expertise and experience that amount of women experience especially in the aesthetic aspect of their housing units and their ability to perform the duties entrusted to it Devising and and rapid completion.

- Interest in the work outreach programs to educate the head of the family about the importance of the positive energy of the house and how it can be made available, and the things that bring negative energy to get rid of them

- Need to take account of family planning in line with the income of the family as the appropriate number of children contributes to the opportunity to raise the performance of the head of the family for all the family responsibilities and provide the level of positive energy 